\title{
A Comprehensive Evaluation of a Home Visitation Program Model's Prenatal Physical Activity Curriculum Modules Delivered Primarily to Low-income Women
}

\author{
Angela Marie Dyer \\ aadyer@mix.wvu.edu
}

Follow this and additional works at: https://researchrepository.wvu.edu/etd

Part of the Public Health Commons

\section{Recommended Citation}

Dyer, Angela Marie, "A Comprehensive Evaluation of a Home Visitation Program Model's Prenatal Physical Activity Curriculum Modules Delivered Primarily to Low-income Women" (2019). Graduate Theses, Dissertations, and Problem Reports. 3768.

https://researchrepository.wvu.edu/etd/3768

This Dissertation is protected by copyright and/or related rights. It has been brought to you by the The Research Repository @ WVU with permission from the rights-holder(s). You are free to use this Dissertation in any way that is permitted by the copyright and related rights legislation that applies to your use. For other uses you must obtain permission from the rights-holder(s) directly, unless additional rights are indicated by a Creative Commons license in the record and/ or on the work itself. This Dissertation has been accepted for inclusion in WVU Graduate Theses, Dissertations, and Problem Reports collection by an authorized administrator of The Research Repository @ WVU.

For more information, please contact researchrepository@mail.wvu.edu. 


\title{
A Comprehensive Evaluation of a Home Visitation Program Model's Prenatal Physical Activity Curriculum Modules Delivered Primarily to Low-income Women
}

\author{
Angela M. Dyer, MSPH \\ Dissertation submitted \\ to the School of Public Health \\ at West Virginia University \\ in partial fulfillment of the requirements for the degree of \\ Doctor of Philosophy in \\ Social and Behavioral Sciences
}

\author{
Christiaan G. Abildso, Ph.D., MPH, Chair \\ Sara Anderson, Ph.D. \\ Danielle Davidov, Ph.D. \\ Peter Giacobbi, Ph.D. \\ Christa Lilly, Ph.D. \\ Department of Social and Behavioral Sciences
}

Morgantown, West Virginia

2019

Keywords: Home Visitation, Pregnant, Prenatal, Physical Activity, Low-income Copyright 2019 Angela M. Dyer, MSPH 


\title{
ABSTRACT \\ A Comprehensive Evaluation of a Home Visitation Program Model's Prenatal Physical Activity Curriculum Modules Delivered Primarily to Low-income Women
}

\author{
Angela M. Dyer, MSPH
}

\begin{abstract}
Background. Many low-income pregnant women receive prenatal physical activity (PA) curricula modules through home visitation programs. However, there is a lack of scientific evidence on the structural capacity, processes, and outcomes relating to these modules. Aims. The objective of this dissertation project was to examine the aforementioned in a single home visitation program model - the Maternal Infant Health Outreach Worker (MIHOW) program. More precisely, the aims of this study were to: (Aim 1) examine home visitors' (i.e., Outreach Workers [OWs]) competencies in implementing the MIHOW program's prenatal PA curriculum modules (i.e., structural capacity), (Aim 2) investigate the fidelity with which the MIHOW program's prenatal PA curriculum modules were delivered to home visitation clients (i.e., processes), and (Aim 3) evaluate the impact of the MIHOW program's curriculum on home visitation clients' prenatal moderate-intensity physical activity (MPA) compared to a propensity score matched comparison group (i.e., outcomes). Methods. (Aim 1) A qualitative research design was used. Data from one interview and three focus groups conducted with OWs and five interviews conducted with their Site Leaders (i.e., supervisors) were used for analysis. (Aim 2) A mixed-methods research design was used. Data sources were the interviews and focus groups conducted in Aim 1 and the checklists of curriculum modules completed with 109 clients. These data sources were analyzed separately and then merged. (Aim 3) A nonrandomized quasiexperimental research design was utilized to evaluate how the MIHOW program's pregnant clients' $(n=98)$ absolute MPA metabolic equivalent of task (MET) minutes per week changed relative to a propensity score matched comparison group of pregnant women $(n=56)$. Physical activity measurements were taken at trimesters one, two and/or three. Generalized linear mixed modeling with a zero inflated negative binomial distribution was used as the statistical analysis strategy. Results. Key findings are shown by each aim. (Aim 1) OWs' depth of knowledge on prenatal PA information and the modules varied; over half the OWs discussed implementing PA, rapport building, communication, adaptability, and/or problem-solving skills; over half the OWs felt comfortable delivering the modules. (Aim 2) Eight OWs discussed delivering the prenatal PA curriculum modules at multiple, most, or all of the home visits whereas the checklist data revealed that only $19.3 \%$ of clients received two or more "prenatal PA" and/or "other" curriculum modules. (Aim 3) The expected log absolute MPA MET minutes per week decreased 1.27 less for the comparison group than for the intervention group by trimester $3\left[\chi^{2}(1)=4.77, p\right.$ $=.0289]$. Conclusion. Taken together, these findings suggest that home visitors' competencies relating to the prenatal PA curriculum modules and home visitors' implementation of the prenatal PA curriculum modules have the potential to influence the recipients of these services. Thus, attention needs to be given to these factors when evaluating the effectiveness of home visitation program models' prenatal PA curricula modules. Insight from this study can be used to enhance how home visitation program models' prenatal PA curricula modules are implemented and evaluated.
\end{abstract}




\section{ACKNOWLEDGEMENTS}

Dr. Christiaan G. Abildso

Dr. Sara Anderson, Dr. Danielle Davidov, Dr. Peter Giacobbi, and Dr. Christa Lilly

MIHOW Site Leaders and

MIHOW Outreach Workers

Tonya Elkins and Barbara Clinton

Katie Oscanyan and Jackie Newson

Dr. Luke Moore, Dr. Amy Root,

Dr. Suzanne Walraff Hartman, and

Ryan Sommerkorn

Dr. Shay M. Daily

Dr. Alfgeir Kristjansson

Dr. Rich Bowden, Dr. Jaime Costales, Dr. Caryl Waggett, and Lynn Zlotkowski

Mom, Dad, April, and Al
I cannot thank you enough for the unwavering support, encouragement, and positivity you provided me with throughout this process. I could not have gotten to this point without you.

Thank you for your willingness to always help me, for your constructive feedback, and for the many research lessons you all imparted to me.

This dissertation would not have been possible without you. Thank you for your participation!

I am extremely grateful for the feedback and edits you both provided.

I very much appreciate everything you both did to help me with this dissertation project.

Thank you for the opportunity to work with you all on the MIHOW evaluation and for your endless support.

I truly appreciated all your help throughout this process.

Thank you for the time you spent guiding me through the manuscript writing process and for helping me to reach my first author requirement.

Thanks for the early academic and research lessons and continued support.

Thank you for always being there for me. 


\section{TABLE OF CONTENTS}

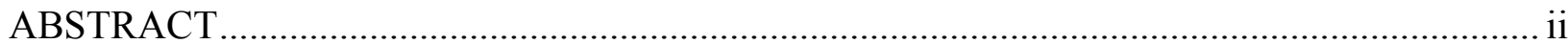

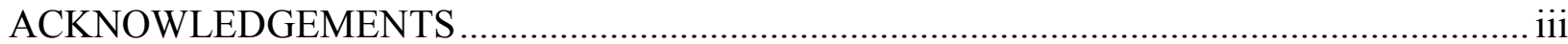

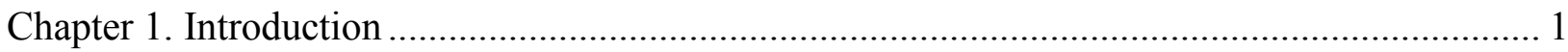

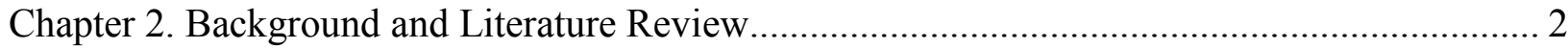

Prenatal Physical Activity Guidelines and Health Benefits ................................................. 2

Unites States Prenatal Physical Activity Prevalence............................................................. 3

Proportion of Low-income Pregnant Women in the United States........................................ 4

Prenatal Physical Activity Interventions .................................................................... 4

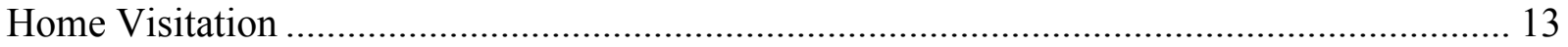

Problem Statement and Research Aims ....................................................................... 15

Chapter 3. A Qualitative Assessment of Home Visitors' Knowledge, Skills, and Abilities in Delivering Prenatal Physical Activity Curriculum Modules ................................................ 17

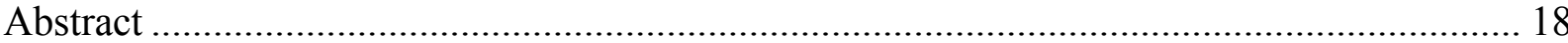

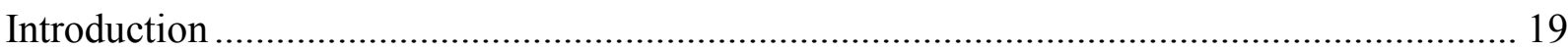

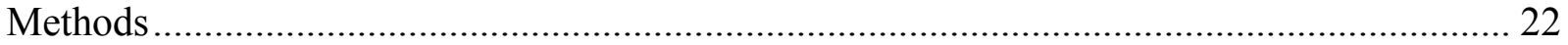

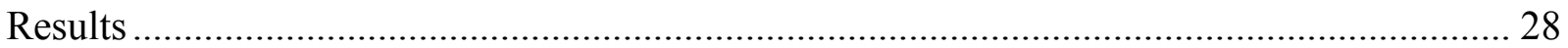

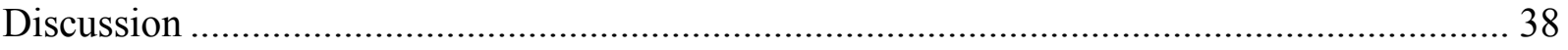

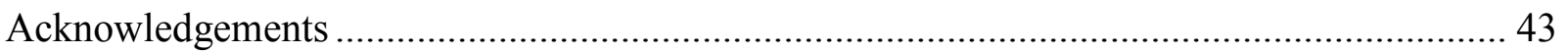

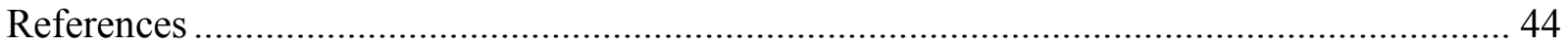

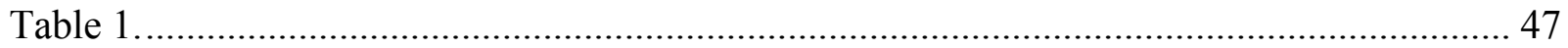

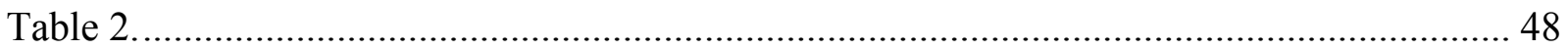

Chapter 4. A Mixed-Methods Investigation of the Fidelity to an Early Childhood Home Visitation Program Model's Prenatal Physical Activity Curriculum Modules ........................... 49

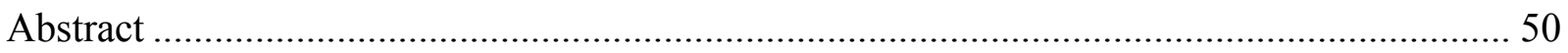

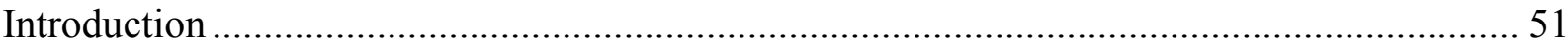




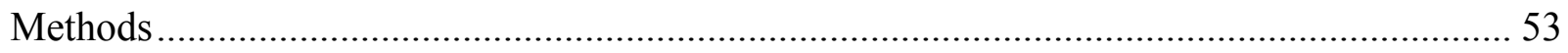

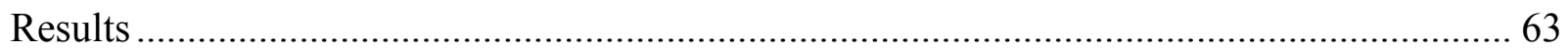

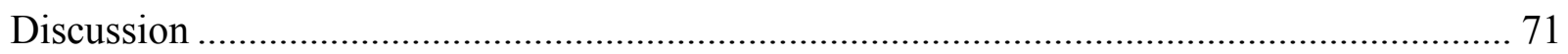

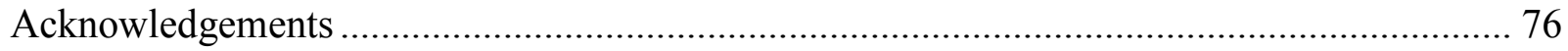

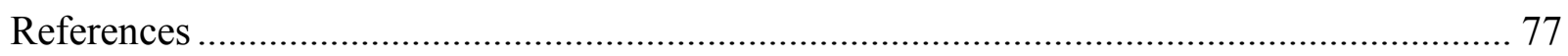

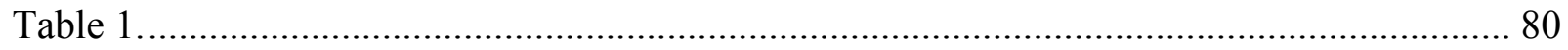

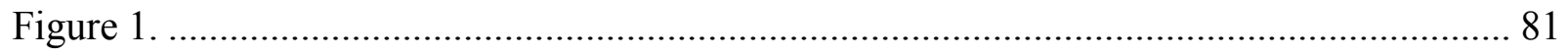

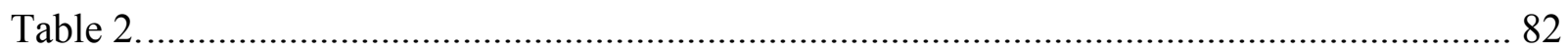

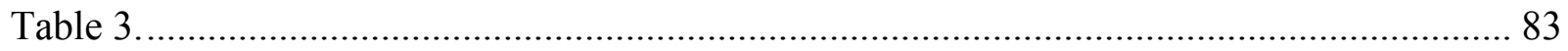

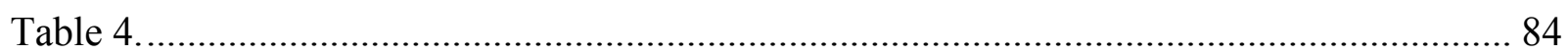

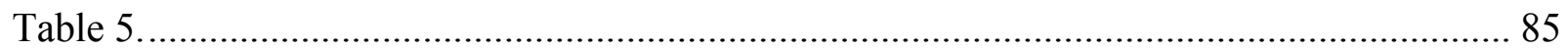

Chapter 5. The Effect of a Home Visiting Program on Pregnant Clients' Moderate-Intensity Physical Activity: A Quasi-Experimental Design with a Propensity Score Matched Comparison

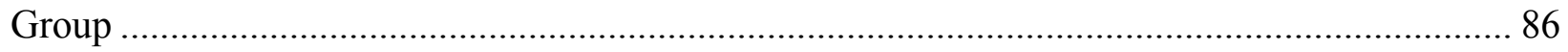

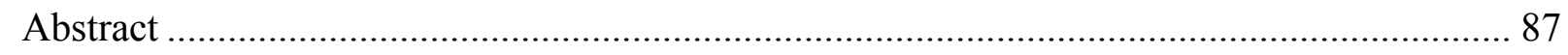

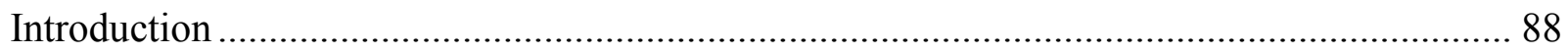

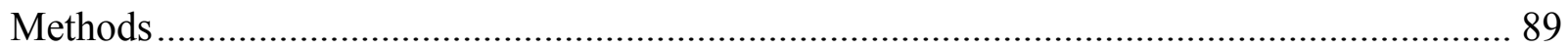

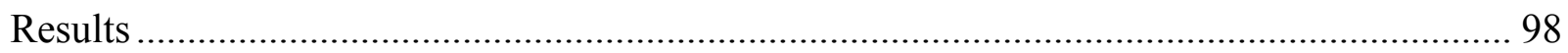

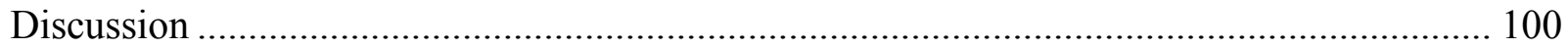

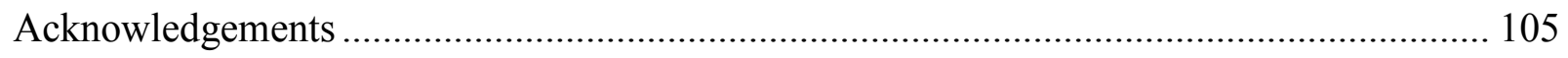

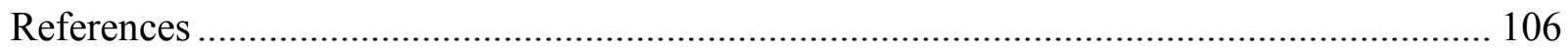

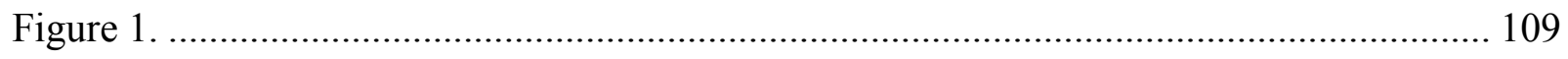

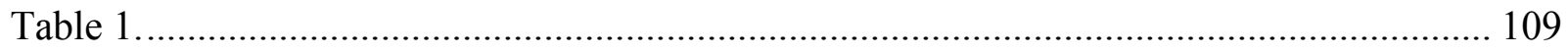

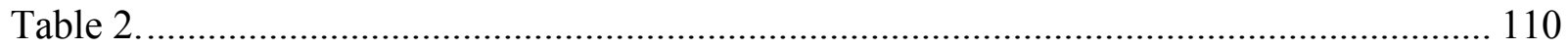

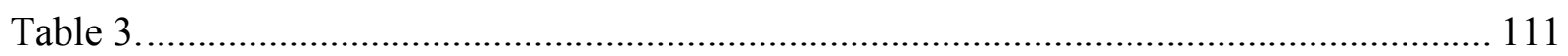




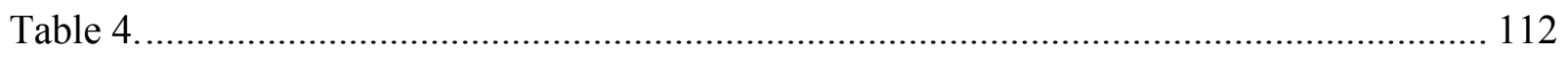

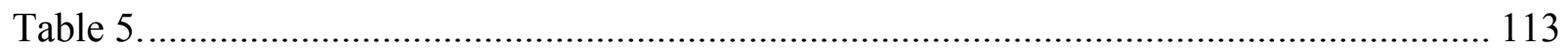

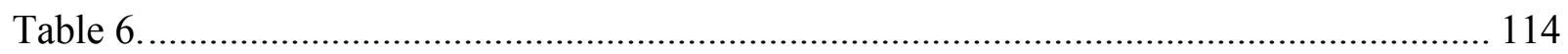

Chapter 6. Overall Discussion and Conclusion ...................................................................... 115

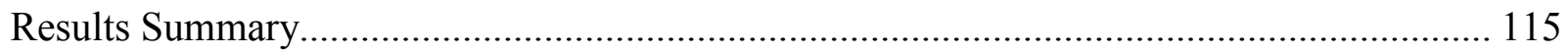

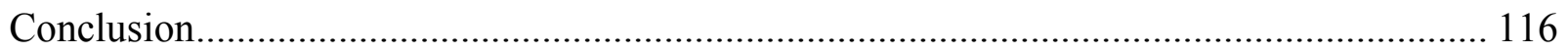

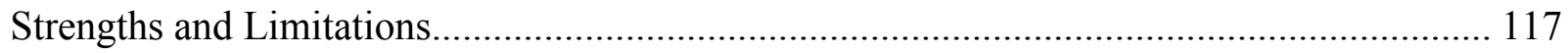

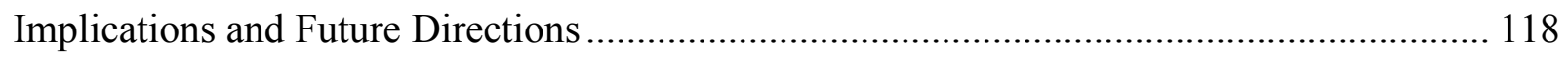

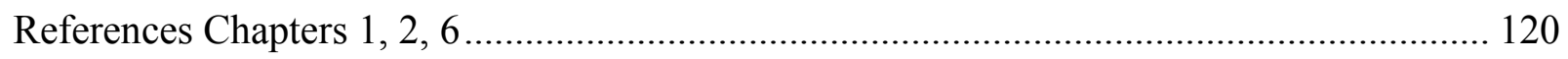

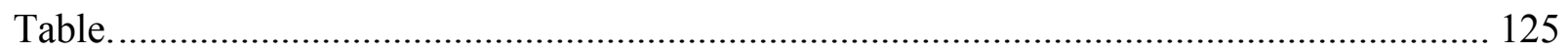

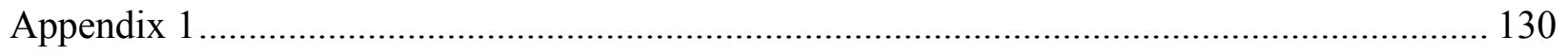

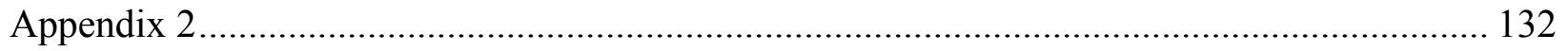

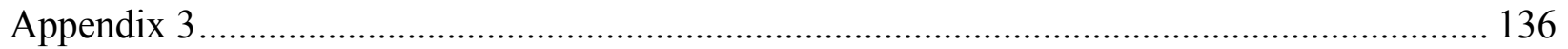

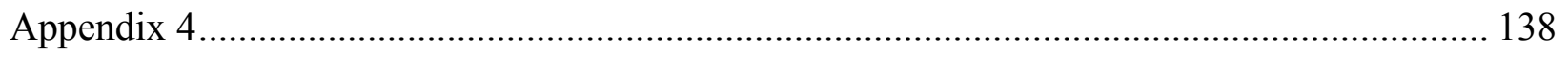

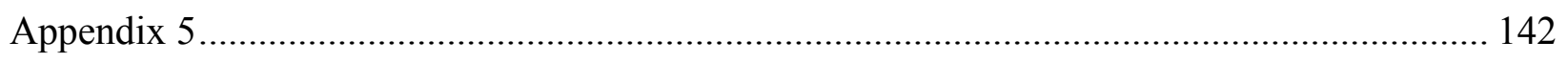




\section{Chapter 1. Introduction}

In the United States (U.S.), low-income women account for roughly $40-45 \%$ of all pregnancies $^{1}$ and are significantly less likely to meet prenatal physical activity (PA) guidelines than high-income pregnant women. ${ }^{2}$ Less physically active pregnant women are less likely to experience the physical and mental health benefits associated with prenatal PA. ${ }^{3}$ Early childhood home visitation program models are used to reach low-income pregnant women across the U.S. ${ }^{4,5}$ As an intervention method, different home visitation program models deliver curricula module(s) focused on prenatal PA and/or exercise to their clients. ${ }^{6-8}$ Despite these efforts, a comprehensive evaluation of the prenatal PA curricula modules' structural capacity, processes, and outcomes has not been done. This knowledge gap has resulted in home visitation program models using un-evaluated prenatal PA curricula module(s). Accordingly, a need exists for more applied research to assess the structural capacity, processes, and outcomes of the prenatal PA curricula modules. 


\section{Chapter 2. Background and Literature Review}

\section{Prenatal Physical Activity Guidelines and Health Benefits}

The debut of the original prenatal PA guidelines in the U.S. in $1985^{9,10}$ were followed with subsequent revisions in $1994^{11}$ and 2002. ${ }^{12}$ The 1985 American College of Obstetricians and Gynecologists (ACOG) prenatal PA guidelines were introduced with three main aerobic prenatal PA constraints which suggested that pregnant women avoid reaching over 140 beats per minute in heartrate, ${ }^{9,10,13}$ reaching over $100.4^{\circ} \mathrm{F}$ in body temperature, ${ }^{10,13}$ or participating in higher intensity PA for more than 15 minutes. ${ }^{10}$ The subsequent 1994 ACOG $^{11}$ prenatal PA guidelines rescinded these constraints and recommended that healthy pregnant women perform PA each week for three or more days. However, recommendations on weekly PA duration and intensity were not outlined. ${ }^{11}$ As a result, the 2002 ACOG $^{12}$ prenatal PA guidelines addressed these components by recommending that moderate-intensity physical activity (MPA) be performed daily, or almost daily, prenatally for at least 30 minutes. MPA is defined as activities that cause changes in heart rate and breathing at a medium level, such as a three mile per hour walk. $^{14}$

With the progression of the prenatal PA field came the acknowledgement that prenatal PA has physical and mental health benefits for the expecting mother. ${ }^{3}$ Prenatal PA has been associated with improved cardiorespiratory fitness ${ }^{15}$ and a reduced risk of gestational diabetes, ${ }^{3,10,15,16}$ preeclampsia, ${ }^{3,10}$ and pregnancy weight gain beyond the clinical guidelines. ${ }^{3,10}$ Pregnant women with higher rates of PA may also experience diminished anxiety and depression symptoms. $^{3}$

Based on the extant evidence, prenatal PA recommendations were sequentially published in the U.S. Department of Health and Human Services' [HHS'] ${ }^{14}$ Physical Activity Guidelines 
for Americans, $1^{\text {st }}$ edition; the 2015 ACOG' ${ }^{17}$ Committee Opinion Number 650, and the HHS ${ }^{15}$ Physical Activity Guidelines for Americans, $2^{\text {nd }}$ edition. At present, in the U.S., MPA is recommended for pregnant women without health restrictions towards PA. ${ }^{15,17}$ The HHS ${ }^{15}$ recommends aerobic prenatal MPA be performed for 150 minutes or more per week. Similarly, the $\mathrm{ACOG}^{17}$ recommends prenatal MPA be performed daily, or almost daily, for 20 to 30 minutes or more. Regarding vigorous-intensity physical activity (VPA), it is defined as activities that cause changes in heart rate and breathing at a high level, such as running or swimming laps. ${ }^{14}$ The HHS ${ }^{15}$ recommends VPA for pregnant women only if three conditions are met: (a) VPA was routine prior to pregnancy, (b) medical guidance is sought regarding the PA routine undertaken throughout pregnancy, and (c) a health restriction towards PA does not develop during pregnancy. A collective understanding of these guidelines is important to help put into context the prenatal PA prevalence rates in the U.S.

\section{Unites States Prenatal Physical Activity Prevalence}

Currently in the U.S., few pregnant women are sufficiently physically active.${ }^{18}$ Based on reports from the 2007 to 2014 National Health and Nutrition Examination Survey, less than 1 in $4(23.4 \%)$ pregnant women performed moderate to vigorous physical activity (MVPA) weekly for 150 minutes or more during leisure-time $;{ }^{18}$ leisure-time PA defined as activities beyond the scope of meeting basic needs. ${ }^{19}$ Moreover, zero prenatal leisure-time PA was performed (i.e., completely sedentary) by $60 \%$ of pregnant women. ${ }^{18}$ For earlier reports from the 1999 to 2006 National Health and Nutrition Examination Survey, Evenson and $\mathrm{Wen}^{20}$ found that MVPA prevalence was $22.9 \%$ among pregnant women. Furthermore, prevalence of achieving the recommended 150 minutes of MPA per week was less than $14 \%$ among pregnant women. ${ }^{20}$

Prenatal PA prevalence further differs by income stratification. ${ }^{2,21,22}$ Across 15 years, 
Behavioral Risk Factor Surveillance System (BRFSS) data indicated a positive linear relationship between prenatal PA and income., ${ }^{2,22}$ From 1994 to 2000, BRFSS data reported highincome pregnant women $(\$ 50,000-\$ 74,999$ and $\geq \$ 75,000$, respectively) were 2.03 to 2.95 times more likely to meet the recommended guidelines for MPA than low-income pregnant women $(<$ $\$ 20,000){ }^{2}$ This trend continued for 2001-2009 BRFSS data which found that high-income pregnant women $(\geq \$ 50,000)$ were 2.5 times more physically active during leisure than lowincome pregnant women $(<\$ 15,000) .{ }^{22}$

\section{Proportion of Low-income Pregnant Women in the United States}

National data consistently show a high proportion of pregnant women in the U.S. are characterized as low-income. ${ }^{1}$ Specifically, 2006 Pregnancy Risk Assessment Monitoring System (PRAMS) data from 25 U.S. states reported $43.1 \%$ of pregnant women had incomes below $\$ 25,000 .{ }^{1}$ In comparison, 2011 PRAMS data from these same states showed that $42.3 \%$ of pregnant women had incomes below $\$ 25,000 .{ }^{1}$ These data taken together illustrate the large number of pregnancies among low-income women that are at-risk for insufficient PA and subsequently demonstrate the utility of PA interventions targeting low-income pregnant women.

\section{Prenatal Physical Activity Interventions}

Many prenatal PA interventions exist, and systematic reviews of these interventions have provided insight into their design and outcomes. ${ }^{23-25}$ A review by Pearce and colleagues ${ }^{23}$ analyzed nine randomized controlled trials of prenatal PA interventions. They reported that the most frequent locale for the prenatal PA interventions was a clinical setting. ${ }^{23}$ A review of 14 randomized controlled trial studies by Currie and colleagues ${ }^{24}$ reported similar findings; hospitals were the most frequent prenatal PA intervention setting. Lastly, Craike and colleagues ${ }^{25}$ reviewed peer-reviewed and grey literature articles on randomized controlled trials and quasi- 
experimental interventions. The authors indicated that only a few of these studies published details on staff demographics or the intervention's fidelity. ${ }^{25}$

The review by Pearce and colleagues ${ }^{23}$ also provided insight into outcomes. Specifically, at post-intervention, PA increased significantly more in the intervention group compared to the control group in three studies. ${ }^{23}$ Comparatively, Currie and colleagues ${ }^{24}$ examined postintervention outcomes among the 10 studies detailing this information and reported that five studies found a higher increase in PA among pregnant participants in the intervention group than in the control group. Additionally, Currie and colleagues ${ }^{24}$ reported that three studies found PA to be higher in the intervention group than in the control group whereas Craike and colleagues ${ }^{25}$ reported that 19 out of the 38 studies found that the intervention group was more physically active than the control group post-intervention. Although these reviews included intervention designs in conjunction with their outcomes, the role of income was not examined. ${ }^{23-25}$ This analysis is imperative given that research has indicated that prenatal PA prevalence differs by income stratification. ${ }^{2,21,22}$ Thus, there is a need to examine and critique prenatal PA interventions which report information on income.

Role of income level in prenatal physical activity interventions. Within the current literature on prenatal PA interventions, three patterns emerge regarding income: (1) it is rarely reported; (2) when it is reported, it is done so with inconsistency across studies; and (3) there are few studies specifically focusing on low-income pregnant women. At present, 10 intervention studies, where the primary intent was to improve prenatal PA levels, provide information about participant income. ${ }^{26-35}$ Given the inconsistencies in reporting income levels, these studies are compared in the following paragraphs using three income classifications: low income (less than $\$ 25,000)$, middle income $(\$ 25,000-\$ 49,999)$, and high income $(\$ 50,000$ or more). This 
classification scheme was based on the household income groupings used in PRAMS (i.e., $<$ $\$ 10,000 ; \$ 10,000-\$ 24,999 ; \$ 25,000-\$ 49,999 ;$ and $>\$ 50,000) .{ }^{1}$

Over half of the studies (6/10) had samples which primarily represented middle- to highincomes. ${ }^{26,29,31-33,35}$ In addition, one study's sample could not be classified due to the way it operationalized the participants' income (i.e., $62 \%$ with an income below $\$ 100,000$ and $38 \%$ with an income from $\$ 100,000$ to $\$ 150,000) .{ }^{34}$ Of particular interest to this review, three of the 10 studies were delivered primarily or exclusively to low-income pregnant women. ${ }^{27,28,30}$ These three studies will be described in greater detail in the following paragraphs.

Two of the three studies ${ }^{27,30}$ had primarily low-income participants and reported the income level of participants. Hawkins and colleagues ${ }^{30}$ found among the pregnant women who reported their income that $42 \%$ had an income at or below $\$ 15,000,15 \%$ of had an income between $\$ 15,000$ to $\$ 30,000$, and $23 \%$ had an income above $\$ 30,000$. In comparison, ChasanTaber and colleagues ${ }^{27}$ found among the pregnant women who reported their income that $56.6 \%$ had an income at or below $\$ 15,000,15.7 \%$ had an income between $\$ 15,000$ to $\$ 30,000$, and $27.7 \%$ had an income above $\$ 30,000$. Both Chasan-Taber and colleagues ${ }^{27}$ and Hawkins and colleagues ${ }^{30}$ operationalized income in the same way which is a strength of their research because it enables comparisons to be made between the studies. For example, one can compare how many pregnant women reported an income below $\$ 15,000$ in both research articles. However, a weakness of these studies was the lack of analysis of changes in PA amount by income level.

The third study ${ }^{28}$ had a sample of pregnant women that solely represented one income level and used the term "low-income" to describe the participants. However, the authors did not provide a definition of the term low-income or statistical data (i.e., ranges) on the participants' 
income. Consequently, an uncertainty exists as to whether Jackson and colleagues ${ }^{28}$ sample was truly representative of low-income pregnant women.

These findings illustrate a lack of prenatal PA interventions delivered primarily to lower income pregnant women. Delivering prenatal PA interventions to all women without considering the role of income is problematic because lower income women likely face different barriers to PA (e.g., access to PA resources) than middle- to high-income women. Without addressing these differences, the effectiveness of prenatal PA interventions may be reduced.

\section{Design and outcomes of prenatal physical activity interventions by income level.}

Prenatal PA intervention designs and their outcomes were not examined in conjunction with income in prior systematic reviews. ${ }^{23-25}$ Therefore, this researcher identified and examined 10 prenatal PA intervention studies that reported information on income and had a primary intent to improve prenatal PA levels post-intervention. ${ }^{26-35}$ Six of these studies ${ }^{26-31}$ were in at least one of the earlier systematic reviews by Craike and colleagues, ${ }^{25}$ Currie and colleagues, ${ }^{24}$ and Pearce and colleagues. ${ }^{23}$ Also, one study ${ }^{34}$ was excluded from this review due to the way it operationalized income, as described in paragraph two of the prior section. Among the remaining nine studies, the following design subcategories were explored in relation to income level: race/ethnicity, locale, setting, PA intervention structure, intervention delivery method, and measurement of PA outcomes. Intervention outcomes were also examined. Emphasis was placed on studies with primarily or exclusively low-income participants.

Race/ethnicity. Prenatal PA interventions stratified by income lacked diverse target populations. The six studies with primarily middle- to high-income participants correspondingly had predominantly White and/or Caucasian participants. ${ }^{26,29,31-33,35}$ In comparison, the three studies with primarily or exclusively low-income participants had predominantly Hispanic 
participants, at $40.5 \%,{ }^{28} 55 \%,{ }^{30}$ and $60.2 \%{ }^{27}$ of the study samples. Among these three studies, the strength was a focus on a less active subpopulation (i.e., compared to Blacks and Whites) ${ }^{36}$ However, a limitation of these studies is that the generalizability is limited because interventions designed for a single race/ethnicity will likely not meet the cultural needs of other races/ethnicities. Researchers that develop prenatal PA interventions going forward should consider race/ethnicity in their design as well as target diverse samples of low-income pregnant women for intervention inclusion.

Locale. Among the U.S. studies in this review (7/9), one was delivered nationally ${ }^{35}$ and six were done in one of four states..$^{27,28,30-33}$ Specifically, interventions were delivered to middleto high-income participants in California's San Francisco Bay Area, ${ }^{32}$ Iowa, ${ }^{31}$ and Pennsylvania, ${ }^{33}$ respectively. For the studies with primarily or exclusively low-income participants, one was delivered in California's San Francisco Bay Area ${ }^{28}$ and two others were delivered in Massachusetts. ${ }^{27,30}$ These studies suggest that prenatal PA intervention research targeting primarily or exclusively low-income women is not concentrated in states where PA is lowest among adult females. ${ }^{37}$ For example, in $2015,58.0 \%$ of adult females in California and $49.6 \%$ of adult females in Massachusetts met the HHS ${ }^{14}$ adult PA guidelines compared to $46.0 \%$ and 35.6\% of adult females in West Virginia and Mississippi, respectively. ${ }^{37}$ Therefore, forthcoming prenatal PA intervention research should be expanded to other states with greatest need (i.e., lowest prevalence of meeting PA guidelines).

Setting (on-site versus off-site). The majority of the studies with predominantly middleto high-income participants were designed to be completed exclusively off-site (e.g., at home or elsewhere) ${ }^{35}$ or primarily off-site (e.g., once in an unspecified on-site setting and then the participants completed the remainder of the intervention off-site, such as at home ) ${ }^{29,31,32} \mathrm{~A}$ 
separate study by Downs and Colleagues ${ }^{33}$ compared one intervention done in an unspecified onsite setting to another intervention done once in an unspecified on-site setting prior to the participants completing the remainder of the intervention off-site (i.e., at home). The final study with predominantly to middle- to high-income participants was done on-site in an obstetrician's office. ${ }^{26}$ For the studies with primarily or exclusively low-income participants, Jackson and colleagues ${ }^{28}$ study was done in on-site settings (i.e., hospitals and academic practices) whereas Hawkins and colleagues ${ }^{30}$ and Chasan-Taber and colleagues ${ }^{27}$ both delivered their studies once in an on-site setting (i.e., medical center) and then participants completed the remainder of the intervention off-site (e.g., at home or elsewhere). Generally, on-site settings, such as clinical settings, may be difficult to utilize among hard-to-reach populations who do not seek early prenatal care or who do not have transportation. Therefore, to reach these hard-to-reach pregnant women, interventions designed to be done in off-site settings (e.g., participants' homes) may be more practical.

Physical activity intervention structure. The Table (see p. 125) outlines the prenatal PA interventions' structures regarding the intervention delivery method, frequency of PA, intensity of PA, amount of time PA was performed, type of PA, and length of the intervention. Overall, the structural features of these prenatal PA interventions varied or were unknown. However, several of the prenatal PA interventions did target aspects of the prenatal PA guidelines ${ }^{, 15,17}$ regarding frequency of PA, intensity of PA, and/or amount of time PA is to be performed. ${ }^{27,30-33}$

Intervention delivery method. When examining intervention delivery, electronic communication was used in most of the studies (7/9) to deliver all or part of the interventions. ${ }^{27-}$ 30,32,33,35 Based on income level stratification, electronic communication was used in four of the six studies that had predominantly middle- to high-income participants..$^{29,32,33,35}$ For example, 
Gaston and Prapavessis ${ }^{29}$ used the telephone and computer to reach participants who lived far from the research setting. Also, Downs and colleagues ${ }^{\prime 33}$ used the telephone to deliver PA counseling for one of their two intervention groups, Huberty and colleagues ${ }^{35}$ tested the influence of receiving prenatal PA text messages on PA behavior, and Choi and colleagues ${ }^{32}$ tested an intervention in which participants used Fitbits and a mobile phone app that delivered prenatal PA messages and videos. In comparison, electronic communication was used in all of the studies that had predominantly or exclusively low-income participants. ${ }^{27,28,30}$ Jackson and colleagues ${ }^{28}$ prenatal PA intervention was delivered through a computer counseling program called Video Doctor and both Chasan-Taber and colleagues ${ }^{27}$ and Hawkins and colleagues ${ }^{30}$ prenatal PA interventions consisted of telephone calls delivered by health educators after an initial in-person meeting. Although electronic communication may reduce the burden of participant travel in some circumstances, these delivery forms may lose the human element of the intervention and add a burden of cell phone, computer, and/or internet access to the participants. Researchers should consider these barriers when designing prenatal PA interventions and explore other avenues of intervention delivery (e.g., in-person home visits) to reach populations that may not have access to the forms of delivery outlined above.

Measurement of physical activity outcomes. Another variation among the studies in this review was the instruments used to measure prenatal PA. Among the studies with predominantly middle- to high-income participants, these measures were used: Fitbits, ${ }^{32,35}$ pedometers, ${ }^{33}$ an altered Godin Leisure-Time Exercise Questionnaire (Downs and colleagues ${ }^{33}$ stated the alterations made in the article whereas Gaston and Prapavessis ${ }^{26,29}$ alterations were evidenced by examining Godin and Shephard's ${ }^{38}$ study), hip worn accelerometers, ${ }^{29}$ and ankle worn accelerometers. ${ }^{31}$ A strength of five of the six studies was the use of objective instruments (i.e., 
accelerometers, pedometers, Fitbits) to measure prenatal PA. ${ }^{29,31-33,35}$ This was a strength because objective instruments can mitigate bias due to recall and social desirability. ${ }^{10,39}$ Still, all six studies also had limitations. First, objective instruments have limitations in what they can measure (e.g., no PA performed in water), are costly to buy and use in research studies, and may be worn incorrectly or not at all. ${ }^{10,39}$ Second, Gaston and Prapavessis ${ }^{26,29}$ did not report that they adapted the Godin Leisure-Time Exercise Questionnaire to ask about 30 minutes rather than 15 minutes of daily PA, as evidenced by Godin and Shephard. ${ }^{38}$ This change may have reduced the instrument's validity. Finally, Downs and colleagues ${ }^{33}$ and Gaston and Prapavessis ${ }^{26,29}$ did not use a validated questionnaire to assess prenatal PA, in comparison to using validated questionnaires outlined by Evenson and colleagues ${ }^{40}$ This shortcoming may have reduced the internal validity of these studies' results. Taken together, these issues reduce validity and hinder comparability among prenatal PA intervention studies. Moving forward, researchers should use validated measures to assess prenatal PA and acknowledge any changes made to them.

Compared to the above studies, none of the three primarily or exclusively low-income studies measuring prenatal PA outcomes used objective PA measurement instruments..$^{27,28,30}$ Instead, two studies ${ }^{27,30}$ administered the Pregnancy Physical Activity Questionnaire. This strengthens the internal validity of these studies because the Pregnancy Physical Activity Questionnaire is a validated instrument. ${ }^{40}$ In contrast to these studies, Jackson and colleagues ${ }^{28}$ administered two questions about PA, which were not validated. ${ }^{40}$ As a result, the validity of this study's PA measurement and subsequent results may be reduced. To improve the validity of study results moving forward, validated measures should be used to assess prenatal PA among low-income women. 
Outcomes. Only two studies in this review analyzed MPA outcomes. ${ }^{27,31}$ These studies assessed prenatal MPA intervention effects among women enrolled relative to a control or comparison group. ${ }^{27,31}$ Among these studies, Chasan-Taber and colleagues, ${ }^{27}$ which had primarily low-income participants, found no statistically significant effects. Comparatively, Kong and colleagues, ${ }^{31}$ which had primarily middle- to high-income participants, found statistically significant effects. Specifically, intervention participants who were overweight had higher prenatal MPA (i.e., walking) levels at 17 to 19, 27 to 29, and 34 to 36 weeks of pregnancy than women in the control group. ${ }^{31}$ Also, intervention participants who were obese had higher prenatal MPA (i.e., walking) levels at 17 to 19 and 34 to 36 weeks than women in the control group. ${ }^{31}$ Taken together, these studies illustrate the need for more studies which focus on MPA outcomes given that MPA is the recommendation for U.S. pregnant women without health restrictions towards PA. ${ }^{15,17}$

A related point to consider is the definition of prenatal PA post-intervention success. Prior research suggests that MPA levels tend to drop when women enter their third trimester. ${ }^{20}$ For example, Evenson and $\mathrm{Wen}^{20}$ found on average that women in their second trimester performed MPA daily for 13.9 minutes whereas women in their third trimester performed MPA daily for 7.4 minutes. Accordingly, the definitions of prenatal PA post-intervention success should not be limited to the intervention group increasing their MPA more or meeting the recommended guidelines for $\mathrm{MPA}^{15,17}$ more than the comparison group. Rather, prenatal PA post-intervention success can also be defined as preventing a decrease in MPA minutes over the course of the prenatal period in the intervention group compared to the comparison group.

Overview. Prenatal PA interventions varied in their design and outcomes. ${ }^{26-33,35}$ Further, only a limited number of these interventions have targeted low-income pregnant women. ${ }^{27,28,30}$ 
This lack of focus on low-income pregnant women indicates that there is a critical need for prenatal PA interventions which target low-income women using a delivery method common among low-income populations.

\section{Home Visitation}

Home visitation is used as an intervention method to reach low-income pregnant women across all 50 U.S. states. ${ }^{4,5}$ At least 45 evidence- and non-evidence based home visitation programs models exisit $;{ }^{5}$ however, a national monitoring system is not in place to track services. ${ }^{4}$ Even so, recent reports showed home visits exceeded 2.3 million in 2015 among a subsample of four U.S. evidence-based home visitation program models reporting data (i.e., Healthy Families America, Home Instruction for Parents of Preschool Youngsters, Nurse-Family Partnership, Parents as Teachers). ${ }^{4}$ Furthermore, in 2015 , U.S. poverty guidelines were met by over $75 \%$ of the 79,062 families receiving home visits from federally funded home visitation program models (i.e., funded with Maternal, Infant, and Early Childhood Home Visiting funds). ${ }^{4}$

Many home visitation program models are similar in that they facilitate the connection of clients to resources through home visits done by a trained professional (e.g., peer, nurse, social worker) within the home of the client. ${ }^{4,41}$ Additionally, home visitors often deliver extensive health education curricula modules to their clients. ${ }^{6,42,43}$ Within these curricula modules, prenatal PA and/or exercise is a topic (hereafter, "prenatal PA modules") covered by different home visitation program models. ${ }^{6-8}$ However, there is limited scientific evidence on home visitation program models' prenatal PA modules. ${ }^{8}$

Empirical support is needed to assess the effectiveness of prenatal PA modules on lowincome women's prenatal PA levels. Ideally, a comprehensive evaluation of the different home visitation program models' prenatal PA modules should be done and compared to each other. At 
present, only one study has assessed the outcomes for one home visitation model's prenatal PA modules in use. ${ }^{8}$ A key finding from this study was that the change in MVPA levels over months four to eight of pregnancy was the same for women who were subdivided into two distinct prenatal PA modules (Parents as Teachers curriculum and Parents as Teachers Enhanced curriculum). ${ }^{8}$ Although this study's findings were important, three notable limitations were present: (1) income level data were not reported, (2) a comparison group not receiving any prenatal PA module was not used to determine intervention effects, and (3) the structural capacity and processes of the prenatal PA module were not assessed. ${ }^{8}$ Consequently, a matter of conjecture remains regarding the structural capacity, processes, and outcomes of the different home visitation program models' prenatal PA modules.

A framework that can be applied to comprehensively evaluate the different home visitation program models' prenatal PA modules is Handler and colleagues ${ }^{44}$ Conceptual Framework for the Public Health System. This framework consists of the "Macro Context" which influences the "Public Health System". ${ }^{44}$ Within the "Public Health System" is the "Public Health System Mission and Purpose" linked to the interconnected units comprised of "Structural Capacity" (i.e., resources and relationships), "Processes", and "Outcomes". ${ }^{44}$ In applying this framework to home visitation program models' prenatal PA curricula modules, particular attention needs to be given to: (1) the home visitors' knowledge, skills and abilities in delivering the prenatal PA modules (i.e., the human resources subcomponent of structural capacity), ${ }^{45,46}(2)$ whether home visitors implement the prenatal PA modules with fidelity (i.e., process), and (3) the effectiveness of the prenatal PA modules (i.e., outcomes). A joint focus on these three areas is needed to attain comprehensive evaluations of the different home visitation program models' prenatal PA modules. 
As a first step in putting Handler and colleagues ${ }^{44}$ framework into practice, researchers should target home visitation program models delivering prenatal PA modules to low-income women in states where PA is lowest among adult females. One home visitation program model that fits these criteria is the Maternal Infant Health Outreach Worker (MIHOW) program. The MHOW program's services are primarily offered to pregnant women or families with a child younger than 3 years of age meeting one or more of the following conditions: (1) lowincome, ${ }^{47,48}$ (2) no social support, ${ }^{48}$ and/or (3) isolated due to household location (e.g., rural locale). ${ }^{47,48}$ Moreover, the MIHOW program's services are implemented in Kentucky, Mississippi, Tennessee, and West Virginia ${ }^{47}$ which in 2015 were the states who ranked $6^{\text {th }}, 1^{\text {st }}$, $8^{\text {th }}$ and $11^{\text {th }}$ lowest in the U.S. for the percentage of females who met the adult PA guidelines. ${ }^{14,37}$ These aspects make the MIHOW program a key home visitation program model to evaluate in order to understand the staff capacity to deliver, processes to implement, and outcomes of its prenatal PA modules.

\section{Problem Statement and Research Aims}

To understand the use of home visitation program models' prenatal PA modules as interventions to improve PA among low-income women, a comprehensive evaluation of these modules is needed. To date, only one study has examined the outcomes ${ }^{8}$ and no studies have examined the structural capacity or processes associated with home visitation program models' prenatal PA modules. Furthermore, no study has examined the staff capacity, processes, or outcomes associated with the MIHOW program's modules pertaining to prenatal PA. Thus, the aims of this study were to (1) examine home visitors' (i.e., Outreach Workers [OWs]) competencies in implementing the MIHOW program's prenatal PA modules, (2) investigate the fidelity with which the MIHOW program's prenatal PA modules were delivered to home 
visitation clients, and (3) evaluate the impact of the MIHOW program's curriculum on home visitation clients' prenatal MPA compared to a propensity score matched comparison group. 
Chapter 3. A Qualitative Assessment of Home Visitors' Knowledge, Skills, and Abilities in Delivering Prenatal Physical Activity Curriculum Modules 


\begin{abstract}
Different early childhood home visitation program models include prenatal physical activity (PA) modules within their curricula. This study's intent was to examine home visitors' knowledge, skills, and abilities (KSAs) in delivering these modules, by conducting three focus groups and one interview with home visitors, "Outreach Workers" (OWs), and five interviews with Site Leaders from the Maternal Infant Health Outreach Worker (MIHOW) home visitation program. Findings showed: (1) OWs' depth of knowledge on prenatal PA information and the modules varied; (2) over half the OWs discussed implementing PA, rapport building, communication, adaptability, and/or problem-solving skills; (3) over half the OWs felt comfortable delivering the modules; and (4) OWs' KSAs were influenced by their life experiences and by their clients either directly or indirectly. These findings suggest that prenatal PA is an important aspect of the MIHOW program and that OW' KSAs could be enhanced through a prenatal PA focused competency and trainings.
\end{abstract}




\section{Introduction}

In the United States (U.S.), early childhood home visitation program models ("programs") are part of a large public health system working to address the health disparities experienced by disadvantaged pregnant women and/or families with young children (e.g., lowincome families, families with a child who has a developmental disability). ${ }^{1}$ Over 14,500 home visitors were employed in the U.S. in 2015 by eight evidence-based home visitation programs. ${ }^{1}$ Additional home visitors were also employed by at least 17 other home visitation programs, ${ }^{2}$ including five evidence-based home visitation programs - although 2015 employment statistics were unreported for these home visitation programs. ${ }^{1}$ This home visitation workforce is composed of peers, ${ }^{3}$ nurses, and social workers, among others, ${ }^{1}$ who deliver in-home services to clients. $^{1-4}$

In accordance with Handler and colleagues ${ }^{5}$ Conceptual Framework of the Public Health System, home visitors represent one "human resource" among many fulfilling the public health services of the maternal and child health system. The performance of this system, or any organization or program within the system (such as a single home visitation program), is heavily dependent on the capacity, including the workforce's capacity, to implement processes and provide services to recipients. ${ }^{5}$ Home visitors in particular are a critical human resource in the maternal and child health system due to their broad national coverage ${ }^{1}$ and, as such, their knowledge (i.e., known information on a topic), skills (i.e., strategies used to deliver information), and abilities (i.e., comfort level in using their knowledge and skills with clients) are vital in delivering in-home services.

Home visitors deliver in-home services ${ }^{1-4}$ often following curriculum modules that cover a wide variety of topics (e.g., child development, substance use, prenatal physical activity 
$[\mathrm{PA}]) .^{6-8}$ For this reason, home visitors must possess a broad array of knowledge, skills, and abilities (KSAs). In an attempt to organize these broad competencies, over 100 competencies applicable to the home visiting workforce were outlined in the National Family Support Competency Framework published in June 2018. ${ }^{9}$ Notably, an "Exercise" competency with a focus on family exercise was included within the framework. ${ }^{9(\mathrm{p} 22)}$ Missing from this framework though was a competency on prenatal PA, inclusive of exercise, ${ }^{9}$ despite different home visitation programs having curriculum modules on this topic; ${ }^{6,10,11}$ the existence of national evidence-based guidelines recommending that healthy pregnant women participate in weekly, moderate-intensity, aerobic $\mathrm{PA}^{12,13}$ for 150 minutes or more; ${ }^{13}$ and a call for the use of PA curriculum modules with prenatal and post-partum women and their families as an intervention against childhood obesity. ${ }^{14}$

Although a broad competency about PA is important, it is worth noting that curricula ${ }^{15}$ and workforce qualifications ${ }^{1}$ vary among home visitation programs. For instance, the Maternal Infant Health Outreach Worker (MIHOW) program hires peers but does not specify an educational requirement, ${ }^{3,16}$ whereas Nurse-Family Partnership hires individuals with a bachelor's degree in nursing. ${ }^{1}$ Thus, any investigation of home visitors' KSAs should be conducted with specific focus on one home visitation program to inform program-specific training.

The focus of this study was the MIHOW program, which has unique design features. The MIHOW program was designed to strengthen the help that women traditionally offer each other during pregnancy and early parenting in communities where health resources are limited. The breadth and complexity of the information and support provided to mothers is possible because of the program's approach to planning home visits. For each home visit, preparatory 
articles and other information are provided to home visitors, known as Outreach Workers (OW), to facilitate their design of each home visit based on the mothers' individual needs. The OWs use the MIHOW program's curriculum, handouts and educational tools to help the mothers understand a wide variety of topics including the elements and importance of prenatal care, strategies for self-care during pregnancy and after the birth, maternal and child nutrition, early child development, preventive health, literacy and the importance of reading to children, maternal goal setting, self-esteem and problem solving, communication strategies that can enhance family relationships, and physical activity. ${ }^{6}$

Prenatal PA as a topic is included in three of the 33 modules in The MIHOW Home Visit Guide: The Prenatal Period (herafter, "curriculum guide") as one of many important facets that the MIHOW program covers on pregnancy and parenting. ${ }^{6}$ The curriculum guide includes one module focused on prenatal PA and two modules where prenatal PA is included as secondary content (i.e., the module focus was not prenatal PA). ${ }^{6}$ The module focused on prenatal PA includes a handout; discussion points on prenatal PA safety; and activities to be completed with clients, such as assessing PA participation, planning PA, and assisting with goal setting. ${ }^{6}$ The modules where prenatal PA is included as secondary content include discussion points on the benefits of prenatal PA and/or activities to be completed with clients, such as planning PA. ${ }^{6}$ The MIHOW programs inclusion of prenatal PA as a module is important since one of its target populations is low-income pregnant women, ${ }^{3,16}$ who typically are less physically active than high-income pregnant women. ${ }^{17,18}$ Also, the MIHOW program operates in four states in the bottom quartile for female prevalence of meeting the Physical Activity Guidelines for Americans. ${ }^{19,20}$ 
A notable feature of the MIHOW program is its use of peers as OWs to deliver its modules. ${ }^{3,16}$ The MIHOW program's strategy of hiring peers as the OWs ${ }^{3,16}$ enables the MIHOW program to work with hard-to-reach clients that are demographically and culturally similar to the OWs. ${ }^{3}$ However, due to this hiring strategy, the OWs may also have unique training needs to build KSAs to augment their educational background. For instance, the MIHOW program's new hire training for OWs does not cover prenatal PA content. Rather, OWs are required to have monthly trainings covering a wide variety of topics related to pregnancy and parenting and are encouraged to use the information and materials gained through those trainings on home visits (see Elkins and colleagues ${ }^{3}$ for further details on the MIHOW program). There has not yet been an evaluation of OWs' competency in delivering prenatal PA content, however.

With these points in mind, an evaluation of the capacity of MIHOW OWs in delivering prenatal PA curriculum modules (hereafter, "prenatal PA modules") was performed to inform future OW training and the development of a prenatal PA competency for the home visitation workforce. The purpose of this qualitative descriptive study was to examine OWs' competencies in implementing the prenatal PA modules of the MIHOW program. The guiding research questions assessed: (a) the OWs' KSAs in delivering these modules, and (b) the Site Leaders' (SLs') perceptions of the OWs' KSAs in delivering these modules.

\section{Methods}

\section{Study Setting}

This study focused on the MIHOW staff who provided services in one Middle Atlantic state. In August 2017, twenty-two OWs were employed across four sites in the state. At the time of this study, three sites had one SL (i.e., supervisor) and one site had two Co-Leaders. Between December 2016 and April 2018, approximately 117 prenatal clients received services. 


\section{Study Design}

This study was guided by the Pragmatism Interpretive Framework ${ }^{21}$ and by the qualitative descriptive research approach outlined by Sandelowski. ${ }^{22}$ The Pragmatism Interpretive Framework guided our research design and influenced (1) the primary intent of this study being to answer the research questions, and (2) answering these questions through utilizing two qualitative methods and two sources of data. ${ }^{21}$ Moreover, the qualitative descriptive research approach was chosen in order to present the data as described by the OWs and SLs rather than as described through in-depth interpretations of the data by the research team. ${ }^{22}$ Applied together, the Pragmatism Interpretive Framework ${ }^{21}$ and the qualitative descriptive research approach led to the rich summary of the OWs' KSAs in delivering the prenatal PA modules presented in the results.

The two qualitative methods used to gather the data were: (1) focus groups with MIHOW OWs, and (2) in-person, semi-structured, one-on-one interviews with MIHOW SLs. A singular recruitment procedure led to the collection of both sources of data. The participants, data collection, and measures for each source of data differed and are therefore described separately.

\section{Sampling Frame}

Outreach Workers. Study participation was open to OWs who met all of the following conditions: (a) were currently working for the MIHOW program, (b) had at least a Level 1 completion of the Competencies for OWs, ${ }^{23}$ and (c) had discussed prenatal PA at one or more home visit(s). 
Site Leaders. Study participation was open to the SLs who were supervising the OWs in this study. The SLs were interviewed to cross-verify the study findings about the OWs' KSAs from a different source. ${ }^{24}$

\section{Recruitment}

All interview and focus group participants were recruited through purposive sampling. ${ }^{21}$ As the first step, study approval was sought and obtained from the MIHOW program's leadership and Institutional Review Board approval was obtained (protocol number 1801913621). After approval was granted, SLs from four delivery sites were separately emailed the following: (a) a recruitment paragraph, (b) an interview cover letter, and (c) a focus group cover letter. The email invited the SLs to participate in an interview and asked them to (a) respond by email if they wanted to participate in the study, (b) share the focus group cover letter and information with their OWs who met the focus group eligibility criteria, and (c) email the first author (AMD) the OWs' contact information who wanted to volunteer or instruct their OWs to complete this step.

\section{Outreach Worker Focus Groups}

Data collection. Three focus groups, consisting in size of two, three, and four participants, were held at the offices of the OWs. The fourth site had only one OW. Thus, an inperson, semi-structured one-on-one interview was conducted with this participant. The interview and focus groups ranged from 55 to 95 minutes. Both the interview and focus groups were conducted by the first author from March 5, 2018 to March 23, 2018, audio recorded, and done in a private location. The private location was generally devoid of interruptions and nonparticipants. Food and a $\$ 20 \mathrm{Wal}^{*}$ Mart ${ }^{\circledR}$ gift card were provided to participants. Before each focus group and interview, three steps were completed: (1) the cover letter was read aloud and 
clarified, (2) the participants were asked to complete a Focus Group Participant Demographic Questionnaire (see Appendix 1), and (3) verbal informed consent was obtained. After obtaining consent, the first author conducted the focus groups and interview using a semi-structured focus group guide with open-ended questions (see Appendix 2). Brief field notes were taken throughout by the first author. Focus group field notes were also taken by the second (SMD) or seventh (RES) author. At the end of each focus group and interview and again after data analysis, member checking (verifying what the participants said) ${ }^{24}$ was done by the data collector. Specifically, after data analysis, the first author sent a Qualtrics ${ }^{25}$ link to the participants via email. The link, when clicked, displayed a summary of the findings (i.e., themes) and prompted participants with a series of questions to agree with or comment on what was missing or wrong with the findings.

Measures. The MIHOW OW Focus Group Guide was developed by the first author. It encompassed guiding open-ended questions to examine the OWs' perceived KSAs in delivering the MIHOW program's prenatal PA modules to their clients. KSA example questions from the guide are as follows: (1) knowledge: "Can you tell me a little bit about what the MIHOW prenatal home visit guide says in regard to physical activity during pregnancy," (2) skills: "How might you rate your skills in discussing the physical activity during pregnancy curriculums in MIHOW's prenatal home visit guide with your clients," and (3) Abilities: "How does the physical activity during pregnancy curriculums influence or not influence your ability to discuss physical activity with your clients?" OWs were not asked questions about the national prenatal PA guidelines. ${ }^{12,19}$ Although this guide was not pilot tested, the content was reviewed prior to its use by the third (DMD) and senior (CGA) authors with prior experience conducting qualitative research among home visitors. 
Data analysis. Each audio recording was transcribed verbatim by a paid professional transcriptionist and checked for accuracy by the first coder (AMD). NVivo $11^{26}$ was used for data analysis.

Table 1 shows the 12 steps of the qualitative data analysis process. During Steps 1 through 9, a conventional content analysis approach was used to analyze the data. ${ }^{27}$ Codes derived from Step 3 were recorded by the first coder in a code book. The code book was shared with the second (SMD) and third coder (CGA) before proceeding to Step 4. During Step 10, a directed approach was taken in which the categories were organized into the research question focus areas of KSAs. ${ }^{27}$ Finally, during Steps 11 and 12, a conventional content analysis approach was used to identify sub-themes within and across each theme. ${ }^{27}$

----- Table 1 about here -----

Throughout analysis, intercoder agreement was reached through subjective assessment. ${ }^{28}$ This process consisted of frequent debriefing meetings to discuss the codes, categories, and themes and the consultation of a third coder for discrepancies that arose. ${ }^{28}$ The decision to use the subjective assessment procedure over quantitative methods of agreement was guided by the literature. Specifically, this research team had a small number of transcripts to analyze $(\mathrm{N}=9)$ and both coders coded each transcript in their entirety whereas quantitative methods of agreement are described as useful if a high number of transcripts require analysis and a portion of the transcripts are not coded by each coder. ${ }^{28,29}$

\section{Site Leader Interviews}

Data collection. Four in-person, semi-structured one-on-one interviews were held at the offices of the SLs and one semi-structured one-on-one interview was held by telephone. 
Interviews were conducted in a location that was generally devoid of interruptions and nonparticipants by the first author from March 5, 2018 to April 10, 2018, audio recorded, and finished in 48 to 71 minutes. Food was provided to in-person participants and a $\$ 20 \mathrm{Wal}{ }^{*}$ Mart ${ }^{\circledR}$ gift card was provided to all participants. Before each interview, three steps were completed: (1) the cover letter was explained, (2) the participants were asked to complete an Interview Participant Demographic Questionnaire (online via Qualtrics software, Version $37.892^{25}$ for the phone interviewee, see Appendix 3), and (3) verbal informed consent was obtained. After obtaining consent, the first author conducted the interviews using a semi-structured interview guide with open-ended questions (see Appendix 4). Field notes were taken throughout the interview. The member checking process was equivalent to the member checking process used for the focus groups.

Measures. The MIHOW SL Interview Guide was constructed by the first author. It encompassed guiding open-ended research questions to examine the MIHOW SLs' perceptions of the OWs' KSAs in delivering the prenatal PA curricula module to their clients. KSA example questions are as follows: (1) knowledge: "How knowledgeable are the home visitors of the physical activity during pregnancy curriculums in the MIHOW prenatal home visit guide," (2) skills: "What is your opinion of the home visitors' skills in discussing the physical activity during pregnancy curriculums in MIHOW's prenatal home visit guide with their clients," and (3) Abilities: "How effective do you think the physical activity during pregnancy curriculums are at helping the home visitors discuss physical activity with clients?" Similar to the MIHOW OWs Focus Group Guide, the MIHOW SL Interview Guide was not pilot tested but the content was reviewed prior to its use by the same two authors (DMD, CGA) that reviewed the focus group guide. 
Data analysis. Interview audio file transcription and analysis procedures matched the procedures used for the focus groups.

\section{Data Presentation}

Table 2 shows the coding structure for the themes of Knowledge, Skills, and Abilities. Codes that were assigned to participants' responses were organized into unifying categories and fit into sub-themes. In one instance, the cross-cutting categories of "client generated influencer", "physical activity guidance", and "staff attributes" were sorted into the sub-theme of Influencers with applicability to each of the three themes. In other instances, categories were sorted into subtheme(s) with applicability only to a sole theme. For example, the sub-theme of External Prenatal PA Knowledge is only applicable to the theme of Knowledge. The naming presented for the themes and sub-themes in Table 2 aligns with the results presented below. The naming presented for the categories and codes in Table 2 does not consistently align with the results presented below, however, because data collection and analysis (i.e., assigning codes and categories) was done simultaneously for three studies. Therefore, a description of what data formed each theme and sub-theme is provided in the results.

----- Table 2 about here -----

Quotes were cleaned to enhance readability (e.g., extra or unfinished words were removed, consecutive repeated words or word groupings were removed).

\section{Results}

\section{Data Saturation}

Data saturation was discussed by the first and second coders at the in-person meeting held to discuss preliminary codes. The first and second coders concluded that data saturation had 
been reached because reoccurring information was present in the discussions with the OWs across the MIHOW sites. Also, the coders did not identify any findings they felt the need to follow-up on with the participants.

\section{Participants}

Outreach Worker participants. Ten OWs participated in the study. The OWs' median age was 45 years $(\mathrm{IQR}=38-49$ years $)$. Among the OWs, nine self-identified as nonHispanic/Latino, nine self-identified as Caucasian/White; six self-reported having an undergraduate college degree or higher, and eight reported working part-time as a MIHOW OW. Eight of the OWs had worked as a MIHOW OW for less than four years.

Site Leader participants. Five SLs participated in the study. The SLs' median age was 42 years $(\mathrm{IQR}=40-63$ years). Among the SLs, five self-identified as non-Hispanic/Latino, Caucasian/White; three self-reported as having an undergraduate college degree or higher, and four reported working full-time as a MIHOW SL. All of the SLs had worked as a MIHOW SL for 4 or more years.

\section{Outreach Workers' Knowledge, Skills, and Abilities}

Knowledge. Data on the OWs' perceptions and knowledge of prenatal PA external to the prenatal PA modules; the OWs' awareness of the curriculum guide, inclusive of the prenatal PA modules; and the factors influencing the OWs' knowledge in delivering the prenatal PA modules (i.e., sub-theme of Influencers) formed the theme of Knowledge. Key aspects in the discussions among the OWs and SLs centered around the OWs' prenatal PA knowledge external to the curriculum guide and the OWs' awareness of the curriculum guide. This information formed the 
sub-themes of External Prenatal PA Knowledge and Curriculum Guide Awareness as shown in Table 2. Each sub-theme is presented in-depth in the sections below.

External prenatal physical activity knowledge. Data on the OW' perceptions and knowledge of prenatal PA (e.g., low-impact activities, social-oriented activities) that were not specified as deriving from the prenatal PA modules formed the sub-theme of External Prenatal PA Knowledge. Individually, the OWs' depth of external knowledge described on prenatal PA varied and revealed insightful perceptions about healthy PA during pregnancy. All of the OWs shared the perception that low impact activities constitute PA and indicated that prenatal PA is beneficial for women's mental and/or physical health.

Over half of the OWs shared the perception that low intensity, low impact activities, with an emphasis on household activities, constitute PA. This was clearly described by OW 2 who stated, "Washing dishes, cleaning up. I mean anything that you do that requires moving is physical activity,” and OW 7 explained, “They're getting physical activity when they're up cutting and preparing food." Another OW also said, "Walking is usually the safest unless someone's been limited by their physician." (OW 3). This notion was clearly supported and well described by SL 5 who commented,

I guess, when you say physical activity during pregnancy, I don't really think of going out and exercising. I guess when it comes to my mind, I just think of getting up and doing your everyday activities, life activities, which means getting dressed, taking your kids to school, going to the grocery store, and running errands.

In line with this common perception of PA among the OWs, eight of them also discussed how PA is linked to mental health benefits. Broadly, OW 4 commented, "Exercise as medicine," 
and OW 2 explained, "If mom isn’t happy, nobody's happy.... and it starts with physical activity." In more detail, OWs mentioned reductions in anxiety, stress, and depression as key mental health benefits of being active. Supplemental to these remarks, OW 5 replied “... exercise is the most underutilized anti-depressant, anti-anxiety medication out there."

Positive impact on the birthing process was the most commonly described physical health benefit linked with prenatal PA by six OWs. OWs 2 and 7 discussed how PA impacts labor. An additional labor and delivery benefit of prenatal PA was described by OW 6: "Labor and delivery, making sure that they understand the toning, the breathing. All of this factors into having a positive birth experience."

Curriculum guide awareness. Data on the OWs' awareness of the content of the prenatal PA modules formed the sub-theme of Curriculum Guide Awareness. It is important to note that the OWs are not expected to memorize the content of the modules, including handouts. Instead, due to the wide range of topics that they cover, they are instructed to use the curriculum guide and its modules to facilitate the design of the home visit based on the mother's individual need(s). Thus, the OWs diverged in their reports on what content is in the prenatal PA modules specifically about if the curriculum had information on stretching and if the curriculum recommended the OW walk with the participant or if the OW should simply encourage the participant to walk on her own time. Adding to the OWs' reports, the SLs uniformly perceived that their OWs were knowledgeable of the prenatal PA modules. As SL 2 articulated, “... I think exercise is something that our home visitors know well."

Skills. Data on the OWs' actions in implementing didactic and therapeutic strategies to deliver the curriculum and the factors that influence these actions (i.e., sub-theme of Influencers) formed the theme of Skills. Key aspects in the discussions among the OWs and SLs revealed that 
the OWs often utilize strategies such as PA, rapport building, communication, adaptability, and/or problem-solving to engage and educate their clients. Data on PA, Rapport Building, and Communication formed distinct sub-themes and are shown in Table 2 and presented in-depth in the sections below. The adaptability and problem-solving skills are related to the sub-theme of Influencers and are described in the Influencers section.

Physical activity. Data on the OWs demonstrating or participating in (i.e., modeling) PA with clients formed the sub-theme of PA. Eight of the OWs have skills they use to enhance the delivery of the prenatal PA modules, which was evident through their descriptions of how they demonstrate or model PA with their clients. OW 7 said,

Well, the Home Visitor Guide tells you how to do it with them. You can give it to them as a hand out, but I'm a hands-on person, so I'll show them. We'll do it together, just to make sure that it's step-by-step what's on the hand-out, so that they won't overdo themselves or hurt themselves or anything like that.

In conversations with the OWs' SLs, four SLs also noted OWs demonstrating or participating in (i.e., modeling) PA with clients. One SL even described an exercise class facilitated by their site and how the OWs teach fun ways to exercise in the class:

They actually just do different things like teaching them how to do things at home to exercise and get physical activity. They did one class where they taught them line dances and showed them that they could get exercise just by having fun and dancing. (SL 1)

Although PA skills were present among most of the OWs, one OW shared a lack of knowledge on how to do personal PA. As a result, the OW did not know how to demonstrate PA 
properly with clients. Specifically, OW 8 stated, "Well, just once again not knowing how to deliver it properly. Even when I exercise on my own at home, I don't know if I'm doing it right. Then, I wake up the next day and I'm horribly tired and sore."

Rapport building. Data on the relationships and trust between the OWs and their clients formed the sub-theme of Rapport Building. Rapport was often described as playing a key role in the home visits and, once established, is the bedrock for curriculum delivery, clients sharing and seeking guidance from the OWs, and clients trusting in the OWs' advice. Accordingly, over half of the OWs expressed spending time building this rapport with their clients. As one example, OW 1 explained how building rapport with clients was needed before any of the curriculum was delivered:

I feel like where I'm at right now is I'm still building relationships with these women. I don't want to say that I haven't followed the curriculum, because I do. I give my handouts and I talk about those, but I haven't pushed anything. Do you know what I mean? I don't feel like I really have built those relationships to the point where I can just be like, "You know what? This is what you need to do." I feel like I'm still just kind of working on... building relationships with these clients.

Reciprocally, OW 5 described how developing relationships with clients can, over time, lead to clients seeking guidance (even medical guidance) from their OW:

That's the thing too because as time progresses, you do get the relationship. You do develop these relationships. These women trust you over their pediatrician. I can't tell you how many times I've had clients call me and say, "The doctor told me this. Is this okay?" So, there's that level of trust. 
Another OW also indicated how building rapport with clients can lead to clients telling them that they are not going to participate in PA. Specifically, OW 9 stated, "You build that rapport with them to where they'll just tell you. ... 'just don't want to do it!'" The importance of these rapport building skills for PA were corroborated by SL 2:

So, visitors have pretty close relationships with their families. They build those as they visit, so they know what the woman is already doing. If she's participating in something like yoga or an exercise class, then they would know that and they would be able to support that and encourage that, as long as there's no medical reason they couldn't.

Communication. Data on the OWs engaging and interacting with clients formed the subtheme of Communication. More than half of the OWs described using their communication skills to facilitate curriculum delivery. For example, OW 1 explained that, during a home visit, she starts with conversation and when the participant mentions something she can tie into the visit's objectives, she transitions into curriculum delivery. OW 1 continued, “... I feel like it just kind of sets it up and I'm just used to doing it that way." One specific skill mentioned was active listening. For example, OW 7 commented, “And then I say, 'Did I hear you say this?' Repeat it back to them."

When asked directly about their skills in delivering the prenatal PA modules, the OWs gave varying scaled responses, with more than half at the midpoint of the scale or higher. Three OWs did rank their skills lower or with uncertainty, suggesting an opportunity for training and learning from their peers. Importantly, for conversations focused on PA, OW 6 detailed the process of guiding such conversations: 
So, I always say, "Have you been outside? Did you get fresh air today," or, ". . . What have you done? What's been the routine for the day? Has it been busy? Has it been quiet," and again, we let them guide us in that direction. We know where we want to go, but we're trying to let them open the door for us to guide it without too much pressure, but they're pretty open to it, usually. I mean you are coming to spend time with them; they're pretty pumped about that.

Adding to the OWs' perceptions of their skills, none of the SLs perceived that their OWs were unskilled in delivering the prenatal PA modules. One SL highlighted the strength-based approach and another noted the varying approaches of OWs and their many important counseling skills:

...I feel like she just has really good engagement skills. She's really good at engaging people in what we're going to talk about today ... she uses her facial expressions and her body language to let people know that she's interested in what they have to say. So, she uses her engagement skills, but she also is very gentle in the way that she talks to people. Me, I'm brash and I'm loud and I'm overpowering and her, she's super sweet and like, "What do you think about this?" So, everyone kind of has their different approach... (SL 3)

Abilities. Data on the OWs' comfort level in delivering the prenatal PA modules and the factors that influence their comfort level in delivering the prenatal PA modules (i.e., sub-theme of Influencers) formed the theme of Abilities. The key aspect in the discussions among the OWs and SLs centered around the OWs' comfort level in delivering the prenatal PA modules. This information formed the sub-theme Comfort Level as shown in Table 2. The sub-theme is presented in-depth in the section below. 
Comfort level. Data on the OWs' comfort level in delivering the prenatal PA modules formed the sub-theme of Comfort Level. Eight of the OWs felt comfortable delivering the prenatal PA modules. To demonstrate, OW 7 stated "We always discuss it, there's nothing to hold us back. We follow the curriculum." Also, OW 6 remarked, "I'm comfortable with it." and OW 3 added, "I don't think it's anything too intrusive." On the other hand, two OWs expressed some discomfort with recommending exercises or teaching exercise techniques because of limited knowledge about exercise safety. OW 5 explained,

I'm not comfortable saying to someone, "Hey, this is how you exercise," because I don't know. I look at this handout, but what if my interpretation of this handout is different than the true intention of how that was supposed to be done, and then they get hurt?

All of the SLs perceived that their OWs were comfortable in delivering the prenatal PA modules.

Influencers. Data on the factors that influence the OWs' KSAs in delivering the curriculum modules, including the prenatal PA modules, formed the sub-theme of Influencers, which had applicability to the themes of Knowledge, Skills, and Abilities (see Table 2). This sub-theme included training the OWs have received, the ease of using the curriculum guide, and work experience as an OW. The two primary influencers, however, were their own attributes (i.e., staff attributes) and their clients directly or indirectly influencing them (i.e., client generated influencer). These influencers were distinct categories within this sub-theme and are described in the sub-sections below.

Staff attributes. Data on the OWs' attributes, particularly their life experiences, that influence their KSAs in delivering the prenatal PA modules formed the category of staff attributes. Five of the OWs discussed how their life experiences influenced their knowledge, 
skills, and/or abilities in delivering the prenatal PA modules. Life experiences the OWs referenced included being a parent and having different backgrounds. For example, when the OWs were asked how comfortable they were in discussing the PA during pregnancy curriculum, OW 4 stated, “. . I've been a personal trainer for 15 years, and a competitive runner and all that kind of stuff, so I know it inside out" Later, when asked how they might rate their skills in discussing the PA during pregnancy curriculum in the MIHOW prenatal guide, OW 4 responded, "I think mine's pretty good. But, again, I come from a different background, from a physical activity background." Consistent with what OW 4 described, SL 4 explained that "All of the staff come from different backgrounds.... So, they bring that with them those skills that are associated with that." These backgrounds included life, academic, and/or professional experiences with poverty, public health, personal training, and preschool education.

Client generated influencer. Data on clients directly or indirectly influencing the OWs' KSAs in delivering the curriculum modules, including the prenatal PA modules, formed the category of client generated influencer. As an example, a direct influencer may consist of a client teaching her OW information on a topic. Comparatively, an indirect influencer may consist of an OW observing that her client has a health problem and subsequently adapting the prenatal PA module(s) to fit the client. Consistent with the program's emphasis on individualizing the home visits and focusing on the strength of clients, more than half of the OWs described how their knowledge, skills, and/or abilities were influenced by their clients either directly or indirectly. OW 10 described this knowledge attainment as their clients teaching them information, whereas OW 6 described gaining knowledge from research they do using MIHOW resources (e.g., the MIHOW website, supervisor, directors) and outside resources (e.g., local doctors, websites) to address issues with their families. OW 6 explained, 
We learn something new every day. So just researching ourselves. If we have a specific issue with a family, it's our duty to study up on those things and at least educate ourselves about what questions to ask or concerns to watch for.

Critical to this point, all the OWs discussed how they adapt and problem solve because of their clients' situations regardless of curriculum module. For instance, OW 3 remarked,

Discussions with my participant that has the heart issues opened up the door for her to tell me about her heart condition and her concerns about that and so you just have to be open to go wherever the conversation takes you.

Likewise, all the SLs discussed how OWs adapt and problem solve. SL 2 pointed out: ... they're not going through a checklist. They're talking to this mom and talking about her concerns and what she needs and what she feels she wants and figuring out ways to provide the information. I make home visitors sound like they're wonder women, and they pretty much are.

\section{Discussion}

This was the first study to investigate home visitors' KSAs in delivering prenatal PA modules. The HVs in this study - MIHOW OWs - expressed having inherent abilities and learned therapeutic skills that are applicable in promoting PA among low-income pregnant women, specifically building rapport, communicating, and solving problems with clients. With respect to PA knowledge and skills, the OWs appeared to prioritize low intensity, low impact activities over moderate-intensity activities; supplement their knowledge through resources external to the curriculum guide; and have different levels of PA skills. These opportunities for knowledge and skill improvements could be addressed by establishing a prenatal PA competency to drive PA- 
specific trainings, providing the home visiting workforce with knowledge and skills transferrable across home visiting programs. Our findings highlight the need for prenatal PA competencies that will be discussed in subsequent paragraphs, such as (1) knowledge of the prenatal PA guidelines; ${ }^{12,13}$ (2) knowledge on the frequency, intensity, time, type, volume, and progression (FITT-VP) principle of PA; ${ }^{30}$ (3) skills on how to apply the FITT-VP principle of PA; $;^{30}$ (4) skills on how to safely demonstrate prenatal PA with clients; and (5) knowledge of reputable prenatal PA information sources (e.g., U.S. Department of Health and Human Services ${ }^{\text {'13 }}$ Physical Activity Guidelines for Americans, $2^{\text {nd }}$ edition; American College of Obstetricians and Gynecologists ${ }^{12}$ prenatal PA guidelines).

Much of what the OWs knew about prenatal PA was influenced by their background, the information they sought to augment their own knowledge, and professional training. In order for OWs to reach a prenatal PA competency, trainings inclusive of evidence-based information (knowledge) and theory-based behavior change technique (skills) are needed. Results from this study suggest that OWs' knowledge can be augmented through trainings on the health benefits that derive from participation in moderate-intensity prenatal PA, ${ }^{13}$ knowledge of and skills on how to apply the FITT-VP principle of $\mathrm{PA}^{30}$ with clients during home visits, and skills on how to safely demonstrate the specific prenatal exercises outlined in the prenatal PA modules. To date, no trainings exist for home visitors specific to prenatal PA, but can be advised by these findings as well as literature detailing trainings where home visitors' KSAs concerning intimate partner violence $^{31}$ and knowledge, skills, and confidence concerning oral health ${ }^{32}$ were targeted. Collectively, these studies can advise the: (1) rationale for home visitor trainings, (2) key training techniques to use to change home visitors' knowledge, skills, and/or abilities (e.g., interactive discussions), ${ }^{31,32}$ and (3) application of theories in home visitor trainings. ${ }^{31}$ 
The elements of knowledge and skills (i.e., implementing topic specific knowledge and building clients' topic-specific knowledge and skills for use) form the myriad of competencies outlined in the National Family Support Competency Framework. ${ }^{9}$ The results of this study support this framework's design and, moreover, suggest that the OWs' KSAs form a triad which expounds the OWs' competencies in delivering the prenatal PA modules. Specifically, the results revealed how limited knowledge on specific prenatal exercises influences an OWs' skills in teaching techniques for this exercise which both, in turn, influence the OW's perceived ability to recommend exercises or teach exercise techniques. These results and the Conceptual Framework of the Public Health System ${ }^{5}$ suggest that home visitors' KSAs should be jointly targeted in prenatal PA trainings and any developed prenatal PA competency. Future research should explore the direct and indirect pathways of the KSAs to identify the optimum approaches towards improving home visitors' KSAs.

Aside from this triad, the results showed a reciprocal relationship between the OWs' KSAs and their perceptions of their clients' receipt of the prenatal PA modules. The pathway consisted of the OWs applying their KSAs to curricular delivery and in return the clients' situations influencing the OWs' KSAs (i.e., adapting to clients' situations, problem-solving, learning new information). Although adapting and problem solving to meet a clients' needs can be beneficial for the therapeutic relationship, these actions could lead to home visitors gaining inaccurate knowledge and/or skills that are outside their home visitation program's core competencies. These results emphasize the importance that home visitation programs' curricula guides contain evidence-based prenatal PA resources and for home visitors to be trained on where to access reputable prenatal PA information. 
Although this study provides a detailed portrayal of the OWs' KSAs in delivering this specific program's prenatal PA modules, it was not without limitations. First, the OWs who participated in this study were not asked to report their frequency in sharing the prenatal PA modules. Therefore, future studies are needed that examine the OWs' KSAs by experience level in delivering the prenatal PA modules. Second, the findings are specific to the MIHOW program and a small number of its peer OWs; ${ }^{3,16}$ subsequent studies are needed on a larger sample of MIHOW OWs in addition to home visitors from other home visitation programs. Another notable limitation was that this study was conducted parallel to a statewide evaluation of the MIHOW program's effectiveness. This statewide program evaluation may have heightened the OWs' awareness of the prenatal PA modules, but may have also helped to provide insight into KSAs from practitioners with some experience. A fourth limitation of this study was the use of a different notetaker for the final focus group, which may have influenced the focus group atmosphere. To minimize possible variation associated with this change, a backup notetaker was selected who was the same sex and approximately the same age. Also, the backup notetaker was introduced to the OWs and provided the same instructions and materials as the primary notetaker. A final limitation of this study was that the settings of the focus groups and interviews were not devoid of interruptions. Data collection was done, except for one interview, at the OWs' respective worksites to reduce the burden of travel on the OWs. However, utilizing the worksites led to some minor interruptions during the data collection process. Going forward, researchers should consider using a private, third-party site near participants' offices.

A notable strength of this study was that steps were taken to ensure its trustworthiness, as recommended by Shenton. ${ }^{24}$ These steps included interviewing the OWs' SLs to achieve data triangulation and providing a rich description of the methods. Member checking was also done 
with the participants during data collection and after data analysis (four out of the four participants who took part felt that the results were complete, correct, and rang true). Another strength of this study was that the first author already had a connection with the MIHOW program and staff prior to this study due to serving as a research assistant on the aforementioned MIHOW evaluation. To minimize biases that may have arisen from this connection, a second coder was used during the data analysis process who had no familiarity with the program or staff. In addition, to augment any lack of historical knowledge of the MIHOW program, "member checking" of the results was conducted with programmatic staff. The completion of each step outlined here helped to strengthen this study's overall trustworthiness.

Taken together, the present findings detailed the OWs' KSAs in delivering the prenatal PA modules independently, jointly, and reciprocal to other factors. This information can be used to inform model-specific trainings, future revisions of the National Family Support Competency Framework, ${ }^{9}$ and subsequent research. Preeminently, even with this study, there is a continued need to investigate home visitors' KSAs in delivering the prenatal PA modules. Home visiting is a profession in the public health system with national coverage that provides services to populations, including low-income populations, in their homes. ${ }^{1}$ Utilization of this national coverage could further progress in meeting the Healthy People 2020 objectives, such as objective PA-1 which targets the reduction in the number of adults who are completely inactive during their leisure-time. ${ }^{33}$ Therefore, ensuring a well-trained home visiting workforce is vital to public health. 


\section{Acknowledgements}

Vanderbilt University's Maternal Infant Health Outreach Worker Program is the source of the model and curriculum in this manuscript. The authors wish to thank the Outreach Workers and Site Leaders of this model who participated in this study. 


\section{References}

1. National Home Visiting Resource Center. 2017 home visiting yearbook. https://www.nhvrc.org/wp-content/uploads/NHVRC_Yearbook_2017_Final.pdf. Published 2017. Accessed April 8, 2019.

2. U.S. Department of Health and Human Services, Administration for Children and Families. Effectiveness research. Home Visiting Evidence of Effectiveness Web site. https://homvee.acf.hhs.gov/Models.aspx. Accessed April 9, 2019.

3. Elkins T, Aguinaga Mdel P, Clinton-Selin C, Clinton B, Gotterer G. The Maternal Infant Health Outreach Worker program in low-income families. J Health Care Poor Underserved. 2013;24(3):995-1001. doi:10.1353/hpu.2013.0143.

4. Gaylor E, Spiker D. Home visiting programs and their impact on young children's school readiness. In: Tremblay RE, Boivin M, Peters RDeV, eds. Encyclopedia on Early Childhood Development [online]. http://www.child-encyclopedia.com/homevisiting/according-experts/home-visiting-programs-and-their-impact-young-childrensschool. Updated September 2012. Accessed April 9, 2019.

5. Handler A, Issel M, Turnock B. A conceptual framework to measure performance of the public health system. Am J Public Health. 2001;91(8):1235-1239.

6. Vanderbilt University Center for Health Services. The MIHOW Home Visit Guide: The Prenatal Period. Nashville, TN: Vanderbilt University Center for Health Services; 2009.

7. Filene JH, Snell EK, Lee H, Knox V, Michalopoulos C, Duggan A. The mother and infant home visiting program evaluation-strong start: first annual report. OPRE report 2013-54.

https://www.acf.hhs.gov/sites/default/files/opre/mihope_ss_final_12_24_13.pdf.

Published 2013. November 30, 2017.

8. Culp AM, Culp RE, Hechtner-Galvin T, Howell CS, Saathoff-Wells T, Marr P. First-time mothers in home visitation services utilizing child development specialists. Infant Ment Health J. 2004;25(1):1-15. doi:10.1002/imhj.10086.

9. Institute for the Advancement of Family Support Professionals. National Family Support Competency Framework for Family Support Professionals. June 1, 2018. https://cpprinstitute-

prod.s3.amazonaws.com/modules/Approved\%20National\%20Family\%20Support\%20Co mpetency\%20Framework_FINAL_7_18_2018.pdf. Accessed April 9, 2019.

10. O'Brien R. Nurse-Family Partnership Theory of Change Logic Model. 2008. https://fhop.ucsf.edu/sites/fhop.ucsf.edu/files/wysiwyg/NFP_TOC_Logic_Model.pdf. Accessed April 4, 2019. 
11. Thomson JL, Tussing-Humphreys LM, Goodman MH, Olender SE. Physical activity changes during pregnancy in a comparative impact trial. Am J Health Behav. 2016;40(6):685-696. doi:10.5993/AJHB.40.6.1.

12. American College of Obstetricians and Gynecologists. ACOG committee opinion no. 650: physical activity and exercise during pregnancy and the postpartum period. Obstet Gynecol. 2015;126(6):e135-e142. doi:10.1097/AOG.0000000000001214.

13. U.S. Department of Health and Human Services. Physical activity guidelines for Americans, 2nd edition. https://health.gov/paguidelines/secondedition/pdf/Physical_Activity_Guidelines_2nd_edition.pdf. Published 2018. Accessed April 9, 2019.

14. Salvy SJ, de la Haye K, Galama T, Goran MI. Home visitation programs: an untapped opportunity for the delivery of early childhood obesity prevention. Obes Rev. 2017;18(2):149-163. doi:10.1111/obr.12482.

15. Howard KS, Brooks-Gunn J. The role of home-visiting programs in preventing child abuse and neglect. Future Child. 2009;19(2):119-146. doi:10.1353/foc.0.0032.

16. Vanderbilt University School of Nursing. The MIHOW program. Vanderbilt University School of Nursing Web site. https://www.mihow.org/. Accessed April 9, 2019.

17. Petersen AM, Leet TL, Brownson RC. Correlates of physical activity among pregnant women in the United States. Med Sci Sports Exerc. 2005;37(10):1748-1753.

doi:10.1249/01.mss.0000181302.97948.90.

18. Evenson KR, Wen F. Prevalence and correlates of objectively measured physical activity and sedentary behavior among US pregnant women. Prev Med. 2011;53(1-2):39-43. doi:10.1016/j.ypmed.2011.04.014.

19. U.S. Department of Health and Human Services. 2008 physical activity guidelines for Americans. http://health.gov/PAGuidelines/pdf/paguide.pdf. Published 2008. Accessed November 29, 2017.

20. Centers for Disease Control and Prevention, National Center for Chronic Disease Prevention and Health Promotion, Division of Nutrition, Physical Activity, and Obesity. Data, Trends and Maps [database online]. https://www.cdc.gov/nccdphp/dnpao/datatrends-maps/index.html. Accessed April 9, 2019.

21. Creswell JW. Qualitative Inquiry \& Research Design: Choosing Among Five Approaches. 3rd ed. Thousand Oaks, CA: SAGE Publications, Inc.; 2013.

22. Sandelowski M. Whatever happened to qualitative description? Res Nurs Health. 2000;23(4):334-340. doi:10.1002/1098-240X(200008)23:43.0.CO;2-G. 
23. Vanderbilt University School of Nursing. Core components. Vanderbilt University School of Nursing Web site. https://www.mihow.org/about/corecomponents.php. April 9, 2019.

24. Shenton AK. Strategies for ensuring trustworthiness in qualitative research projects. Education for Information. 2004;22(2):63-75. doi:10.3233/EFI-2004-22201.

25. Qualtrics Software [computer program]. Version 37.892. Provo, UT: Qualtrics; 2015.

26. NVivo 11 Qualitative Data Analysis Software [computer program]. Version 11. QSR International Pty Ltd; 2015.

27. Hsieh HF, Shannon SE. Three approaches to qualitative content analysis. Qual Health Res. 2005;15(9):1277-1288. doi:10.1177/1049732305276687.

28. Guest G, MacQueen KM, Namey EE. Validity and reliability (credibility and dependability) in qualitative research and data analysis. Applied Thematic Analysis. Thousand Oaks, CA: SAGE Publications, Inc.; 2012:79-106. http://methods.sagepub.com.www.libproxy.wvu.edu/book/applied-thematicanalysis/n4.xml. Accessed April 9, 2019.

29. Burla L, Knierim B, Barth J, Liewald K, Duetz M, Abel T. From text to codings: intercoder reliability assessment in qualitative content analysis. Nurs Res. 2008;57(2):113-117. doi:10.1097/01.NNR.0000313482.33917.7d.

30. American College of Sports Medicine. ACSM's Guidelines for Exercise Testing and Prescription. 9th ed. Philadelphia, PA: Lippincott Williams \& Wilkins; 2013.

31. Dyer AM, Abildso CG. Impact of an intimate partner violence training on home visitors' perceived knowledge, skills, and abilities to address intimate partner violence experienced by their clients. Health Educ Behav. 2019;46(1):72-78. doi:10.1177/1090198118796882.

32. Glatt K, Okunseri C, Flanagan D, Simpson P, Cao Y, Willis E. Evaluation of an oral health education session for Early Head Start home visitors. J Public Health Dent. 2016;76(3):167-170. doi:10.1111/jphd.12140.

33. U.S. Department of Health and Human Services, Office of Disease Prevention and Health Promotion. Physical activity. Healthy People $2020 \mathrm{Web}$ site. https://www.healthypeople.gov/2020/topics-objectives/topic/physical-activity/objectives. Updated April 10, 2019. Accessed April 10, 2019. 
Table 1. Qualitative Data Analysis Process

\begin{tabular}{|c|c|c|}
\hline Step & Task & Coder(s) \\
\hline 1 & Read the transcript independently and recorded memos & AMD, SMD \\
\hline 2 & $\begin{array}{l}\text { Re-read the transcripts independently in order to detect and } \\
\text { record preliminary codes }\end{array}$ & AMD, SMD \\
\hline 3 & $\begin{array}{l}\text { Met in-person to discuss the preliminary codes and establish } \\
\text { an agreed upon list of codes }\end{array}$ & AMD, SMD \\
\hline 4 & $\begin{array}{l}\text { Re-read the transcripts independently with the code book and } \\
\text { recorded codes }\end{array}$ & AMD, SMD \\
\hline 5 & $\begin{array}{l}\text { Met in-person to discuss the codes and examine the coding } \\
\text { agreement }\end{array}$ & AMD, SMD \\
\hline 6 & Met in-person to arrange the codes into categories & AMD, SMD \\
\hline 7 & $\begin{array}{l}\text { Read the data for each category to identity discrepancies } \\
\text { between the coders }\end{array}$ & AMD \\
\hline 8 & $\begin{array}{l}\text { Provided commentary and resolutions on the discrepancies } \\
\text { that were identified }\end{array}$ & SMD, CGA \\
\hline 9 & Addressed the discrepancies & AMD \\
\hline 10 & Met by video call to organize the categories into themes & AMD, SMD \\
\hline 11 & Identified sub-themes & AMD \\
\hline 12 & Verified sub-themes & SMD \\
\hline
\end{tabular}

Coder $1=$ AMD, Coder $2=$ SMD, Coder $3=$ CGA 
Table 2. Qualitative Coding Structure for the Themes of Knowledge, Skills, and Abilities

\begin{tabular}{|c|c|c|c|}
\hline Themes & Sub-Themes & Categories & Codes \\
\hline \multirow{6}{*}{ Knowledge } & \multirow{2}{*}{$\begin{array}{c}\text { External } \\
\text { Prenatal PA } \\
\text { Knowledge }\end{array}$} & - PA guidance & $\begin{array}{l}\text { - low-impact activities } \\
\text { - } \text { social-oriented activities }\end{array}$ \\
\hline & & - staff attributes & $\begin{array}{l}\text { - life experience } \\
\text { - perception of PA } \\
\text { - job commitment }\end{array}$ \\
\hline & $\begin{array}{l}\text { Curriculum } \\
\text { Guide } \\
\text { Awareness }\end{array}$ & - guide awareness & - guide awareness \\
\hline & \multirow{3}{*}{ Influencers } & - client generated influencer & - client generated influencer \\
\hline & & - PA guidance & $\begin{array}{l}\text { - low-impact activities } \\
\text { - } \text { social-oriented activities }\end{array}$ \\
\hline & & - staff attributes & $\begin{array}{l}\text { - } \text { life experience } \\
\text { - } \text { perception of PA } \\
\text { - } \text { job commitment }\end{array}$ \\
\hline
\end{tabular}

\begin{tabular}{|c|c|c|c|}
\hline \multirow{10}{*}{ Skills } & \multirow{2}{*}{ PA } & - OWs' skillset & $\begin{array}{ll} & \text { skill proficiency } \\
\text { - } & \text { engagement skills }\end{array}$ \\
\hline & & $\begin{array}{l}- \text { teaching through } \\
\text { application }\end{array}$ & $\begin{array}{l}\text { - teaching through } \\
\text { application }\end{array}$ \\
\hline & \multirow{2}{*}{$\begin{array}{l}\text { Rapport } \\
\text { Building }\end{array}$} & - rapport & - rapport \\
\hline & & - OWs' skillset & $\begin{array}{l}\text { - } \text { skill proficiency } \\
\text { - } \text { engagement skills }\end{array}$ \\
\hline & \multirow{3}{*}{ Communication } & - OWs' skillset & $\begin{array}{ll}\text { - } & \text { skill proficiency } \\
\text { - } & \text { engagement skills }\end{array}$ \\
\hline & & - rapport & - rapport \\
\hline & & $\begin{array}{l}- \text { teaching through } \\
\text { application }\end{array}$ & $\begin{array}{l}\text { - teaching through } \\
\text { application }\end{array}$ \\
\hline & \multirow{3}{*}{ Influencers } & - client generated influencer & - client generated influencer \\
\hline & & - PA guidance & $\begin{array}{l}\text { - low-impact activities } \\
\text { - } \text { social-oriented activities }\end{array}$ \\
\hline & & - staff attributes & $\begin{array}{l}\text { - life experience } \\
\text { - perception of PA } \\
\text { - job commitment }\end{array}$ \\
\hline
\end{tabular}

\begin{tabular}{|c|c|c|c|}
\hline \multirow{5}{*}{ Abilities } & \multirow{2}{*}{ Comfort Level } & - OWs' comfort level & - OWs' comfort level \\
\hline & & - ease of use & - ease of use \\
\hline & \multirow{3}{*}{ Influencers } & - client generated influencer & - client generated influencer \\
\hline & & - PA guidance & $\begin{array}{ll}\text { - low-impact activities } \\
\text { - } & \text { social-oriented activities } \\
\end{array}$ \\
\hline & & - staff attributes & $\begin{array}{l}\text { - life experience } \\
\text { - perception of PA } \\
\text { - } \text { job commitment }\end{array}$ \\
\hline
\end{tabular}

$\mathrm{PA}=$ Physical Activity, $\mathrm{OW}=$ Outreach Worker 
Chapter 4. A Mixed-Methods Investigation of the Fidelity to an Early Childhood Home Visitation Program Model's Prenatal Physical Activity Curriculum Modules 


\begin{abstract}
This mixed-methods study investigated the fidelity with which the Maternal Infant Health Outreach Worker program's prenatal physical activity (PA) curriculum modules were delivered to clients. Data sources were: one interview and three focus groups with home visitors, termed Outreach Workers (OWs); five interviews with Site Leaders; and checklists of curriculum modules completed with 109 clients. One key finding was that eight OWs discussed delivering the prenatal PA curriculum modules at multiple, most, or all of the home visits whereas the checklist data revealed that only $19.3 \%$ of clients received two or more "prenatal PA" and/or "other" curriculum modules. Findings can be applied to enhance fidelity assessment and the fidelity with which the prenatal PA curriculum modules are delivered.
\end{abstract}




\section{Introduction}

Early childhood home visits delivered across the United States (U.S.) in 2015 totaled over 2 million. ${ }^{1}$ This statistic represented only a subsample of four ${ }^{1}$ of an estimated 25 early childhood home visitation program models ("programs") ${ }^{2}$ whose staff (e.g., peer home visitors, ,- $^{3-}$ ${ }^{5}$ nurse home visitors) ${ }^{1}$ provided home visits. Recipients of home visitation are often low-income families, first-time mothers, or other parents and children who are disadvantaged. ${ }^{1}$ Moreover, the services that are offered during home visits are not standardized across home visitation programs. ${ }^{6}$ A common service, however, is curricula delivery done in-person at clients' homes. ${ }^{2}$

One curricula module topic of public health importance that is delivered by home visitors of different home visitation programs is prenatal physical activity (i.e., prenatal physical activity and/or exercise). ${ }^{7-9}$ Prenatal physical activity (PA) modules have the potential to facilitate positive impacts on pregnant clients' mental and physical health, including but not limited to reduced anxiety symptoms, ${ }^{10}$ reduced gestational diabetes risk, ${ }^{10-13}$ and improved cardiorespiratory fitness. ${ }^{13}$ These benefits demonstrate the importance of home visitors promoting prenatal PA, particularly the recommended guideline of 150 minutes or more of weekly aerobic moderate-intensity PA for healthy pregnant women set forth by the U.S. Department of Health and Human Services. ${ }^{13}$ However, the extent to which home visitors promote prenatal PA, including this guideline, ${ }^{13}$ and the precise number of home visitation programs who have prenatal PA curriculum module(s) are unknown due to the private, copyrighted nature of home visitation programs' curricula. Moreover, little is known about the effectiveness of prenatal PA curricula modules because no studies have been done on their implementation and only one study has been done on their impact. ${ }^{9}$ 
To date, the sole study on the effectiveness of curriculum with prenatal PA modules found no intervention effects on moderate to vigorous physical activity among women receiving the Parents as Teachers curriculum or women receiving the Parents as Teachers Enhanced curriculum with added content on PA, diet, and weight control. ${ }^{9}$ Although a seminal work, the study lacked an assessment of fidelity to the prenatal PA curriculum modules' implementation protocols which may have provided insight as to the reason(s) for the null findings. ${ }^{9}$ As a result, future studies are needed on both the fidelity to and impact of home visitation programs' prenatal PA curricula modules. Research that reveals high fidelity and no impact or low fidelity and high impact may indicate the content, coverage, frequency, or timing of the prenatal PA curricula modules need to be reconsidered.

To further the research on the effectiveness of prenatal PA curricula modules, this study focused on the Maternal Infant Health Outreach Worker (MIHOW) program because it has prenatal PA curriculum modules (hereafter, prenatal PA modules) ${ }^{7}$ and design features that enable it to promote PA among pregnant women at risk for insufficient PA. One key design feature is that the four states where the MIHOW program provides services (Mississippi, Kentucky, Tennessee, and West Virginia) ranked $50^{\text {th }}, 45^{\text {th }}, 43^{\text {th }}$, and $40^{\text {th }}$ out of all 50 states, respectively, in 2015 for prevalence of women meeting PA guidelines. ${ }^{3,14,15}$ Another design feature is that service delivery is provided to expectant families or those with a child aged three years or younger-particularly low-income families and/or families who are isolated due to locale ${ }^{3,5}$ or social support. ${ }^{5}$ Notably, national data suggests there is a positive relationship between attaining the prenatal moderate-intensity PA guideline and income. ${ }^{16}$ Given these features, the MIHOW program is an ideal target for investigating the fidelity to and impact of the prenatal PA modules. Therefore, this study used mixed-methods to investigate the fidelity with 
which the MIHOW program's prenatal PA modules were delivered to home visitation clients while a separate, concurrent quantitative study investigated their impact.

\section{Methods}

\section{Module Implementation Procedures}

The MIHOW program's services are delivered by home visitors, termed Outreach Workers (OWs), who are themselves peer mothers. ${ }^{3}$ Part of these services include client group meetings ${ }^{4}$ and one-on-one client in-home visits. ${ }^{7}$ Client group meetings are held for educational and social purposes; these group meetings may focus on topics of interest to the families. Oneon-one client in-home visits are also conducted for educational purposes; discussion topics for these visits are guided by The MIHOW Home Visit Guide: The Prenatal Period (hereafter, "curriculum guide"). ${ }^{7}$

Pregnant clients enrolled in the MIHOW program may receive up to nine one-on-one client in-home visits. ${ }^{7}$ The total number of received home visits is contingent upon (1) the point during a woman's gestation period that she enrolls in the MIHOW program ${ }^{7}$ and (2) the woman's continued participation in the MIHOW program. To plan each prenatal home visit, the OWs are required to use the curriculum guide. Seasoned OWs review the curriculum guide prior to a home visit whereas new OWs may follow it more closely.

The curriculum guide has 33 total modules. ${ }^{7}$ Suggestions are given in the curriculum guide on three to four modules to deliver at each of the nine home visits; however, the OWs individualize each client home visit, often prioritizing the modules that are of higher concern or benefit to the mother. ${ }^{7}$ As a result, a module may be delivered at the home visit outlined in the curriculum guide, delivered at a home visit that differs from the timing suggested in the 
curriculum guide, or not delivered. ${ }^{7}$ In selecting which modules to deliver to a client, the OW can choose from modules with content including but not limited to nutrition, social support, postpartum contraception, and PA. ${ }^{7}$

Prenatal PA content is in three of the curriculum guide modules. ${ }^{17}$ Home Visit 2 (no trimester listed) has a module with only prenatal PA content (e.g., safety information; PA assessment, planning, and goal setting activities; handout). ${ }^{7}$ In comparison, Home Visits 3 (trimester 1) and 5 (trimester 2) have modules which include prenatal PA content (e.g., information on the benefits, activity for planning PA) but it is not the focus. ${ }^{7}$ As noted above, the delivery of these modules is flexible and need not align with the home visit number or trimester.

Once a home visit is complete, the OW documents what she considered to be the "content" for the home visit. This step is done through a checklist (i.e., Prenatal Home Visit Report Form, see Appendix 5). ${ }^{18}$ For this checklist, the OW checks off the module(s) that were completed with the client. ${ }^{18}$ If the OW delivered a curriculum module or other content outside the home visit number, then she can select "other" on the checklist and record, on the line next to “other", what "other" represented. ${ }^{18}$ Thus, the "other" module could represent prenatal PA content.

\section{Study Design}

A statewide quantitative effectiveness evaluation of four MIHOW sites in a Middle Atlantic state was conducted from December 2016 to September 2018. Twenty-two OWs were reported as delivering services at these sites as of August 2017. The OWs provided in-home services to about 117 prenatal clients from December 2016 to April 2018. Supervising the OWs across the four sites were two Site Leaders (SLs) at one site and one SL at each of the three other sites. 
As this quantitative effectiveness evaluation was underway, we had the opportunity to simultaneously measure (1) OWs' competencies in implementing the prenatal PA modules, (2) the fidelity to the MIHOW program's prenatal PA modules, and (3) the effectiveness of the curriculum with prenatal PA modules. Discussed hereafter are the methods and results for the fidelity to the MIHOW program's prenatal PA modules.

To investigate the fidelity of the OWs' delivery of the prenatal PA modules, this study applied Carrol and colleagues ${ }^{19}$ Conceptual Framework for Implementation Fidelity. This framework recommends implementation fidelity be measured using four variables: content, coverage, frequency, and duration..$^{19}$ Collectively, these four variables form the variable of adherence; however, for the purpose of this study, the term fidelity will continue to be used. ${ }^{19}$

Thus, fidelity, in the context of this study, was measured using: (1) content: the prenatal PA information and/or activities that were discussed and/or completed with clients; (2) coverage: the percentage of clients who received the prenatal PA and/or "other" module(s) among clients who received Home Visits 1, 2, 3, 4, 5, 6, 7, 8, and/or 9; (3) frequency: the percentage of clients who received zero up to nine prenatal PA and/or "other" module(s); and (4) timing: the percentage of clients who received one or more prenatal PA and/or "other" module(s) in trimester one, two, and/or three among clients who received one or more home visit(s) in trimester one, two, and/or three, respectively. Timing was measured in place of duration because the prenatal PA and/or "other" module(s) can be delivered during trimester(s) one, two, and/or three but there is not a length of time that these modules are expected to last during a home visit. Additionally, the "other" module(s) were included in the measures above because "other" may represent the delivery of prenatal PA content. 
Three sources of data were used to assess these aspects of fidelity: (1) an interview and focus groups among the OWs, (2) interviews among the SLs, and (3) a quantitative secondary data analysis of the checklists of curriculum modules. Usage of qualitative and quantitative data (i.e., a mixed-methods approach) was undertaken because there is not a single data source that collectively provides information on the above fidelity variables of content, coverage, frequency, or timing. For this reason, we employed a convergent parallel design ${ }^{20}$ in which we collected qualitative and quantitative data simultaneously, analyzed the qualitative and quantitative data separately, and then merged the qualitative and quantitative data. For the qualitative research section, the focus groups and interviews provided data on the content variable and were used to support the qualitative and quantitative outcome integration for the variables of frequency and timing. Approval for the qualitative portion of this study was obtained from the staff who form the MIHOW program's leadership structure and a University Institutional Review Board under protocol number 1801913621. For the quantitative research section, the checklists of curriculum modules provided data for the coverage variable and were used to support the qualitative and quantitative outcome integration for the variables of frequency and timing. Approval for the statewide effectiveness evaluation, which encompassed the quantitative portion of this study, was obtained from a University Institutional Review Board under protocol number 1606174076A006. An illustration of this study's convergent parallel design ${ }^{20}$ is shown in Figure 1 and details on the qualitative and quantitative research sections of this study are described indepth below.

----- Figure 1 about here -----

\section{Qualitative Research Section}

\section{Outreach Worker interview and focus groups.}


Sampling frame. Targeted participants were individuals who were current OWs at 1 of the 4 MIHOW sites participating in the statewide evaluation, reached Level 1 of the Competencies for OWs, ${ }^{4}$ and completed a prenatal home visit where prenatal PA was discussed.

Recruitment. Purposive sampling was used to select the SLs and OWs. ${ }^{21}$ The first author (AMD) sent each SL a study recruitment email which included a cover letter requesting their participation for an interview. If they chose to participate, they were asked to respond with their available dates and times for an interview. In this same email correspondence, the SLs also received eligibility criteria for their OWs to participate in a focus group and a separate cover letter to distribute to their eligible OWs. If the OWs chose to participate, a request was made for each OW to send the first author her name, email address, and site name or for the SLs to send the first author the OWs names and email addresses. Each SL was also asked to provide dates and times a focus group could be held at the MIHOW site.

Data collection. Implementation of one in-person, semi-structured one-on-one interview and three focus groups ( $n=2, n=3$, and $n=4)$ occurred across four MIHOW program sites from March 5, 2018 to March 23, 2018. Data collection was done in a private setting at each MIHOW program site, such as an onsite conference room. Although doors were closed, mild interruptions, such as background noise from adjacent rooms and unintentional interruptions from non-participants, sometimes occurred. All sessions offered complimentary food and were completed by the first author using the following sequential steps: explained the focus group cover letter, administered a paper-and-pencil Focus Group Participant Demographic Questionnaire (see Appendix 1), asked for permission to audio record each session, acquired verbal informed consent, used the MIHOW OWs Focus Group Guide (see Appendix 2) to facilitate discussion, took brief field notes during the sessions, and conducted member checking 
during and at the end of the sessions by summarizing what the participant(s) said and asking for verification. ${ }^{22}$ A separate notetaker (SMD or RES) was present to take field notes during each focus group. All sessions were audio recorded and 55 to 95 minutes in length. Each participant received a $\$ 20 \mathrm{Wal}^{*}$ Mart ${ }^{\circledR}$ gift card. Member checking was repeated once data analysis was complete through sending summarized data consisting of the themes via a Qualtrics ${ }^{23}$ email link to the OWs for verification.

Measures. The first author created the MIHOW OWs Focus Group Guide, which was comprised of a series of guiding-opened questions. Questions focused on the OWs' timing in delivering the prenatal PA modules to their clients (i.e., "When is it [the physical activity during pregnancy curriculums in the MIHOW prenatal home visit guide] actually/usually discussed?) and the OWs' delivery of the content of the prenatal PA modules to their clients (e.g., "What information in the prenatal home visit guide regarding physical activity during pregnancy do you discuss with your clients?"). Prior to the guide's use, it was reviewed by the third and senior authors. Both authors have previously facilitated qualitative research with home visitors.

Data analysis. A paid professional transcriptionist transcribed the nine audio recordings verbatim, with Coder 1 (AMD) reviewing each transcript to verify their accuracy. Following transcript verification, conventional and directed content analysis approaches ${ }^{24}$ were carried out by Coders 1 and 2 (SMD) using NVivo $11^{25}$ to look for the variable of fidelity and its subvariables as well as themes not expected to emerge. Table 1 outlines the steps followed during the qualitative data analysis. A conventional content analysis approach ${ }^{24}$ was carried out for Steps 1 to 10 (i.e., identifying codes and categories) and Step 12 (i.e., looking for emerging themes). Comparatively, a directed content analysis approach ${ }^{24}$ was carried out for Steps 11 (i.e., 
identifying categories related to fidelity and its sub-variables) and 13 (i.e., organizing categories into the variables of content, frequency, and timing).

----- Table 1 about here -----

To achieve intercoder agreement, two steps were taken: (1) the first and second coders met regularly and (2) a third coder (CGA) provided resolutions for the unresolved discrepancies between the first and second coders. This procedure is known as subjective assessment. ${ }^{26}$ The subjective assessment procedure was used over quantitative methods of agreement (e.g., Cohen's Kappa statistic procedure) because the literature suggests that quantitative calculations of interrater agreement are useful for projects with many transcripts and where double-coding of transcripts is not applied, ${ }^{26,27}$ while this study only had nine transcripts and two coders who coded each transcript completely and independently.

Data saturation. At the first in-person qualitative coding meeting, Coders 1 and 2 discussed whether data saturation had been met. Both coders agreed that (1) the transcripts contained repetitive information, (2) no sections of the transcripts relating to the research questions needed further clarification, and (3) no sections of the transcripts relating to the participants' responses required further investigation. Given this agreement, the coders concluded that data saturation was met.

Trustworthiness. The trustworthiness of this study's qualitative results was established through (1) outlining extensive details on the methods, (2) completing the data triangulation procedures, (3) completing member checking with OWs, SLs, and programmatic staff, and (4) having a data collector/first coder with knowledge of the MIHOW program and connections to its staff and a second coder who did not have this knowledge or personal connection. These outlined differences between the first and second coder were built into the study design to 
identify potential biases that may need addressed because of the first coders role as a research assistant for the statewide evaluation of four MIHOW sites. Also, four individuals among the OWs and SLs provided feedback on the findings; their feedback indicated that the findings were accurate, complete, and resonated with them. Collectively, these processes add validity to the results presented.

\section{Site Leader interviews.}

SL interviews were used in conjunction with the OW interview and focus groups to triangulate the $\mathrm{OW}$ interview and focus group data. ${ }^{22}$ The SL interview recruitment, member checking, data analysis, data saturation, and trustworthiness procedures matched the OW interview and focus group procedures outlined above.

Sampling frame. Targeted participants were individuals who were a current SL at 1 of the 4 MIHOW sites participating in the statewide evaluation

Data collection. Implementation of one telephone and four in-person, semi-structured one-on-one interviews occurred across four MIHOW program sites from March 5, 2018 to April 10, 2018. In-person data collection was done in a private setting at each MIHOW program site, such as an onsite conference room. Although doors were closed, mild interruptions, such as background noise from adjacent rooms and unintentional interruptions from non-participants, sometimes occurred. In-person sessions offered complimentary food. All sessions were completed by one trained data collector (AMD) who completed the following sequential steps: reviewed the interview cover letter, administered a paper-and-pencil Interview Participant Demographic Questionnaire (see Appendix 3) for the in-person interview or shared a Qualtrics ${ }^{23}$ email link for the telephone interview, asked for permission to audio record each session, acquired verbal informed consent, used the MIHOW SL Interview Guide (see Appendix 4) to 
facilitate discussion, and took field notes during the sessions. All sessions were audio recorded and 48 to 71 minutes in length. Each participant received a $\$ 20 \mathrm{Wal}{ }^{*}$ Mart ${ }^{\circledR}$ gift card.

Measures. The creation and review of the MIHOW SL Interview Guide matched the MIHOW OWs Focus Group Guide procedures outlined above. The MIHOW SL Interview Guide was comprised of a series of guiding-opened questions on the OWs' timing in delivering the prenatal PA modules to their clients (i.e., "When during pregnancy is the physical activity during pregnancy curriculums in the MIHOW prenatal home visit guide discussed with clients?") and the OWs' delivery of the content of the prenatal PA modules to clients (e.g., "What information in the prenatal home visit guide regarding physical activity during pregnancy is discussed with clients?”).

\section{Quantitative Research Section}

\section{Checklists of curriculum modules.}

Sampling frame. As part of the statewide evaluation of the MIHOW program, data were collected on all pregnant clients and clients up to 3 months postpartum who enrolled in a MIHOW site and agreed to participate in the evaluation. This study used data on a subpopulation of this sampling frame. The subpopulation was composed of women who (1) were in their first, second, or third trimester of pregnancy; (2) received at least one home visit, and (3) had an expected due date between December 2016 to June 2018. These criteria were set to safeguard against analysis of incomplete cases (i.e., clients who were still receiving the prenatal curriculum at the time of analyses).

Data collection and retrieval procedures. At each enrollment visit, the $\mathrm{OW}$ administered demographic questionnaires to their client. After each home visit where curriculum module(s) 
were delivered, the OW completed the Prenatal Home Visit Report Form. ${ }^{18}$ On this form, the OWs checked which module(s) were completed with each client. As this information was collected, it was sent to the state's epidemiologist. Data from December 2016 through June 2018 were requested and obtained from the state's epidemiologist.

Measures and variables. Data were extracted from the Prenatal Home Visit Report ${ }^{18}$ to create variables for coverage, frequency, and timing. These variables are described in detail below.

Coverage. A 4-item categorical variable was created for each of the nine home visits (i.e., $0=$ received no prenatal PA or "other" module at Home Visit \#, $1=$ received the prenatal PA module at Home Visit \#, 2 = received the "other" module at Home Visit \#, and $3=$ received both the prenatal PA and "other" modules at Home Visit \#).

Frequency. The nine categorical coverage variables were counted to create a categorical frequency variable summarizing the number of home visits at which a prenatal PA and/or "other" module was received, ranging from 0-9.

Timing. For each trimester, a 5-item categorical variable was created to report if clients received the prenatal PA and/or "other" module in that trimester (i.e., $0=$ did not receive a prenatal PA or "other" module during that trimester, $1=$ received the prenatal PA module during that trimester, 2 = received the "other" module during that trimester, $3=$ received both the prenatal PA and "other" module during that trimester, $4=$ did not receive a home visit that trimester). Thus, there were Timing variables for trimester 1 , trimester 2 , and trimester 3 .

Data cleaning and analyses. Data were examined visually for missing values and univariate outliers. All data cleaning was based on rules that were set before analyses, with 
observation discrepancies handled on a case-by-case follow-up with the epidemiologist. Two clients were excluded from analyses because their expected due dates were missing and seven clients were excluded from analyses because their expected due dates were after June 30, 2018. One client was retained in analyses despite us being unable to confirm our receipt of all the client's curriculum data with the epidemiologist because visual analysis of the data suggested it to be complete or at the most missing one home visit. For analyses, SAS ${ }^{\circledR}$ Software, Version $9.4^{28}$ was used. The frequency and valid percent for each categorical variable was reported.

\section{Qualitative and Quantitative Results Merged}

As shown in Figure 1, the qualitative and quantitative results were merged to assess fidelity. Qualitative data was used exclusively to understand the variable of content. Quantitative data was used exclusively to understand the variable of coverage. Both qualitative and quantitative data were used to understand the variables of frequency and timing. For the qualitative data, changes, such as the removal of repetitive words and filler words, were made to the participants' quotes to enhance readability. Results are presented below by the fidelity variables of content, coverage, frequency, and timing.

\section{Results}

\section{Participants and Sample}

Outreach Worker participants. Participating OWs $(n=10)$ were primarily Caucasian/White $(n=9)$ and non-Hispanic/Latino $(n=9)$. Median age among the OWs was 45 years $(\mathrm{IQR}=38-49$ years). Over half of the OWs had an undergraduate college degree or higher $(n=6)$. Additionally, most of the OWs worked as a MIHOW OW part-time $(n=8)$ and had worked less than 4 years as a MIHOW OW $(n=8)$. 
Site Leader participants. Participating SLs $(n=5)$ were all Caucasian/White and nonHispanic/Latino. Median age among the SLs was 42 years ( $\mathrm{IQR}=40-63$ years). Over half of the SLs had an undergraduate college degree or higher $(n=3)$. Additionally, most of the SLs worked as a MIHOW SL full-time $(n=4)$ and all of the SLs had worked more than 4 years in this role.

Client sample. One hundred and nine out of 117 prenatal MIHOW clients met the sampling frame criteria. Clients had a mean age of 25 years $(S D=5$ years), were mostly White $(85.0 \%, n=100)$, were non-Hispanic/Latino $(100.0 \%, n=106)$, and were largely at or below the U.S. poverty line $(78.5 \%, n=62)$.

\section{Fidelity}

\section{Content.}

----- Table 2 about here -----

Table 2 shows the results for Content by data sources (i.e., interview and focus groups with OWs and interviews with SLs). In reference to client group meetings, six OWs and four SLs from three of the four sites reported that they have or have had PA focused classes or groups for their clients. Prior activities consisted of a walking group at one site and a prenatal yoga class at another site. Ongoing activities include an exercise class at one site and walking groups at two sites.

In reference to one-on-one client in-home visits, the OWs varied in their reports on what information and activities are in the prenatal PA modules that they deliver to their clients. Although the MIHOW program encourages OWs to cover modules most needed or identified by the client, four of the OWs expressed that they deliver all the information and activities in the prenatal PA modules to clients. OW 7 stated, "I think we go over everything that's in the 
curriculum" and OW 9 added, "One way or another, everything that you need to discuss with your client during that visit will come up in conversation, and you address it." Four other OWs expressed that they deliver the information in the prenatal PA modules; however, three of these OWs reported not completing all the activities. For example, OW 1 explained, "We haven't done much outside stuff, but I do know that it's in there. But personally, no I haven't, because it's been cold." Among the last two OWs, one explained that effort is made to get through all the actual curriculum whereas the other, when asked what information is not discussed, stated, "As we've said before, because it's so weak [the information regarding PA], it's just kind of really at our discretion." (OW 5). Overall, there was not one piece of information or activity in the prenatal PA modules that all the OWs reported delivering. To explain, if walking with a client was mentioned, it was not mentioned by everyone.

The SLs did not corroborate the OWs' reports, but rather suggested that the OWs do follow the prenatal PA modules more closely. One SL noted that all the information in the prenatal PA modules is delivered to clients and the other four SLs expressed that both information and activities in the prenatal PA modules are typically delivered in their entirety to their clients. SL 4 remarked, "they [OWs] have looked at the curriculum and then they just follow that [curriculum objectives] unless something else is happening."

Consistent with this comment, all the OWs and SLs discussed that the content is individualized to the clients for different reasons, such as the client's physical health and needs. Two OWs notably described what prenatal PA information or activities they deliver to clients who are on bed rest. OW 5 stated, “... I've had some that are on bed rest that you really can't discuss physical activity because they can't do any," whereas OW 7 explained, "We work with them even if they're on bed rest, but. ... It's not intense like it is before, because they're limited 
from the belly down." In line with these remarks, SL 5 described working with an OW to individualize the activities to an overweight mom:

...one of the moms was really overweight before she ever got pregnant. She was probably 400 pounds plus, and so I was just saying to [OW], "She's not going to be able to get down on the floor and do an activity," so we talked about doing chair activities like we would do with elderly people...

Another anecdotal account was shared by SL 3 who described a home visit that she observed. SL 3 detailed how the OW's client shared that she had a substance use disorder and how the OW was using the prenatal PA information to help the mom go through pregnancy without relapsing:

... "I [client] don't know if [OW] told you, but I'm a recovering addict and I've had six [re]lapses in the past six years... And we were talking about ways that I could prevent myself from having another relapse while I'm still pregnant because I really don't want my baby born addicted." She looked at [OW] and [OW] says, "You know, you didn't have to share that," and she goes, "No, I want her to understand why it would be good for me to take a walk every day." So, she [OW] was using that information to help her [client] cope with other things in her life, not just, we need to encourage you to have physical activity.... She was using some of the information from the curriculum to say, "Well let's use this strategy as a way to not use, but also to get you some physical activity in too."

Related to these examples of how the prenatal PA modules are individualized to the clients due to their physical health status, the OWs also shared specific examples of how the prenatal PA modules are individualized to the clients due to their needs. 
Specifically, OW 2 described working with clients to fit PA into their lives without added costs: "You can use your canned food as weight, you don't have to go and buy all of this stuff, these heavy weights that cost $\$ 10$ and $\$ 15, \$ 20, \$ 30$ dollars." For clients who are overly active because of a lack of transportation, OW 6 conveyed how conversations are approached with these clients:

I know this may sound silly, but I really do have those moms who walk 10 miles in a day. You're like, "Maybe you should cut back," and that seems funny but it really is because they're living. . . in the holler and they're going up to the middle of town in a snow storm and you're like, "I really don't think you should do that," or, "How do you feel when you make it all the way to town?" Again, it's just a conversation because gosh, they do more than I could and they're eight months pregnant.

Parallel to this individualized approach, four of the OWs described adding noncurriculum-based information to the curricular delivery process but agreed that for the topic of prenatal PA that they mostly use the handouts from the curriculum guide. One OW also reported using a self-created document for PA:

I have a 13-page document, and it shows all sorts of exercises: upper body, lower body, core, abdominal, back, and how to do the workouts. So warm up, your main set, cool down, and stretching. It has a bunch of stretching exercises too. (OW 4)

Four of the SLs also shared that the OWs add non-curriculum-based information to the curricular delivery process. SL 4 explained, 
I think we use the curriculum, but you know you might be where you hear an interesting talk, and somebody does a handout and you say, "Oh, I was here and this sounds interesting. What do you think?" Or you might read an article on the internet that you think is really interesting about physical activity.

Moreover, SL 5 shared,

Whatever's in there is what they're supposed to discuss. I've always stressed to them, because they want to add things all the time to something. They'll go and look up something to add to a visit, and I tell them that's fine, but make sure they use what's in the curriculum and then add to it.

\section{Coverage.}

----- Table 3 about here -----

Table 3 shows the results for Coverage by data source (i.e., checklists of curriculum modules). The prenatal PA modules were delivered to $66.7 \%$ (22 out of 33 clients), $68.4 \%$ (13 out of 19 clients), and $66.7 \%$ of clients (12 out of 18 clients) that received Home Visits 2, 3, and 5 , respectively. The "other" module was delivered to $60.0 \%$ of clients (15 out of 25 clients) that received Home Visit 8 and less than 1/5 of clients that received Home Visits 1 (11 out of 79 clients), 2 ( 4 out of 33 clients), 3 ( 2 out of 19 clients), 6 ( 2 out of 25 clients), 7 ( 1 out of 23 clients), and/or 9 ( 5 out of 29 clients). Moreover, the prenatal PA and "other" modules were delivered together to $6.1 \%$ of clients ( 2 out of 33 clients) that received Home Visit 2 and 10.5\% of clients ( 2 out of 19 clients) that received Home Visit 3.

\section{Frequency.}


Table 4 shows the results for Frequency by data sources (i.e., interview and focus groups with OWs, interviews with SLs, and checklists of curriculum modules). Of the 109 clients, fortynine clients $(45.0 \%)$ did not receive any prenatal PA or "other" modules and 39 clients (35.8\%) received one prenatal PA or "other" module. Additionally, only 21 clients (19.3\%) received two or more prenatal PA and/or "other" modules.

In contrast to these findings, seven OWs discussed delivering the prenatal PA modules at most or all of the home visits and one OW discussed delivering it multiple times. OW 7 stated, "I do exercise every month with them. . . Even though in the third visit is exercises and being healthy, we still discuss that up until way after they've had the baby." Furthermore, OW 4 remarked, “... I do it all the time even if it's not on the agenda or the plan. I mean, just because one month says it and the other month doesn't, doesn't mean that all months shouldn't have it."

Three SLs corroborated these reports. SL 4 noted that the OWs should deliver the prenatal PA modules monthly: “... you should be probably doing that once a month, on your monthly visit." Additionally, SL 1 described that the prenatal PA module(s) frequency of delivery may vary but that it can be every visit: "It's just different home visits. It can be every. Like I said, if you have to push them and give them a little bit of a go, then you can take something every home visit."

Compared to what most of the OWs reported, two OWs described just following the curriculum guide. OW 1 stated, "We'll usually talk about it when it's just listed in the curriculum. .." Likewise, OW 8 expressed following the curriculum and why this is done:

... your expertise is exercising and physical well-being, mine is not. I don't even really think about that because I'm focused so much on their actual curriculum 
that they have and trying to get through all that. That really physical exercise goes by the wayside.

Compliance to the prenatal PA modules' frequency of delivery was also noted by SL 5:

Unless they see an opportunity or see a reason that they need to elaborate on something, then I think they stick to the home visit guide. Like I said, a couple of the girls really have a passion for it right now, so they may push it more because of their own personal agenda, but I think the other girls do go by the home visit guide, yeah.

\section{Timing.}

----- Table 5 about here

Table 5 shows the results for Timing by data sources (i.e., interview and focus groups with OWs, interviews with SLs, and checklists of curriculum modules). Among clients receiving one or more home visit(s) in their first trimester, 10 out of 27 clients (37.0\%) received the prenatal PA module, other module, or both. Among clients receiving one or more home visit(s) in their second trimester, 28 out of 52 clients (53.8\%) received the prenatal PA module, other module, or both. Lastly, among clients receiving one or more home visit(s) in their third trimester, 35 out of 69 clients (50.7\%) received the prenatal PA module, other module, or both.

The data in Table 5 corroborates the data from the focus groups and interviews. Over half of the OWs described delivering the prenatal PA modules irrespective of a client's trimester, with two SLs corroborating these descriptions. OW 6 explained:

... if we start later in a pregnancy, we do recap. We would start with visit one, and we would go back and hit the highlights. But, physical activity is definitely 
one that we would include. If we start at month six, we would still go back to that second visit curriculum and pull up the exercises to share with mom. That's something we always carry into, no matter where we start.

Other OWs described delivering the prenatal PA modules every month.

Reports on timing did differ for two of the OWs and one SL. These OWs described following the curriculum guide, and likewise the SL expressed that most of the OWs primarily stick to the curriculum guide.

\section{Discussion}

To date, no study has examined the fidelity with which home visitation programs' prenatal PA modules are delivered. In addressing this need, this mixed-methods study showed that the OWs do not strictly adhere to the curriculum in terms of the prenatal PA modules' content, coverage, frequency, and timing, but rather follow the MIHOW program's protocol of individualizing the delivery of the modules to fit their clients and the context. Findings revealed that less than half the OWs delivered all the content in the prenatal PA modules and that coverage was highest for Home Visits 2, 3, and 5 where the prenatal PA modules are outlined in the curriculum guide. ${ }^{7}$ Discrepancies also existed between the checklist data and the OWs' reports for the variable of frequency of content delivery. The checklist data indicated that $19.3 \%$ of clients received two or more prenatal PA and/or other curriculum modules whereas eight of the OWs expressed that they deliver the prenatal PA modules at multiple, most, or all the home visits. The checklist data also showed that the prenatal PA modules were delivered inside and outside the trimesters outlined in the curriculum guide, which is consistent with the MIHOW program's protocol and what the OWs reported. 
Collectively, the quantitative results suggest that the MIHOW program's prenatal PA modules are delivered with fidelity whereas the qualitative results suggest some departure from fidelity attributable to the OWs occasional use of non-curriculum-based information. Notably, the qualitative results also revealed implementation of creative content variations. This creativity of the OWs was shown in how they insert PA into discussions of health relating to bedrest, obesity, substance use, and other topics. The OWs' creativity was also shown in how they individualize the prenatal PA modules to the meet the clients' needs, such as suggesting the use of canned foods for resistance exercises to minimize PA related costs. These findings offer an extensive, albeit varied, look at the fidelity of the prenatal PA modules whereas prior studies have reported on the fidelity of curricula more broadly. Drotar and colleagues ${ }^{29}$ reported in their methods section that attainment of the curriculum objectives was over $90 \%$. Likewise, Hebbeler and Gerlach-Downie ${ }^{30}$ described in their methods section that there was minimal variation in what lesson was delivered for each of the four measured time points (a statistic was not reported) and in their results section that relatively high fidelity was achieved for curriculum delivery (fidelity to specific modules was not reported). One study also reported the time percentage home visitors devoted to nine different curriculum topics at three different time points, but did not state whether fidelity was met for the timing that was reported. ${ }^{31}$ Instead, the authors stated that high home visitation program fidelity, inclusive of procedure compliance for the curriculum and implementation, was achieved. ${ }^{31}$ Together with these findings, our findings suggest that indepth fidelity assessments of home visitation programs' module are needed and may reveal fidelity variations that go undetected with broad fidelity assessments of home visitation programs' curricula. For this reason, moving forward, researchers should consider investigating the fidelity of modules rather than the fidelity of curricula broadly. Also, researchers should 
consider applying the Conceptual Framework for Implementation Fidelity ${ }^{19}$ in these studies to guide the assessment of fidelity. Application of these suggestions has the potential to provide indepth insight of the fidelity to modules, and subsequently identify reasons that modules' outcomes are or are not met.

A qualitative study done among SafeCare home visitors, SafeCare coaches (i.e., implementation advisory staff), and supervisors identified a concern among the SafeCare coaches that the checklist, completed for the delivery of the different modules, may not adequately reflect model fidelity. ${ }^{32}$ The findings from this study support this position. The conflicting results found in this study between the checklist data and the OWs' reports suggest that the checklists do not adequately reflect the OWs' delivery of the prenatal PA modules to their clients. This suggestion is further supported by the OWs' descriptions of the content that they deliver to clients. The OWs expressed that the prenatal PA modules are individualized to fit the client and supplemented occasionally with non-curriculum-based information. The identification of details not captured through the checklists implies that different sources of data collected using mixed methods may more accurately portray module delivery. Accordingly, follow-up studies investigating the fidelity with which home visitation programs' modules are delivered to clients should be designed using mixed-methods to more accurately depict the changes that the home visitors do or do not make to the curricular delivery process and why. Moreover, the use of mixed-methods could also highlight program strengths and weakness, including flaws in fidelity assessment tools, that quantitative and qualitative methods are not likely to capture alone.

In this study, OWs did not collectively describe one activity or piece of information in the prenatal PA modules that they all deliver to clients. This finding and the deviations to the 
curricular delivery process outlined above calls attention to the need for more clarity on the essential elements of the prenatal PA modules (i.e., elements, such as a specific activity, that need to be implemented in order for prenatal PA behavior change to occur) and how these elements are expected to lead to changes in prenatal PA levels among clients. To begin to refine this clarity, the Intervention Mapping Approach outlined in Bartholomew and colleagues ${ }^{33}$ can be utilized by home visitation programs' developers or others tasked with the development or revisions of the prenatal PA modules. This six step approach specifies how to apply the steps to construct and organize an intervention's design (e.g., theoretical underpinning, determinants, performance objectives), implementation (e.g., change objectives), and evaluation (e.g., indicators, measures).$^{33}$ Defining the essential elements and processes of the prenatal PA modules, as well as other modules, will provide home visitors with clearer module delivery expectations. Also, designing and facilitating process and impact evaluations of the modules will identify elements of the modules that are or are not working. In return, these actions can help enhance fidelity to modules.

In this study, the OWs were a part of a larger statewide effectiveness evaluation of four MIHOW sites. This evaluation did not appear to change how the OWs approached the delivery of the prenatal PA modules with clients. Separate limitations were that the OWs may not record a module as being covered if they only check in with a client on a topic, and we could not confirm with the epidemiologist if the "other" module contained any prenatal PA content. Additionally, the study was not designed to assess (1) the fidelity of other modules, (2) the fidelity moderators outlined in the Conceptual Framework for Implementation Fidelity, ${ }^{19}$ (3) the coverage and frequency variables using qualitative data, or (4) the findings in relation to client dropout, because we did not have client discharge and reenrollment information. These 
limitations are all avenues that can be explored with future studies; however, information on frequency did emerge from the qualitative data and is presented within the study. Other study limitations also included a switch in the final focus group's notetaker because of scheduling conflicts and minor focus group and interview interruptions because of data collection being held at the participants' worksites. In response, the data collection atmosphere may have been affected by these limitations. However, the switch in the notetaker was addressed by (1) requiring the notetakers to follow the same procedures, (2) using notetakers who were similar in demographic characteristics (e.g., age, sex), and (3) making introductions between the second notetaker and the OWs prior to the start of the focus group because the primary notetaker was known by the OWs but the second notetaker was not. Moreover, the minor interruptions at the worksites were a tradeoff to reducing the participants' travel burden.

Variations existed in the OWs' delivery of the prenatal PA modules as a result of the steps they take to enhance the content, timing, and frequency of the modules to better fit their clients and the context. Variations made to the prenatal PA modules as well as others have the potential to influence module outcomes. Thus, future fidelity evaluations should coincide with impact evaluations of home visitation programs' modules in order to draw meaningful conclusions about the impact of fidelity on modules' outcomes. Moreover, these evaluations are needed to enhance module delivery expectations for the home visitors while still allowing them the flexibility to customize module delivery to their clients and the context. 


\section{Acknowledgements}

The authors thank the Outreach Workers and Site Leaders who participated in this study and Vanderbilt University's Maternal Infant Health Outreach Worker Program who was the source of the model and curriculum in this manuscript. Also, the quantitative portion of this study was supported by the Health Resources and Services Administration (HRSA) of the U.S. Department of Health and Human Services (HHS) as part of an award (X10MC31178) from the Maternal, Infant, and Early Childhood Home Visiting Program to the West Virginia Office of Maternal, Child, and Family Health. The quantitative research was conducted by the Program Evaluation and Research Center in the College of Education and Human Services at West Virginia University (PI: Lucas Moore; co-Is: Amy Root; Suzanne Hartman; Sara Anderson). The contents are those of the author(s) and do not necessarily represent the official views of, nor an endorsement, by HRSA, HHS, or the U.S. Government. For more information, please visit HRSA.gov. 


\section{References}

1. National Home Visiting Resource Center. 2017 home visiting yearbook. https://www.nhvrc.org/wp-content/uploads/NHVRC_Yearbook_2017_Final.pdf. Published 2017. Accessed April 8, 2019.

2. U.S. Department of Health and Human Services, Administration for Children and Families. Effectiveness research. Home Visiting Evidence of Effectiveness Web site. https://homvee.acf.hhs.gov/Models.aspx. Accessed April 9, 2019.

3. Elkins T, Aguinaga Mdel P, Clinton-Selin C, Clinton B, Gotterer G. The Maternal Infant Health Outreach Worker program in low-income families. J Health Care Poor Underserved. 2013;24(3):995-1001. doi:10.1353/hpu.2013.0143.

4. Vanderbilt University School of Nursing. Core components. Vanderbilt University School of Nursing Web site. https://www.mihow.org/about/corecomponents.php. April 9, 2019.

5. Vanderbilt University School of Nursing. The MIHOW program. Vanderbilt University School of Nursing Web site. https://www.mihow.org/. Accessed April 9, 2019.

6. Howard KS, Brooks-Gunn J. The role of home-visiting programs in preventing child abuse and neglect. Future Child. 2009;19(2):119-146. doi:10.1353/foc.0.0032.

7. Vanderbilt University Center for Health Services. The MIHOW Home Visit Guide: The Prenatal Period. Nashville, TN: Vanderbilt University Center for Health Services; 2009.

8. O’Brien R. Nurse-Family Partnership Theory of Change Logic Model. 2008. https://hop.ucsf.edu/sites/fhop.ucsf.edu/files/wysiwyg/NFP_TOC_Logic_Model.pdf. Accessed April 4, 2019.

9. Thomson JL, Tussing-Humphreys LM, Goodman MH, Olender SE. Physical activity changes during pregnancy in a comparative impact trial. Am J Health Behav. 2016;40(6):685-696. doi:10.5993/AJHB.40.6.1.

10. 2018 Physical Activity Guidelines Advisory Committee. 2018 physical activity guidelines advisory committee scientific report. https://health.gov/paguidelines/secondedition/report/pdf/PAG_Advisory_Committee_Report.pdf. Published February 2018. Accessed April 4, 2019.

11. Downs DS, Chasan-Taber L, Evenson KR, Leiferman J, Yeo S. Physical activity and pregnancy: past and present evidence and future recommendations. Res Q Exerc Sport. 2012;83(4):485-502. doi:10.1080/02701367.2012.10599138.

12. Tobias DK, Zhang C, van Dam RM, Bowers K, Hu FB. Physical activity before and during pregnancy and risk of gestational diabetes mellitus: a meta-analysis. Diabetes Care. 2011;34(1):223-229. doi:10.2337/dc10-1368. 
13. U.S. Department of Health and Human Services. Physical activity guidelines for Americans, 2nd edition. https://health.gov/paguidelines/secondedition/pdf/Physical_Activity_Guidelines_2nd_edition.pdf. Published 2018. Accessed April 9, 2019.

14. Centers for Disease Control and Prevention, National Center for Chronic Disease Prevention and Health Promotion, Division of Nutrition, Physical Activity, and Obesity. Data, Trends and Maps [database online]. https://www.cdc.gov/nccdphp/dnpao/datatrends-maps/index.html. Accessed April 9, 2019.

15. U.S. Department of Health and Human Services. 2008 physical activity guidelines for Americans. http://health.gov/PAGuidelines/pdf/paguide.pdf. Published 2008. Accessed November 29, 2017.

16. Petersen AM, Leet TL, Brownson RC. Correlates of physical activity among pregnant women in the United States. Med Sci Sports Exerc. 2005;37(10):1748-1753.

doi:10.1249/01.mss.0000181302.97948.90.

17. SAS Institute Inc. SAS/STAT ${ }^{\circledR} 14.2$ User's Guide. Cary, NC: SAS Institute Inc.; 2016: https://support.sas.com/documentation/onlinedoc/stat/142/psmatch.pdf. Accessed April 9, 2019.

18. Vanderbilt University Center for Health Services. Home visit report forms - prental 2012. Nashville, TN: Vanderbilt University Center for Health Services; 2012.

19. Carroll C, Patterson M, Wood S, Booth A, Rick J, Balain S. A conceptual framework for implementation fidelity. Implement Sci. 2007;2:40. doi:10.1186/1748-5908-2-40.

20. Creswell JW, Plano Clark VL. Designing and Conducting Mixed Methods Research. 3rd ed. Thousand Oaks, CA: SAGE Publications, Inc.; 2018.

21. Creswell JW. Qualitative Inquiry \& Research Design: Choosing Among Five Approaches. 3rd ed. Thousand Oaks, CA: SAGE Publications, Inc.; 2013.

22. Shenton AK. Strategies for ensuring trustworthiness in qualitative research projects. Education for Information. 2004;22(2):63-75. doi:10.3233/EFI-2004-22201.

23. Qualtrics Software [computer program]. Version 37.892. Provo, UT: Qualtrics; 2015.

24. Hsieh HF, Shannon SE. Three approaches to qualitative content analysis. Qual Health Res. 2005;15(9):1277-1288. doi:10.1177/1049732305276687.

25. NVivo 11 Qualitative Data Analysis Software [computer program]. Version 11. QSR International Pty Ltd; 2015.

26. Guest G, MacQueen KM, Namey EE. Validity and reliability (credibility and dependability) in qualitative research and data analysis. Applied Thematic Analysis. Thousand Oaks, CA: SAGE Publications, Inc.; 2012:79-106. 
http://methods.sagepub.com.www.libproxy.wvu.edu/book/applied-thematicanalysis/n4.xml. Accessed April 9, 2019.

27. Burla L, Knierim B, Barth J, Liewald K, Duetz M, Abel T. From text to codings: intercoder reliability assessment in qualitative content analysis. Nurs Res. 2008;57(2):113-117. doi:10.1097/01.NNR.0000313482.33917.7d.

28. $S A S ®$ Software [computer program]. Version 9.4. Cary, NC: SAS Institute Inc.; 20022015.

29. Drotar D, Robinson J, Jeavons L, Lester Kirchner H. A randomized, controlled evaluation of early intervention: the Born to Learn curriculum. Child Care Health Dev. 2009;35(5):643-649. doi:10.1111/j.1365-2214.2008.00915.x.

30. Hebbeler KM, Gerlach-Downie SG. Inside the black box of home visiting: a qualitative analysis of why intended outcomes were not achieved. Early Child Res Q. 2002;17(1):2851. doi:10.1016/S0885-2006(02)00128-X.

31. Culp AM, Culp RE, Hechtner-Galvin T, Howell CS, Saathoff-Wells T, Marr P. First-time mothers in home visitation services utilizing child development specialists. Infant Ment Health J. 2004;25(1):1-15. doi:10.1002/imhj.10086.

32. Willging CE, Trott EM, Fettes D, et al. Research-supported intervention and discretion among frontline workers implementing home visitation services. Res Soc Work Pract. 2017;27(6):664-675. doi:10.1177/1049731515601897.

33. Bartholomew LK, Parcel GS, Kok G, Gottlieb NH, Fernández ME. Planning Health Promotion Programs : An Intervention Mapping Approach. 3rd ed. San Francisco, CA: Jossey-Bass; 2011. 
Table 1. Qualitative Data Analyses Steps

\begin{tabular}{|c|c|c|}
\hline \multirow{10}{*}{$\begin{array}{l}\text { Conventional } \\
\text { Content Analysis } \\
\text { Approach }^{\mathrm{a}}\end{array}$} & 1 & Coders 1 and 2 separately read and memoed each transcript \\
\hline & 2 & $\begin{array}{l}\text { Coders } 1 \text { and } 2 \text { re-read each transcript to assign preliminary codes } \\
\text { to the text }\end{array}$ \\
\hline & 3 & $\begin{array}{l}\text { Coders } 1 \text { and } 2 \text { held an in-person meeting to review the } \\
\text { preliminary coding lists and establish a finalized coding list }\end{array}$ \\
\hline & 4 & Coder 1 created a codebook and shared it with Coders 2 and 3 \\
\hline & 5 & Coders 1 and 2 re-coded each transcript using the codebook \\
\hline & 6 & $\begin{array}{l}\text { Coders } 1 \text { and } 2 \text { held an in-person meeting to assess coding } \\
\text { agreement }\end{array}$ \\
\hline & 7 & $\begin{array}{l}\text { Coders } 1 \text { and } 2 \text { held an in-person meeting to establish categories } \\
\text { based on the codes }\end{array}$ \\
\hline & 8 & $\begin{array}{l}\text { Coder } 1 \text { combined both sets of codes into their assigned } \\
\text { categories and then reviewed the combined text in each category } \\
\text { for discrepancies }\end{array}$ \\
\hline & 9 & $\begin{array}{l}\text { Coders } 2 \text { and } 3 \text { reviewed and returned resolutions and feedback } \\
\text { on the discrepancies }\end{array}$ \\
\hline & 10 & Coder 1 applied the resolutions and feedback \\
\hline $\begin{array}{l}\text { Directed } \\
\text { Content Analysis } \\
\text { Approach }^{\mathrm{a}}\end{array}$ & 11 & $\begin{array}{l}\text { Coder } 1 \text { and } 2 \text { met by videocall to identify categories that were } \\
\text { related to fidelity and its sub-variables }\end{array}$ \\
\hline $\begin{array}{l}\text { Conventional } \\
\text { Content Analysis } \\
\text { Approach }^{\mathrm{a}}\end{array}$ & 12 & $\begin{array}{l}\text { Coder } 1 \text { and } 2 \text { reviewed the categories for emerging themes on } \\
\text { the video call; none were found }\end{array}$ \\
\hline $\begin{array}{l}\text { Directed } \\
\text { Content Analysis } \\
\text { Approach }^{\mathrm{a}}\end{array}$ & 13 & $\begin{array}{l}\text { Coder } 1 \text { organized the categories into the variables of content, } \\
\text { frequency, and timing }\end{array}$ \\
\hline
\end{tabular}

Coder $1=$ AMD, Coder $2=$ SMD, Coder $3=$ CGA

${ }^{a}$ Approaches from Hsieh and Shannon ${ }^{24}$ 


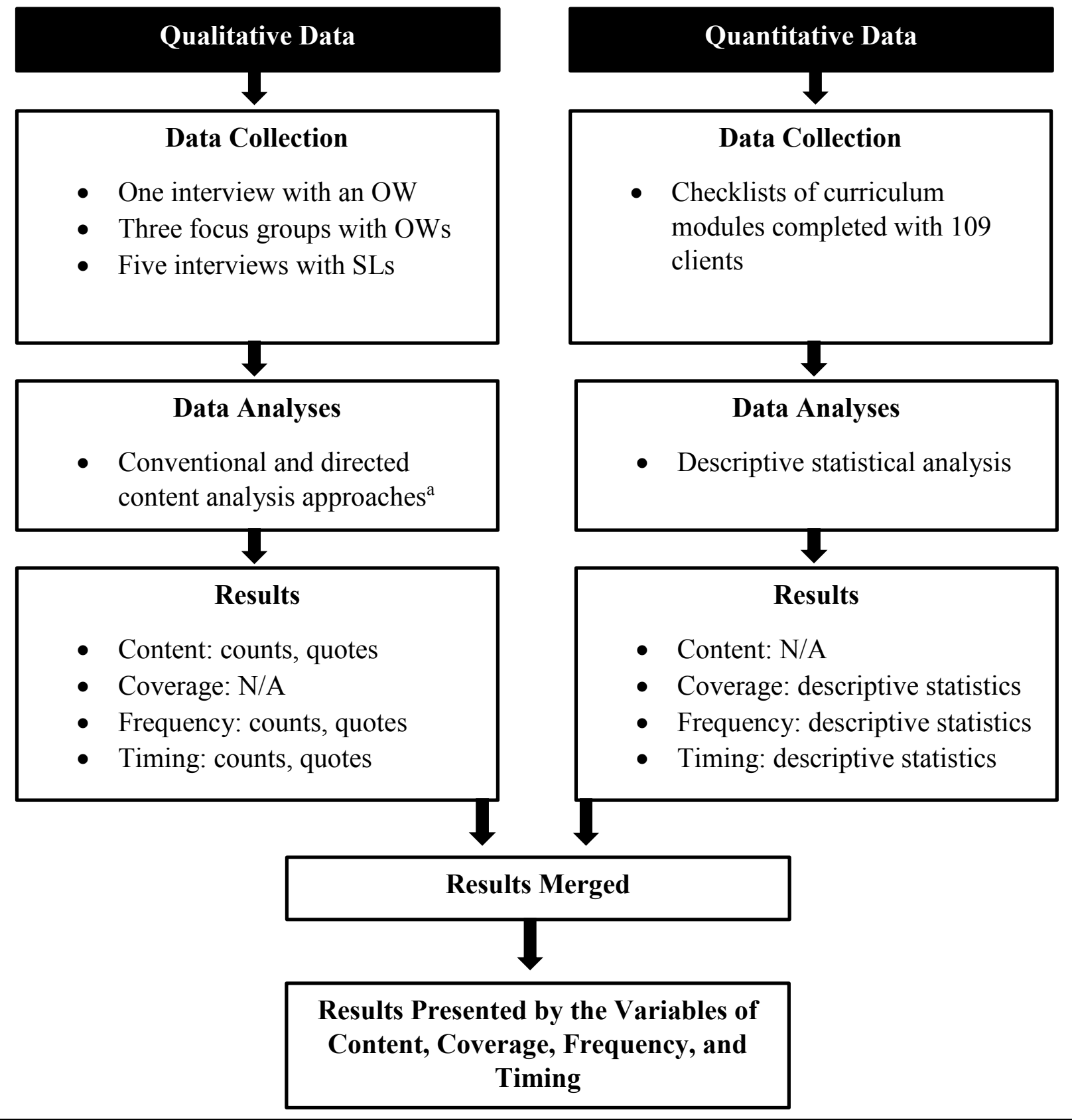

Figure 1. An illustration of this study's convergent parallel design. ${ }^{20} \mathrm{~N} / \mathrm{A}=$ not applicable, $\mathrm{OW}$ $=$ Outreach Worker, SLs = Site Leaders.

${ }^{a}$ Approaches from Hsieh and Shannon ${ }^{24}$ 
Table 2. Findings for the Variable of Content by Data Sources

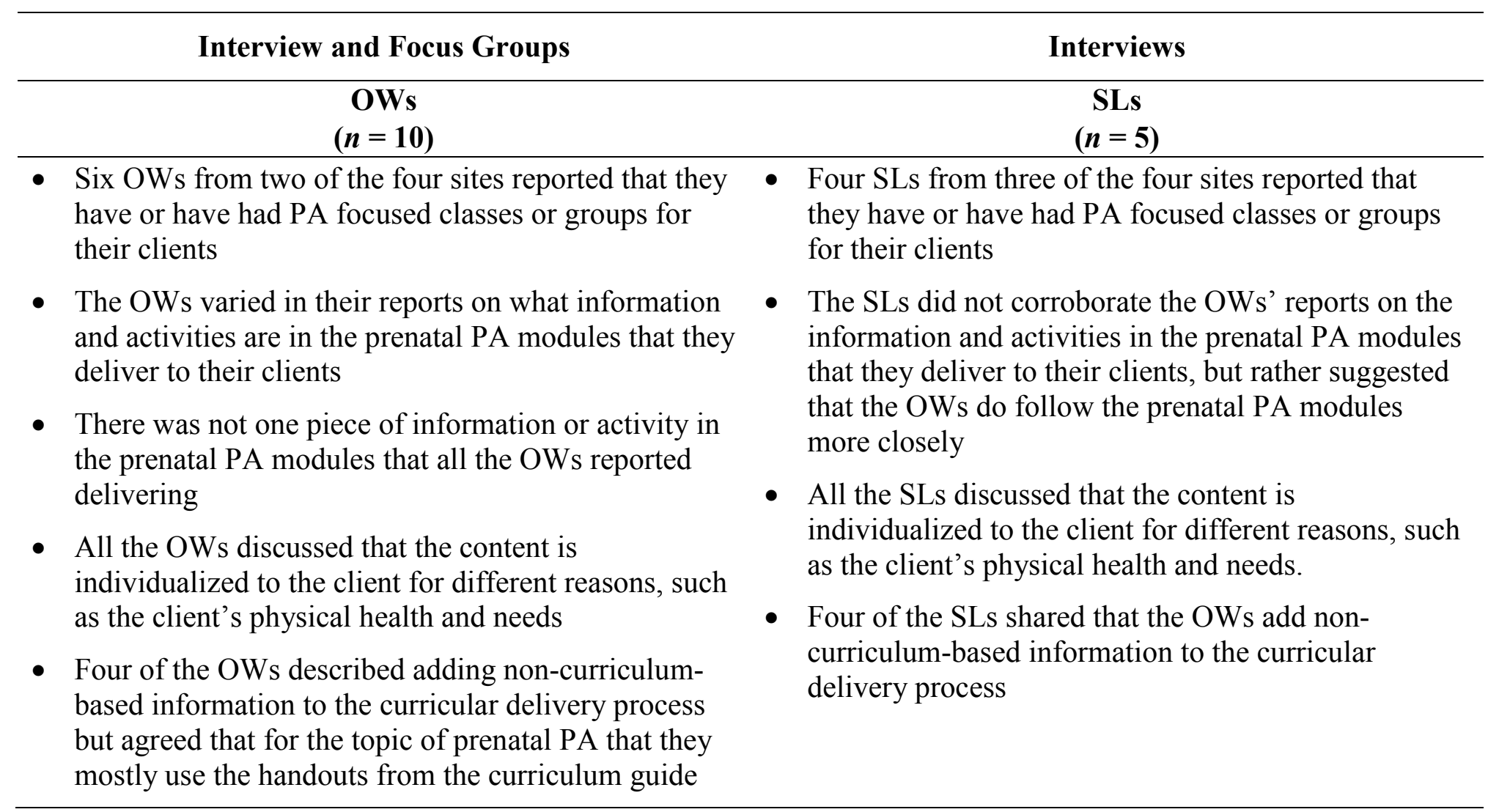

$\mathrm{PA}=$ physical activity, $\mathrm{OW}=$ Outreach Worker, $\mathrm{SL}=$ Site Leader. 
Table 3. Findings for the Variable of Coverage by Data Source

\section{Checklists of Curriculum Modules ${ }^{\mathrm{a}}$}

\begin{tabular}{ccccc}
\hline Home Visit \# & $\begin{array}{c}\text { Completed Visit, } \\
\boldsymbol{n}\end{array}$ & $\begin{array}{c}\text { Received Prenatal PA Module, } \\
\boldsymbol{n}(\mathbf{\%})\end{array}$ & $\begin{array}{c}\text { Received “other" Module, } \\
\boldsymbol{n} \mathbf{( \% )}\end{array}$ & $\begin{array}{c}\text { Received Both Modules, } \\
\boldsymbol{n}(\mathbf{\%})\end{array}$ \\
\hline $\mathbf{1}$ & 79 & 0 & $11(13.9)$ & 0 \\
$\mathbf{2}$ & 33 & $22(66.7)$ & $4(12.1)$ & $2(6.1)$ \\
$\mathbf{3}$ & 19 & $13(68.4)$ & $2(10.5)$ & 0 \\
$\mathbf{4}$ & 14 & 0 & 0 & 0 \\
$\mathbf{5}$ & 18 & $12(66.7)$ & 0 & 0 \\
$\mathbf{6}$ & 25 & 0 & $2(8.0)$ & 0 \\
$\mathbf{7}$ & 23 & 0 & $1(4.4)$ & 0 \\
$\mathbf{8}$ & 25 & 0 & $15(60.0)$ & 0 \\
$\mathbf{9}$ & 29 & 0 & $5(17.2)$ & 0 \\
\hline
\end{tabular}

$\mathrm{PA}=$ physical activity.

${ }^{a}$ After each home visit, Outreach Workers filled out a checklist of the curriculum module(s) that they delivered to clients. 
Table 4. Findings for the Variable of Frequency by Data Sources

\begin{tabular}{|c|c|c|c|}
\hline Interview and Focus Groups & Interviews & Checklists of Curriculum & dules ${ }^{a}$ \\
\hline $\begin{array}{c}\text { OWs } \\
(n=10)\end{array}$ & $\begin{array}{c}\text { SLs } \\
(n=5)\end{array}$ & $\begin{array}{c}\text { \# of prenatal and/or "other" } \\
\text { modules received }\end{array}$ & $\begin{array}{c}\text { Clients, } \\
n(\%)\end{array}$ \\
\hline $\begin{array}{l}\text { - Seven OWs discussed delivering } \\
\text { the prenatal PA modules at most } \\
\text { or all the home visits }\end{array}$ & $\begin{array}{l}\text { - Two SLs corroborated that the OWS } \\
\text { deliver the prenatal PA modules at } \\
\text { most or all the home visits }\end{array}$ & $\begin{array}{l}0 \\
1\end{array}$ & $\begin{array}{l}49(45.0) \\
39(35.8)\end{array}$ \\
\hline $\begin{array}{l}\text { - One OW discussed delivering the } \\
\text { prenatal PA module multiple } \\
\text { times }\end{array}$ & $\begin{array}{l}\text { - One SL corroborated that OWs may } \\
\text { discuss the prenatal PA modules every } \\
\text { visit }\end{array}$ & $\begin{array}{l}2 \\
3\end{array}$ & $\begin{array}{c}14(12.8) \\
5(4.6)\end{array}$ \\
\hline $\begin{array}{l}\text { Two OWs described following } \\
\text { the curriculum guide }\end{array}$ & $\begin{array}{l}\text { - One SL noted that most of the OWs } \\
\text { primarily stick to the curriculum guide }\end{array}$ & $\begin{array}{l}4 \\
5\end{array}$ & $\begin{array}{l}1(0.9) \\
1(0.9)\end{array}$ \\
\hline
\end{tabular}

$\mathrm{PA}=$ physical activity, $\mathrm{OW}=$ Outreach Worker, $\mathrm{SL}=$ Site Leader.

${ }^{a}$ After each home visit, OWs filled out a checklist of the curriculum module(s) that they delivered to clients. 
Table 5. Findings for the Variable of Timing by Data Sources

\begin{tabular}{|c|c|c|c|c|c|c|}
\hline $\begin{array}{l}\text { Interview and } \\
\text { Focus Groups }\end{array}$ & Interviews & & Checklists o & Curriculu & Modules ${ }^{\mathrm{a}}$ & \\
\hline $\begin{array}{c}\text { OWs } \\
(n=10)\end{array}$ & $\begin{array}{c}\text { SLs } \\
(n=5)\end{array}$ & Trimester & $\begin{array}{c}\text { Received } \\
\text { One or More } \\
\text { Home Visit(s), } \\
n\end{array}$ & $\begin{array}{c}\text { Received } \\
\text { Prenatal } \\
\text { PA } \\
\text { Module, } \\
n(\%)\end{array}$ & $\begin{array}{c}\text { Received } \\
\text { "other" } \\
\text { Module, } \\
n(\%)\end{array}$ & $\begin{array}{c}\text { Received } \\
\text { Both } \\
\text { Modules, } \\
n(\%)\end{array}$ \\
\hline \multirow{4}{*}{$\begin{array}{l}\text { - Over half of the OWs } \\
\text { described delivering the } \\
\text { prenatal PA modules } \\
\text { irrespective of a client's } \\
\text { trimester (e.g., deliver the } \\
\text { prenatal PA modules } \\
\text { every month, deliver the } \\
\text { prenatal PA modules } \\
\text { regardless of the client's } \\
\text { trimester when she } \\
\text { enrolls) } \\
\text { Two OWs described } \\
\text { following the curriculum } \\
\text { guide }\end{array}$} & \multirow{4}{*}{$\begin{array}{l}\text { - Two SLs corroborated } \\
\text { that the OWs deliver the } \\
\text { prenatal PA modules } \\
\text { irrespective of a client's } \\
\text { trimester (e.g., deliver } \\
\text { the prenatal PA modules } \\
\text { once a month, deliver the } \\
\text { prenatal PA modules at } \\
\text { later visits) } \\
\text { One SL noted that most } \\
\text { of the OWs primarily } \\
\text { stick to the curriculum } \\
\text { guide }\end{array}$} & 1 & 27 & $5(18.5)$ & $4(14.8)$ & $1(3.7)$ \\
\hline & & 2 & 52 & $18(34.6)$ & $6(11.5)$ & $4(7.7)$ \\
\hline & & 3 & 69 & $7(10.1)$ & $24(34.8)$ & $4(5.8)$ \\
\hline & & & & & & \\
\hline
\end{tabular}

$\mathrm{PA}=$ physical activity, $\mathrm{OW}=$ Outreach Worker, $\mathrm{SL}=$ Site Leader.

${ }^{a}$ After each home visit, OWs filled out a checklist of the curriculum module(s) that they delivered to clients. 
Chapter 5. The Effect of a Home Visiting Program on Pregnant Clients' Moderate-

Intensity Physical Activity: A Quasi-Experimental Design with a Propensity Score Matched

Comparison Group 


\begin{abstract}
Aim: The aim of this study was to evaluate the impact of the Maternal Infant Health Outreach Worker (MIHOW) program's curriculum on pregnant clients' moderate-intensity physical activity (MPA). Methods: This longitudinal study consisted of 98 intervention and 56 comparison group participants with physical activity measurements taken at trimesters one, two and/or three. A nonrandomized quasi-experimental research design was utilized to evaluate how the MIHOW program's pregnant clients' absolute MPA metabolic equivalent of task (MET) minutes per week changed relative to a propensity score matched comparison group of pregnant women. Generalized linear mixed modeling with a zero inflated negative binomial distribution was used as the statistical analysis strategy. Results: The results showed that (1) the expected log absolute MPA MET minutes per week decreased 1.27 less for the comparison group than for the intervention group by trimester $3\left[\chi^{2}(1)=4.77, p=.0289\right],(2)$ the expected log absolute MPA MET minutes per week was 1.49 lower for the comparison group than for the intervention group across time $\left[\chi^{2}(1)=8.12, p=.0044\right]$, and (3) the log odds of not participating in any absolute MPA MET minutes per week was 1.46 lower for the comparison group than for the intervention group $\left[\chi^{2}(1)=4.63, p=.0314\right]$. Conclusions: The results suggest that the more MPA content may be needed in the prenatal physical activity curriculum modules and that greater emphasis may need to be placed on MPA when these modules are delivered to clients.
\end{abstract}




\section{Introduction}

Engagement in prenatal physical activity (PA) has been linked to mental and physical health benefits. ${ }^{1}$ Correspondingly, moderate-intensity physical activity (MPA) is recommended for expectant mothers without health restrictions towards PA. ${ }^{2,3}$ Specifically, Unites States (U.S.) guidelines recommend expectant mothers perform aerobic MPA for 150 minutes or more per week $^{3}$ or as an equivalent perform MPA daily, or almost daily, for 20 to 30 minutes or more. ${ }^{2}$ In the U.S., fewer than $14 \%$ of pregnant women meet prenatal PA guidelines, according to National Health and Nutrition Examination Survey (NHANES) data from 1999 to $2006 .{ }^{4}$ Further, 1994 to 2000 Behavioral Risk Factor Surveillance System data, reveal a positive association with income; compared with pregnant women with annual incomes less than $\$ 20,000$ per year, pregnant women with annual incomes of $\$ 75,000$ or more were 2.95 times more likely to meet the MPA guideline. ${ }^{5}$

Despite these disparities, only a limited number of prenatal PA interventions have targeted primarily or exclusively low-income women. ${ }^{6-8}$ One intervention was delivered to pregnant women in California ${ }^{8}$ and two other interventions were delivered to prengant women in Massachusetts. ${ }^{6,7}$ Although National monitoring systems do not capture prenatal PA prevalence data at the state level, other data among non-pregnant women suggest that the prevalence of pregnant women at-risk for insufficient MPA is higher in certain states. To demonstrate, in 2015, $35.6 \%$ of Mississippi women compared to $60.9 \%$ of Oregon women met the adult U.S. PA Guidelines of 150 minutes of weekly MPA, 75 minutes of weekly vigorous-intensity PA, or a mix of both. ${ }^{9,10}$ These data highlight a need for prenatal PA interventions targeting low-income pregnant women in states with low female PA prevalence.

The Maternal Infant Health Outreach Worker (MIHOW) program is a home visitation 
program model that has prenatal PA curriculum modules which can be delivered to clients during one-on-one in-home visits ${ }^{11}$ and/or group meetings. ${ }^{12}$ The MIHOW program primarily serves those who are low-income, ${ }^{13,14}$ lack social support, ${ }^{14}$ and/or are isolated due to household locale. ${ }^{13,14}$ Furthermore, it is offered in Kentucky, Mississippi, Tennessee, and West Virginia ${ }^{13}$ to pregnant women or families with a child younger than 3 years. ${ }^{14}$ In 2015 , these states ranked $6^{\text {th }}$, $1^{\text {st }}, 8^{\text {th }}$ and $11^{\text {th }}$ lowest among the 50 U.S. states for the percentage of women meeting the adult U.S. PA Guidelines, respectively., ${ }^{9,10}$

Outcome research on the MIHOW program has been reported for different topics, including prenatal care and breastfeeding practices. ${ }^{15,16}$ However, no study has examined the impact of the MIHOW program's curriculum on pregnant clients' MPA. Therefore, the aim of this study was to evaluate the impact of the MIHOW program's curriculum on home visitation clients' prenatal MPA compared to a propensity score matched comparison group. Because research suggests that MPA levels tend to drop when women enter their third trimester, ${ }^{4}$ our hypothesis was that pregnant women who receive the MIHOW program's curriculum will experience a less significant decline in MPA than women who do not receive it.

\section{Methods}

A statewide longitudinal, effectiveness evaluation was conducted on the MIHOW program at four implementation sites in a southern mid-Atlantic state between December 2016 and September 2018. This study on the PA outcomes was part of the statewide evaluation, utilizing a quasi-experimental design to evaluate how the MIHOW program's clients' prenatal MPA levels changed relative to a matched comparison group (see Figure 1). Participant recruitment and data collection were completed concurrently as part of the MIHOW program 
evaluation. Approval from an Institutional Review Board was granted for the MIHOW program evaluation, including this study (IRB\#1606174076A006).

------Figure 1 about here -----

\section{Participants}

To be eligible for the MIHOW program evaluation, women had to (1) enroll in the MIHOW program during the timeframe of the evaluation, and (2) be pregnant or have given birth within three months of enrollment. Additional eligibility criteria for the intervention group participants in this study included: (1) being pregnant (any gestational period), (2) not participating in another PA intervention, and (3) not being enrolled in any other home visitation program model. To meet eligibility criteria for the comparison group for the MIHOW program evaluation, women had to (1) live in the state where this evaluation was conducted, (2) not be enrolled in any home visitation program model, and (3) be pregnant or have given birth within three months of enrollment. Additional eligibility criteria for the comparison group participants in this study included: (1) being pregnant (any gestational period) and (2) not participating concurrently in a PA intervention.

\section{Participant Recruitment}

Recruitment of the MIHOW program evaluation intervention group participants occurred between December 2016 and September 2018. Intervention participants were passively recruited. Specifically, women who voluntarily enrolled in the MIHOW program and met the other eligibility criteria outlined above were included in the MIHOW program evaluation and briefed on it at their enrollment home visit by their Outreach Worker (OW). Women were able to opt out of participation in the evaluation. 
Recruitment of the MIHOW program evaluation comparison group participants occurred between April 2017 and September 2018. Recruitment was done by MIHOW program evaluation team members in-person at Women, Infants, and Children (WIC) breastfeeding classes, through a Facebook page and Facebook ads, and through flyers placed across the state at various organizations that serve low-income pregnant women, such as WIC centers, health departments, Family Resource Networks, and food pantries. The Facebook page, ads, and flyers provided information on the evaluations and links to online consent forms. Women who completed the consent forms in-person at WIC breastfeeding classes or online were contacted via telephone by a MIHOW program evaluation team member to schedule their baseline interview. Information collected on this call, in the consent form(s), and during the baseline interview (by telephone) was used to determine eligibility for the comparison group.

\section{Intervention}

OWs conduct one-on-one in-home visits ${ }^{11}$ and group meetings ${ }^{12}$ with clients for educational purposes. Conversation and/or demonstrations are used by the OWs to deliver the MIHOW program's curriculum modules to clients using The MIHOW Home Visit Guide: The Prenatal Period (hereafter, "curriculum guide") for planning purposes. ${ }^{11}$ This guide outlines nine prenatal in-home visits for OWs to deliver and gives three to four suggested curriculum modules to deliver at each home visit. ${ }^{11}$

Home Visits 2, 3, and 5 have prenatal PA curriculum modules. ${ }^{11}$ In the curriculum guide, Home Visit 2 has a curriculum module that focuses exclusively on prenatal PA; its content includes a PA handout, information on the safety of PA, and activities such as assessing PA levels, planning PA, and goal setting for PA. ${ }^{11}$ Home Visit 3 has a curriculum module that does not focus primarily on prenatal PA but it does include content on planning PA. ${ }^{11}$ Similarly, 
Home Visit 5 has a curriculum module that does not focus primarily on prenatal PA but it does include content on planning PA and its benefits. ${ }^{11}$

Although Home Visit 3 is aligned with trimester one and Home Visit 5 is aligned with trimester 2, OWs are not expected to rigidly adhere to the curriculum guide. ${ }^{11}$ Instead, OWs individualize home visits for reasons such as a woman's needs, interests, and the trimester that she enrolled in the MIHOW program. ${ }^{11}$ Consequently, the content, exposure, timing, and duration of a curriclum module is individualized to each client. ${ }^{11}$

\section{Data Collection}

Intervention Group. Intervention group data were collected via in-person interviews conducted by the OWs who received at least one standardized data collection training conducted by a MIHOW evaluation team member. The first, prior to the start of data collection covered the data collection protocols and questionnaires. The second was a refresher training done during the evaluation; it included content on how to administer the Pregnancy, Infection, and Nutrition (PIN3) PA questionnaire ${ }^{17}$ to augment the fidelity with which it was delivered. Once trained, OWs administered the demographic questionnaires to clients at the enrollment home visit (i.e., baseline) and the PIN $3{ }^{17}$ to clients during a home visit at one of the four sequences outlined in Table 1. Data were sent from the MIHOW sites to an Epidemiologist with the state's Department of Health and Human Resources on an ongoing basis. Data from December 2016 to April 9, 2018 were provided for analyses.

Comparison Group. Comparison group data were collected via telephone interviews conducted by college students who were trained by the same team members that trained the OWs. The training covered the data collection protocols and questionnaires with specific instructions to not deviate from the protocols so as to not provide information, opinions, or 
advice to the comparison participants that might influence their responses. Data collectors administered the demographic questionnaire to participants at baseline (first telephone interview) and the PIN $3{ }^{17}$ to participants at one of the four sequences in Table 1. Data were entered into Qualtrics software, Version $37.892^{18}$ during the interview.

Table 1 about here

Incentives. Participants could earn up to $\$ 130$ in total incentives, $\$ 10$ for each of the 10 MIHOW program evaluation interviews completed, and a bonus of $\$ 30$ for completing at least 6 of the 10 interviews.

\section{Measures}

Age (covariate). ${ }^{19}$ Age was assessed by asking the participant's date of birth and calculating age from the date the questionnaire(s) were administered. Acceptable values were based on childbearing age and set at 15 to 44 years of age. ${ }^{20}$

Employment (inconclusive covariate). ${ }^{21}$ The covariate status of employment is inconclusive, ${ }^{21}$ but it was included as a covariate because income could not be included. Employment was assessed using a single-item with response options of: "Unemployed and looking for work" = 1, "Unemployed and not looking for work" = 2, "Employed part-time (less than 32 hrs per week)" = 3, and "Employed full-time (32+ hours per week)" = 4. The response options were collapsed to create a dummy variable for the propensity score analysis (i.e., 1 and 2 $=0$ and 3 and $4=1)$.

Education (covariate). ${ }^{21}$ Education was assessed using a single item for the highest level of education completed, with response options of: "Less than HS diploma" $=1$, "GED" $=2$, "High School Diploma" = 3, "Some college" = 4, "Technical Training" = 5, "Associate Degree" 
$=6$, "Bachelor Degree or higher" $=7$, and "Other" $=8$. The response options were collapsed to create a dummy variable for the propensity score analysis (i.e., 1, 2, and $3=0$ and 4, 5, 6, 7, and 8 [determined by the participant's response to other] $=1$ ).

Household Size (unknown covariate). The covariate status of household size is unknown, but it was included as a covariate because income could not be included. Household size was assessed by asking participants about the number of people living in the household. Acceptable values were set at 1 person or more.

Group (binary independent variable). A group variable was created and coded as "comparison group" $=0$ and "intervention group" $=1$.

Trimester (categorical independent variable). Trimester was calculated based on participants' expected due dates with the timing of trimesters 1, 2, and 3 being $<13$ weeks pregnant, $14-27$ weeks pregnant, $\geq 28$ weeks pregnant, respectively.

\section{Absolute Moderate-Intensity Physical Activity Metabolic Equivalent of Task}

Minutes per Week (continuous dependent variable). Data for this variable was collected using the PIN3, which is an interview-administered instrument previously validated among pregnant women. ${ }^{17}$ Participants are asked series of questions to collect the specific activities, frequency, intensity, and duration the respondent did in the week prior to the interview in each of eight domains: "recreational" activities, "outdoor household activities", "indoor household activities", "child and adult care - lifting", "transportation - walk", "transportation - bike", "work and school activities", and "other activity". ${ }^{17}$ Regardless of domain, only the moderate-intensity activities were used for this study to match prenatal PA guidelines. ${ }^{2,3}$ To calculate each participant's absolute MPA METs minutes per week, the participant's responses to the questionnaire were scored using the steps outlined in Table 2. 
----- Table 2 about here -----

METs are a measure of energy expenditure of specific activities. ${ }^{3}$ The U.S. Physical Activity Guidelines are based on this variable translated to minutes per week of different intensities of activities. ${ }^{3}$ Specifically, MPA is defined as an activity between 3.0 and 5.9 METs; such as walking at a 3 mile per hour pace $(3.3 \mathrm{METs}) .{ }^{3}$ The PA guideline of 150 minutes of MPA per week is roughly the equivalent of 500 MET-minutes per week, such as walking (i.e., 150 minutes x 3.3 METs per minute) ${ }^{3}$

\section{Data Management and Analyses}

The PIN3 ${ }^{22}$ and International Physical Activity Questionnaire (IPAQ) ${ }^{23}$ cleaning protocols were used to guide data cleaning and the following rules were set for conservative estimates of PA: (1) the midpoint was taken for observations reported as ranges and numbers reported as "<\#”; (2) only the number was retained for observations reported as " $>$ \#", "at least \#", and "approx. \#"; (3) responses such as "everyday" and "multiple times a day" for the number of times an activity was done were set to 7 ; (4) if the number of minutes spent on an activity at one time was 1,260 or more, or per week was 8,400 or more, then the activity was set to missing; (5) if duplicate activities were reported by a participant at one timepoint, the highest total PA minutes per week observation for the duplicate activity was set to missing; (6) if the number of times an activity was done was missing, the observation was set to 1 if minutes were recorded or the observation was set to missing if minutes were also missing; (7) if the number of minutes spent on an activity were missing, the minutes spent on the activity were set using miles (i.e., 20 minutes set per mile) or the activity was set to missing if miles were not reported; (8) if two or more activities were listed as one (e.g. "playing with kids and taking care of them"), the activities were split and their minutes were split evenly, set using miles (i.e., 20 minutes set per 
mile), or set using a combination of both; (9) if the name of an activity was missing or it could not be coded as an activity (e.g., taking child to ball practice), then the activity was set to missing; and (10) if the PIN3 was administered twice to a participant in the same trimester, then their values for the absolute MPA MET minutes per week and total PA minutes per week variables in that trimester were averaged and only the average observation was included in analyses. For the trimester variable, if the PIN3 was administered so that the one-week recall covered two trimesters, the trimester variable was set to the trimester the participant was in for four of the seven days of the recall.

Before analyses, study variables were examined for univariate outliers and values outside their allowable range. Issues were handled jointly by the first and senior author on a case by case basis. Notably, observations by identification number and timepoint (i.e., id\# at trimester\#) were excluded if (1) the date the PIN3 was administered was missing and there were no recorded responses for the questionnaire, (2) the participant's trimester and estimated due date were missing, (3) the PIN3 was administered postpartum, or (4) the participant's value for the total PA minutes per week variable was 7,560 minutes or more (this limit was based on NHANES data adjustments for $\mathrm{PA},{ }^{24}$ see Table 2 for how this variable was scored)

\section{Analyses.}

All analyses were conducted using SAS ${ }^{\circledR}$ Software, Version $9.4 .{ }^{25}$ Descriptive analysis was conducted for the demographic, propensity score, and model variables. Valid percentages were reported for each categorical variable and mean, standard deviation, and upper and lower $95 \%$ confidence intervals of the means were reported for each continuous variable except for absolute MPA MET minutes per week. For absolute MPA MET minutes per week, the median and interquartile range were reported. The distribution analysis for absolute MPA MET minutes 
per week revealed a zero inflated negative binomial (ZINB) distribution; thus, a generalized linear modeling approach was used for analysis. Also, the demographic variables were compared using an independent sample t-test for the continuous variables and Fisher's exact test for the categorical variables. Alpha was set to 0.05 .

Propensity score analysis. The propensity score analysis procedure was used to adjust confounding in order to achieve covariate balance between the intervention group and the comparison group. Since this study used a quasi-experimental research design, propensity score analysis was used to mitigate potential confounding due to any selection bias between the intervention group and the comparison group. ${ }^{26,27}$

Four sequential steps were done as part of the propensity score analysis procedure. First, we identified potential covariates based on the literature and available demographics, and then we examined the data for missingness and group differences, and chose age, employment, highest level of formal education, and household size as the covariates. Second, covariate balance was assessed through examination of the boxplot, bar chart, and standardized variable differences table produced by running SAS $®$ Software, Version 9.4's ${ }^{25}$ PSMATCH Procedure (i.e., we checked that all standardized variable differences were $|0.2|$ or less). ${ }^{27}$ Third, household size was removed as a covariate because of its lack of difference between the two groups. Lastly, the average treatment effect among the treated (ATT) weighting variable was added to the generalized linear model (via SAS ${ }^{\circledR}$ Software, Version 9.4's ${ }^{25}$ PROC GENMOD procedure) in the weight statement. It is important to note that the omission of a covariate occurred if the covariate was not measured in the MIHOW program evaluation study, if the covariate had more than $5 \%$ percent missing data, or its covariate status was unknown. ${ }^{28}$ 
Model fit and analysis. The final dataset for this longitudinal study consisted of 98 intervention and 56 comparison group participants with one, two, or three physical activity measurements taken over their pregnancy (trimester one, two, and/or three). To identify the best fitting model for analyses, six different models were fit using SAS® Software, Version 9.4's ${ }^{25}$ PROC GENMOD procedure. The best fitting model was determined using the Akaike's Information Criterion (AIC) and the Sawa's bayesian information criterion ([BIC], lower was considered better for each). Table 3 shows a summary of the criterion values for each model. The criterion values showed that the zero inflated negative binomial (ZINB) distribution fit best relative to a Poisson distribution or a negative binomial (NB) distribution. Further, model fit assessments revealed the fourth model, ZINB with only group in the excessive zero statement, was the best fitting model. This model has two distinct distributions - the NB distribution and the zero inflated distribution, which models the excess zeros in the data. The following were reported for the chosen model: parameter estimates (i.e., expected log estimates for the NB parameter estimates and log odd estimates for the zero-inflated parameter estimates), standard errors, Wald Chi-Square, and p-values. Alpha was set to 0.05 .

----- Table 3 about here -----

\section{Results}

\section{Descriptive Statistics}

Table 4 shows the baseline descriptive statistics of the intervention and comparison group participants. The intervention group participants had a mean age of 25 years $(S D=5$ years $)$ whereas the comparison group participants had a mean age of 28 years ( $S D=5$ years). More intervention group participants $(n=56,74.67 \%)$ met the U.S. federal poverty guideline than comparison group participants $(n=18,35.29 \%)$. Furthermore, the intervention group 
participants were primarily white $(n=78,86.67 \%)$, non-Hispanic/Latino $(n=96,100.00 \%)$ and unemployed $(n=69,71.13 \%)$ and the comparison participants were primarily white $(n=51$, 91.07\%), non-Hispanic/Latino $(n=56,100.00 \%)$ and employed $(n=32,57.14 \%)$. Additional descriptive statistics are shown in Table 4.

Table 4 about here

Table 5 shows the descriptive statistics for absolute MPA MET minutes per week by trimester for the intervention and comparison group participants. At trimester 1, the intervention group participants had a higher median of absolute MPA MET minutes per week than the comparison group participants (median $1974.00[\mathrm{IQR}=315.00-3570.00]$ and median 1031.00 $[\mathrm{IQR}=693.50-2754.63]$, receptively). By trimester three, the comparison group participants had a higher median of absolute MPA MET minutes per week than the intervention group participants (834.50 [345.00 - 2430.00] and 792.00 [210.00 - 2772.00], receptively). Additional descriptive statistics are shown in Table 5.

----- Table 5 about here -----

\section{Zero-Inflated Negative Binomial Model}

Table 6 shows the parameter estimates for the ZINB model. The NB parameter estimates were not statistically significant for the main effect of trimester $\left[\chi^{2}(1)=0.01, p=.9087 ; \chi^{2}(1)=\right.$ $0.59, \mathrm{p}=.4408$, respectively) and the interaction effect of comparison group by trimester $2\left[\chi^{2}(1)\right.$ $=2.20, \mathrm{p}=.1377]$ but were statistically significant for the interaction effect of comparison group by trimester $3\left[\chi^{2}(1)=4.77, p=.0289\right]$ and the main effect of group $\left[\chi^{2}(1)=8.12, p=.0044\right]$. The findings showed that (1) the expected log absolute MPA MET minutes per week decreased 1.27 less for the comparison group than for the intervention group by trimester 3, and (2) the 
expected log absolute MPA MET minutes per week was 1.49 lower for the comparison group than for the intervention group across time.

The zero-inflated parameter estimate was statistically significant for the main effect of group $\left[\chi^{2}(1)=4.63, p=.0314\right]$. The findings showed that the log odds of not participating in any absolute MPA MET minutes per week was 1.46 lower for the comparison group than for the intervention group.

----- Table 6 about here -----

\section{Discussion}

The intent of this study was to assess whether pregnant women who receive the MIHOW program's curriculum experienced a less significant decline in their MPA levels compared to pregnant women who did not receive it. Descriptive results revealed that the intervention group started off slightly higher in terms of median absolute MPA MET minutes per week at first trimester (1974 v. 1031). Both groups increased their median absolute MPA MET minutes per week from first to second trimester by roughly 300 absolute MPA MET minutes per week, and then both groups saw a decrease in their median absolute MPA MET minutes per week into the third trimester to finish at comparable values (792 v. 834). Results from the propensity score weighted ZINB model revealed: (1) when taking into account participants who do not participate in any absolute MPA MET minutes per week, the comparison group had a lower probability of decreasing their absolute MPA MET minutes per week by trimester three than the intervention group participants, (2) when taking into account participants who do not participate in any absolute MPA MET minutes per week, across time the comparison group participants had a lower probability than the intervention group participants of participating in absolute MPA MET 
minutes per week, and (3) comparison participants were less likely to not participate in any absolute MPA MET minutes per week.

Our findings differ from the findings of Thomson and colleagues ${ }^{29}$ which to date was the only study on the effectiveness of a home visitation program model's curriculum that includes

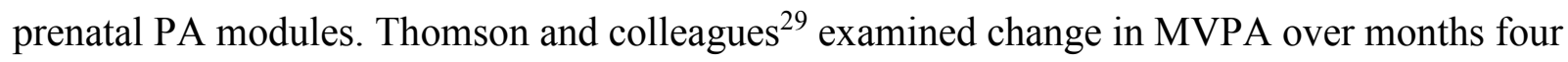
(trimester two) to eight (trimester three) of pregnancy for women who were subdivided into the Parents as Teachers curriculum or an enhanced version of this curriculum. Results for the interaction effect of group by time and the main effect of group were not statistically significant. ${ }^{29}$ Differences between that study's results and ours may be due to three notable study design variations. First, to assess PA levels we used the PIN $3{ }^{17}$ whereas Thomson and colleagues $^{29}$ used the Pregnancy and Physical Activity Questionnaire, which they modified. Second, we focused only on MPA to align with the U.S. prenatal PA guidelines ${ }^{2,3}$ whereas Thomson and colleagues ${ }^{29}$ focused on moderate-to-vigorous PA. Finally, we examined the effectiveness of the MIHOW program's curriculum and Thomson and colleagues ${ }^{29}$ investigated the effectiveness of the Parents as Teachers curriculum compared with the Parents as Teachers Enhanced curriculum - all three curricula are distinct. Accordingly, these findings together demonstrate the importance investigating the effectiveness of different home visitation program models' prenatal PA curricula modules and using comparative PA measures across studies.

The design of the MIHOW program's prenatal PA curriculum modules may provide an explanation for the significant interaction effect (intervention group by trimester 3) that we found. Specifically, the MIHOW program's prenatal curriculum PA modules are not specifically designed to improve or maintain clients' MPA levels. ${ }^{11}$ Instead, OWs individualize these modules to meet their clients' where they are at regarding their interests and needs. ${ }^{11}$ 
Accordingly, the content of the prenatal PA curriculum modules that is delivered and the dosage of the prenatal PA curriculum modules differs by client. ${ }^{11}$ Applying our findings to home visitation practice, the results suggest that more MPA content may need to be incorporated into the prenatal PA curriculum modules and more emphasis may need to be placed on MPA when these modules are delivered to clients to help them reach the U.S. prenatal PA guidelines. ${ }^{2,3}$ Also, moving forward, research is needed which aligns with the MIHOW program's current prenatal PA practices. An example would be to investigate the impact of the MIHOW program's curriculum on pregnant clients' indoor household MPA, since one activity the OWs may implement from the curriculum guide is strengthening clients' awareness of how they get PA through doing household chores. ${ }^{11}$

Our findings were statistically significant for the main effects of group. One explanation for these findings may be that we did not reach covariate balance between the intervention and comparison groups because certain covariates could not be included in our propensity score analysis procedure. For example, the intervention and comparison group participants may have differed in terms of income, ${ }^{19,21}$ pre-pregnancy PA, ${ }^{21}$ and parity, ${ }^{19,21}$ all of which have been found to be associated with prenatal PA and/or more specifically exercise. Yet, these covariates were not included in our propensity score analysis procedure due to more than five percent missing data (i.e., annual household income) or not being measured in the MIHOW program evaluation (i.e., pre-pregnancy PA, parity). Thus, future studies should consider monthly data fidelity checks in order to quickly identify and resolve missing data issues and include measures that capture each of the discussed covariates.

Besides the limitations with the propensity score analysis procedure that may have affected all of the key findings, these findings should be taken in the view of some other 
important limitations. It is important to note that this study had a small sample size and that bias or inaccuracies may have occurred during this study due to (1) the use of non-blinded data collectors, (2) the use of self-reported surveys, and (3) delayed data fidelity checks and subsequent data collector refresher trainings due to the data management system being out of service for several months. To mitigate bias or inaccuracies, prior to data collection, a standardized training was provided to all the data collectors. Also, while the data management system was down, a refresher training was done. In addition to these limitations, the data may represent an underreporting of the participants' involvement in PA interventions. The participants were asked about the current programs they or their children participate in, but the question's primary focus was not on their participation in PA programs. Also, we did not have measures to adequately capture (1) participants who were advised by their medical provider not to participate in PA and (2) MIHOW clients who received the prenatal PA modules in their client group meetings and/or one-on-one client in-home visits. However, research on the fidelity to the MIHOW program's prenatal PA modules conducted parallel to this study suggested that the nearly all the MIHOW clients received one or more of the prenatal PA curriculum modules (A. M. D, unpublished data, 2019). Taking these limitations into account, a replication of this study is warranted to compare the findings between the studies.

Effective, broad-reaching prenatal PA interventions are still needed for low-income women. This study provided insight on one previously unevaluated prenatal PA intervention targeting low-income pregnant women. Our findings suggest that more research is needed on the effectiveness of the MIHOW program's prenatal PA curriculum modules and other home visitation program models' prenatal PA curricula modules. Different home visitation program models provide services across all 50 U.S. states $;{ }^{30}$ reaching many low-income pregnant women 
with prenatal PA curricula; ${ }^{11,29,31}$ yet, little is known about the implementation or effectiveness of these modules. Accordingly, additional research and evaluations are needed on the curricula with prenatal PA modules to build the evidence base of PA behavior change interventions among lowincome pregnant women. 


\section{Acknowledgements}

The authors thank Vanderbilt University’s Maternal Infant Health Outreach Worker Program who was the source of the model and curriculum in this manuscript. Also, this research was supported by the Health Resources and Services Administration (HRSA) of the U.S. Department of Health and Human Services (HHS) as part of an award (X10MC31178) from the Maternal, Infant, and Early Childhood Home Visiting Program to the West Virginia Office of Maternal, Child, and Family Health. The research was conducted by the Program Evaluation and Research Center in the College of Education and Human Services at West Virginia University

(PI: Lucas Moore; co-Is: Amy Root; Suzanne Hartman; Sara Anderson). The contents are those of the author(s) and do not necessarily represent the official views of, nor an endorsement, by HRSA, HHS, or the U.S. Government. For more information, please visit HRSA.gov. 


\section{References}

1. 2018 Physical Activity Guidelines Advisory Committee. 2018 physical activity guidelines advisory committee scientific report. https:/health.gov/paguidelines/secondedition/report/pdf/PAG_Advisory_Committee_Report.pdf. Published February 2018. Accessed April 4, 2019.

2. American College of Obstetricians and Gynecologists. ACOG committee opinion no. 650: physical activity and exercise during pregnancy and the postpartum period. Obstet Gynecol. 2015;126(6):e135-e142. doi:10.1097/AOG.0000000000001214.

3. U.S. Department of Health and Human Services. Physical activity guidelines for Americans, 2nd edition. https://health.gov/paguidelines/secondedition/pdf/Physical_Activity_Guidelines_2nd_edition.pdf. Published 2018. Accessed April 9, 2019.

4. Evenson KR, Wen F. National trends in self-reported physical activity and sedentary behaviors among pregnant women: NHANES 1999-2006. Prev Med. 2010;50(3):123128. doi:10.1016/j.ypmed.2009.12.015.

5. Petersen AM, Leet TL, Brownson RC. Correlates of physical activity among pregnant women in the United States. Med Sci Sports Exerc. 2005;37(10):1748-1753.

doi:10.1249/01.mss.0000181302.97948.90.

6. Chasan-Taber L, Silveira M, Marcus BH, Braun B, Stanek E, Markenson G. Feasibility and efficacy of a physical activity intervention among pregnant women: the Behaviors Affecting Baby and You (B.A.B.Y.) Study. J Phys Act Health. 2011;8(Suppl 2):S228238.

7. Hawkins M, Chasan-Taber L, Marcus B, et al. Impact of an exercise intervention on physical activity during pregnancy: the Behaviors Affecting Baby and You Study. Am J Public Health. 2014;104(10):e74-e81. doi:10.2105/ajph.2014.302072.

8. Jackson RA, Stotland NE, Caughey AB, Gerbert B. Improving diet and exercise in pregnancy with Video Doctor counseling: a randomized trial. Patient Educ Couns. 2011;83(2):203-209. doi:10.1016/j.pec.2010.05.019.

9. Centers for Disease Control and Prevention, National Center for Chronic Disease Prevention and Health Promotion, Division of Nutrition, Physical Activity, and Obesity. Data, Trends and Maps [database online]. https://www.cdc.gov/nccdphp/dnpao/datatrends-maps/index.html. Accessed April 9, 2019.

10. U.S. Department of Health and Human Services. 2008 physical activity guidelines for Americans. http://health.gov/PAGuidelines/pdf/paguide.pdf. Published 2008. Accessed November 29, 2017. 
11. Vanderbilt University Center for Health Services. The MIHOW Home Visit Guide: The Prenatal Period. Nashville, TN: Vanderbilt University Center for Health Services; 2009.

12. Vanderbilt University School of Nursing. Core components. Vanderbilt University School of Nursing Web site. https://www.mihow.org/about/corecomponents.php. April 9, 2019.

13. Elkins T, Aguinaga Mdel P, Clinton-Selin C, Clinton B, Gotterer G. The Maternal Infant Health Outreach Worker program in low-income families. J Health Care Poor Underserved. 2013;24(3):995-1001. doi:10.1353/hpu.2013.0143.

14. Vanderbilt University School of Nursing. The MIHOW program. Vanderbilt University School of Nursing Web site. https://www.mihow.org/. Accessed April 9, 2019.

15. Clinton B. The Maternal Infant Health Outreach Worker project: Appalachian communities help their own. In: Larner M, Halpern R, Harkavy O, eds. Fair Start for Children: Lessons Learned from Seven Demonstration Projects. New Haven, CT: Yale University Press; 1992:23-45.

16. Lutenbacher M, Elkins T, Dietrich MS, Riggs A. The efficacy of using peer mentors to improve maternal and infant health outcomes in Hispanic families: findings from a randomized clinical trial. Matern Child Health J. 2018;22(Suppl 1):92-104. doi:10.1007/s10995-018-2532-z.

17. Evenson KR, Wen F. Measuring physical activity among pregnant women using a structured one-week recall questionnaire: evidence for validity and reliability. Int J Behav Nutr Phys Act. 2010;7:21. doi:10.1186/1479-5868-7-21.

18. Qualtrics Software [computer program]. Version 37.892. Provo, UT: Qualtrics; 2015.

19. Downs DS, Chasan-Taber L, Evenson KR, Leiferman J, Yeo S. Physical activity and pregnancy: past and present evidence and future recommendations. Res Q Exerc Sport. 2012;83(4):485-502. doi:10.1080/02701367.2012.10599138.

20. Johnson K, Posner SF, Biermann J, et al. Recommendations to improve preconception health and health care-United States a report of the CDC/ATSDR Preconception Care Work Group and the select panel on preconception care. MMWR Recommendations and Reports. 2006;55(RR06):1-23.

21. Gaston A, Cramp A. Exercise during pregnancy: a review of patterns and determinants. $J$ Sci Med Sport. 2011;14(4):299-305. doi:10.1016/j.jsams.2011.02.006.

22. Physical activity questionnaire scoring and constructed variables. University of North Carolina at Chapel Hill, Gillings School of Global Public Health, Department of Epidemiology:September 15, 2009. http://www.cpc.unc.edu/projects/pin/design_pin3/docs_3/PIN_PAQ_091509.pdf. 
23. IPAQ Research Committee. Guidelines for the data processing and analysis of the International Physical Activity Questionnaire (IPAQ). November 2005. https://docs.google.com/viewer?a=v\&pid=sites\&srcid=ZGVmYXVsdGRvbWFpbnx0aG VpcGFxfGd4OjE0NDgxMDk3NDU1YWRIZTM.

24. Centers for Disease Control and Prevention, National Center for Health Statistics. How to identify and describe the impact of influential outliers. Centers for Disease Control and Prevention Web site. https://www.cdc.gov/nchs/tutorials/PhysicalActivity/Preparing/PAQ/Info4_Step3.htm. Updated July 10, 2013. Accessed April 9, 2019.

25. SAS@ Software [computer program]. Version 9.4. Cary, NC: SAS Institute Inc.; 20022015.

26. SAS Institute Inc. SAS/STAT ${ }^{\circledR 14.2 ~ U s e r ' s ~ G u i d e . ~ C a r y, ~ N C: ~ S A S ~ I n s t i t u t e ~ I n c . ; ~} 2016$. https://support.sas.com/documentation/onlinedoc/stat/142/psmatch.pdf. Accessed April 9, 2019.

27. Lanza ST, Moore JE, Butera NM. Drawing causal inferences using propensity scores: a practical guide for community psychologists. Am J Community Psychol. 2013;52(34):380-392. doi:10.1007/s10464-013-9604-4.

28. Shadish WR, Cook TD, Campbell DT. Experimental and Quasi-experimental Designs for Generalized Causal Inference. Belmont, CA: Wadsworth Cengage Learning; 2002.

29. Thomson JL, Tussing-Humphreys LM, Goodman MH, Olender SE. Physical activity changes during pregnancy in a comparative impact trial. Am J Health Behav. 2016;40(6):685-696. doi:10.5993/AJHB.40.6.1.

30. National Home Visiting Resource Center. 2017 home visiting yearbook. https://www.nhvrc.org/wp-content/uploads/NHVRC_Yearbook_2017_Final.pdf. Published 2017. Accessed April 8, 2019.

31. O'Brien R. Nurse-Family Partnership Theory of Change Logic Model. 2008. https://fhop.ucsf.edu/sites/fhop.ucsf.edu/files/wysiwyg/NFP_TOC_Logic_Model.pdf. Accessed April 4, 2019.

32. American College of Obstetricians and Gynecologists. How your fetus grows during pregnancy. 2018(FAQ156). https://www.acog.org/Patients/FAQs/How-Your-FetusGrows-During-Pregnancy?IsMobileSet=false. Accessed April 9, 2019.

33. Ainsworth BE, Haskell WL, Herrmann SD, et al. 2011 Compendium of Physical Activities: a second update of codes and MET values. Med Sci Sports Exerc. 2011;43(8):1575-1581. doi:10.1249/MSS.0b013e31821ece12.

34. Physical activity - MET values and categories assigned to activities. August 2, 2007. http://www.cpc.unc.edu/projects/pin/design_pin3/docs_3/PIN-MET-Table-080207.pdf. Accessed April 9, 2019. 
NR (I) $\mathrm{O}_{1} \quad \mathrm{X}_{1} \mathrm{O}_{2} \quad \mathrm{X}_{1} \mathrm{O}_{3}$

$\mathrm{NR}(\mathrm{C}) \mathrm{O}_{1} \quad \mathrm{O}_{2} \quad \mathrm{O}_{3}$

- $\quad$ NR (I): Non-randomized intervention group

- NR (C): Non-randomized comparison group

- $\mathrm{O}_{1}$ : Measures taken during the first trimester (enrollment)

- $\mathrm{O}_{2}$ : Measures taken during the second trimester (or enrollment)

- $\mathrm{O}_{3}$ : Measures taken during the third trimester (or enrollment)

- $\mathrm{X}_{1:}$ Prenatal physical activity curriculum module(s) may be delivered

Figure 1. An illustration of the quasi-experimental research design used in this study.

Table 1. Prenatal Physical Activity Data Collection Sequences ${ }^{\mathrm{a}}$

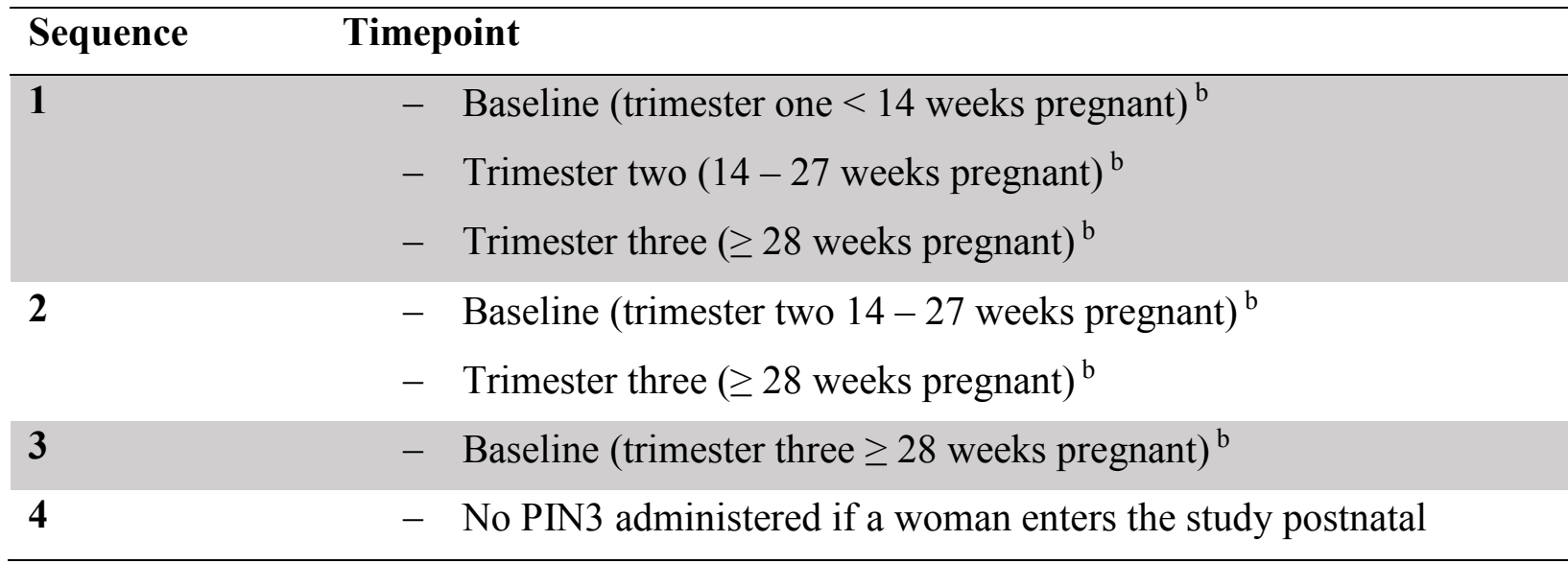

PIN3 = Pregnancy, Infection, and Nutrition PA questionnaire ${ }^{17}$

${ }^{\text {a }}$ The selected sequence was dependent upon the trimester that the participant was in when she had her first interview.

${ }^{\mathrm{b}}$ Trimester length based on American College of Obstetricians and Gynecologists ${ }^{32}$ definition 
Table 2. Steps used to score the Pregnancy, Infection, and Nutrition (PIN3) PA questionnaire

\begin{tabular}{ll}
\hline Step & Action \\
\hline $\begin{array}{l}\text { 1: Assigning METs } \\
\text { values }\end{array}$ & $\begin{array}{l}\text { The 2011 PA Compendium }{ }^{33} \text { and the "Physical Activity-MET Values } \\
\text { and Categories Assigned to Activities"34 documents were used to assign } \\
\text { a MET value to each activity on a participant's questionnaire. }\end{array}$ \\
& $\begin{array}{l}\text { For the domain " "indoor household activities," each activity was } \\
\text { assigned a MET value and then three additional steps were completed for } \\
\text { participants who reported more than one indoor household activity per } \\
\text { timepoint. First, each participant's MET values for indoor household } \\
\text { activities were averaged. Second, this average indoor household }\end{array}$ \\
& $\begin{array}{l}\text { activities METs value for each participant was aligned with one of the } \\
\text { following codes: (1) 2.8 MET - "multiple household tasks all at once, }\end{array}$ \\
& $\begin{array}{l}\text { light effort," (2) 3.5 MET - "multiple household tasks all at once, } \\
\text { moderate effort," or (3) 4.3 MET - "multiple household tasks all at once, }\end{array}$ \\
& $\begin{array}{l}\text { vigorous effort." Third, each activity for the participant was multiplied } \\
\text { by the new MET value assigned in the previous step. }\end{array}$ \\
$\begin{array}{ll}\text { 2: Calculating total } \\
\text { PA minutes per week }\end{array}$ & $\begin{array}{l}\text { Total PA minutes per week for each activity was calculated using the } \\
\text { following formula: "total PA minutes per week for each activity = times } \\
\text { the activity was performed } \times \text { the total number of minutes the activity was }\end{array}$ \\
performed."
\end{tabular}

aDomain = "recreational" activities, "outdoor household activities", "child and adult care lifting", "transportation - walk", "transportation - bike", "work and school activities", and "other activity". MPA = moderate-intensity physical activity, PA = physical activity, MET = metabolic equivalent of task. 
Table 3. Summary Table of the Criterion Values for Each of the Models $(n=154$ for Each Model)

\begin{tabular}{lll}
\hline Random Coefficient Model & AIC & BIC \\
\hline Model 1: Zero Inflated Negative Binomial Distribution & 3560.65 & 3604.28 \\
$\begin{array}{l}\text { Model 2: Zero Inflated Negative Binomial Distribution with only } \\
\text { group and the interaction term in the excessive zero statement }\end{array}$ & 3560.65 & 3604.28 \\
$\begin{array}{l}\text { Model 3: Zero Inflated Negative Binomial Distribution with only } \\
\text { group and trimester in the excessive zero statement }\end{array}$ & 3557.30 & 3594.22 \\
$\begin{array}{l}\text { Model 4: Zero Inflated Negative Binomial Distribution with only } \\
\text { group in the excessive zero statement }\end{array}$ & 3553.61 & 3583.82 \\
$\begin{array}{l}\text { Model 5: Negative Binomial Distribution } \\
\text { Model 6: Poisson Distribution }\end{array}$ & 3660.12 & 3683.62 \\
\hline
\end{tabular}

$\overline{\mathrm{AIC}}=$ Akaike's Information Criterion, $\mathrm{BIC}=$ Sawa's bayesian information criterion 
Table 4. Baseline Descriptive Statistics of the Intervention $(n=98)$ and Comparison Group Participants $(n=56)$

\begin{tabular}{|c|c|c|c|c|c|}
\hline \multirow[t]{2}{*}{ Variable } & \multicolumn{2}{|r|}{$\begin{array}{l}\text { Intervention } \\
\text { Group } \\
\text { Participants }\end{array}$} & \multicolumn{2}{|r|}{$\begin{array}{l}\text { Comparison } \\
\text { Group } \\
\text { Participants }\end{array}$} & \multirow[t]{2}{*}{ p-value } \\
\hline & $n$ & Mean $(S D), \%$ & $n$ & Mean $(S D), \%$ & \\
\hline Age in years & 98 & $24.71(5.16)$ & 56 & $28.38(5.46)$ & $<.0001 *$ \\
\hline Total household size & 94 & $3.32(1.45)$ & 56 & $3.23(1.25)$ & .7086 \\
\hline Race & 90 & & 56 & & $.0296^{*}$ \\
\hline Asian & 2 & $2.22 \%$ & 0 & $0.00 \%$ & \\
\hline Black or African-American & 10 & $11.11 \%$ & 2 & $3.57 \%$ & \\
\hline White & 78 & $86.67 \%$ & 51 & $91.07 \%$ & \\
\hline More than One Race & 0 & $0.00 \%$ & 3 & $5.36 \%$ & \\
\hline Ethnicity & 96 & & 56 & & $\mathrm{n} / \mathrm{a}$ \\
\hline non-Hispanic/Latino & 96 & $100.00 \%$ & 56 & $100.00 \%$ & \\
\hline Highest level of formal education & 94 & & 56 & & $<.0001 *$ \\
\hline Less than high school diploma & 22 & $23.40 \%$ & 3 & $5.36 \%$ & \\
\hline GED & 6 & $6.38 \%$ & 6 & $10.71 \%$ & \\
\hline High school diploma & 43 & $45.74 \%$ & 3 & $5.36 \%$ & \\
\hline Some college & 12 & $12.77 \%$ & 11 & $19.64 \%$ & \\
\hline Technical training & 0 & $0.00 \%$ & 3 & $5.36 \%$ & \\
\hline Associate degree & 1 & $1.06 \%$ & 8 & $14.29 \%$ & \\
\hline Bachelor's degree or higher & 10 & $10.64 \%$ & 21 & $37.50 \%$ & \\
\hline Other & 0 & $0.00 \%$ & 1 & $1.79 \%$ & \\
\hline Employment status & 97 & & 56 & & $<.0001 *$ \\
\hline Employed full-time & 13 & $13.40 \%$ & 23 & $41.07 \%$ & \\
\hline Employed part-time & 15 & $15.46 \%$ & 9 & $16.07 \%$ & \\
\hline Unemployed and looking for work & 61 & $62.89 \%$ & 14 & $25.00 \%$ & \\
\hline Unemployed and not looking for work & 8 & $8.25 \%$ & 10 & $17.86 \%$ & \\
\hline Federal poverty level & 75 & & 51 & & $<.0001 *$ \\
\hline$\leq 100 \%$ & 56 & $74.67 \%$ & 18 & $35.29 \%$ & \\
\hline $101-138 \%$ & 7 & $9.33 \%$ & 4 & $7.84 \%$ & \\
\hline $139-185 \%$ & 6 & $8.00 \%$ & 6 & $11.76 \%$ & \\
\hline$>185 \%$ & 6 & $8.00 \%$ & 23 & $45.10 \%$ & \\
\hline
\end{tabular}

$\mathrm{n} / \mathrm{a}=$ not applicable. Differences in sample sizes were due to missing data. Independent sample ttest $p$-values shown for age in years and total household size. Fisher's exact test p-values shown for race, highest level of formal education, employment status, and federal poverty level. *significant at $\mathrm{p} \leq .05$. 
Table 5. Descriptive Statistics for Absolute Moderate-Intensity Physical Activity Metabolic Equivalent of Task Minutes per Week by Trimester for the Intervention $(n=98)$ and Comparison Group $(n=56)$ Participants

\begin{tabular}{|c|c|c|c|c|c|c|}
\hline \multirow[b]{2}{*}{ Tri } & \multicolumn{3}{|c|}{ Intervention Group } & \multicolumn{3}{|c|}{ Comparison Group } \\
\hline & $n$ & Median & IQR & $n$ & Median & IQR \\
\hline 1 & 29 & 1974.00 & $315.00-3570.00$ & 8 & 1031.00 & $693.50-2754.63$ \\
\hline 2 & 45 & 2238.00 & $130.50-4578.00$ & 39 & 1380.00 & $416.00-3521.00$ \\
\hline 3 & 51 & 792.00 & $210.00-2772.00$ & 47 & 834.50 & $345.00-2430.00$ \\
\hline
\end{tabular}

Differences in sample sizes were due to missing data. IQR = Interquartile Range, Tri = Trimester. 
Table 6. Parameter Estimates for the ZINB Model

\begin{tabular}{|c|c|c|c|c|}
\hline Predictor & Estimate & SE & $\chi^{2}$ & p-value \\
\hline \multicolumn{5}{|l|}{ Negative Binomial } \\
\hline Intercept & 8.27 & 0.27 & 955.53 & $<.0001 *$ \\
\hline Comparison Group $^{\mathrm{a}}$ & -1.49 & 0.52 & 8.12 & $.0044^{*}$ \\
\hline Trimester $2^{\mathrm{b}}$ & 0.04 & 0.34 & 0.01 & .9087 \\
\hline Trimester $3^{\mathrm{b}}$ & -0.26 & 0.34 & 0.59 & .4408 \\
\hline Comparison Group x Trimester $2^{\mathrm{a}, \mathrm{b}}$ & 0.88 & 0.59 & 2.20 & .1377 \\
\hline Comparison Group x Trimester $3^{\mathrm{a}, \mathrm{b}}$ & 1.27 & 0.58 & 4.77 & $.0289 *$ \\
\hline \multicolumn{5}{|l|}{ Zero-Inflated } \\
\hline Intercept & -1.62 & 0.25 & 41.28 & $<.0001^{*}$ \\
\hline Comparison Group $^{\mathrm{a}}$ & -1.46 & 0.68 & 4.63 & $.0314^{*}$ \\
\hline
\end{tabular}




\section{Chapter 6. Overall Discussion and Conclusion}

\section{Results Summary}

This dissertation project applied Handler and colleagues ${ }^{94}$ framework to conduct a comprehensive evaluation of the MIHOW program's prenatal PA curriculum modules delivered primarily to low-income women. A summary of each aim is provided below.

Aim 1 examined OWs' competencies in implementing the MIHOW program's prenatal PA curriculum modules. Findings showed: (1) OWs' depth of knowledge on prenatal PA information and the modules varied; (2) over half the OWs discussed implementing PA, rapport building, communication, adaptability, and/or problem-solving skills; (3) over half the OWs felt comfortable delivering the modules; and (4) OWs' knowledge, skills, and abilities were influenced by their life experiences and by their clients either directly or indirectly. These findings suggest that prenatal PA is an important aspect of the MIHOW program and that OWs' knowledge, skills, and abilities could be enhanced through a prenatal PA focused competency and trainings.

Aim 2 investigated the fidelity with which the MIHOW program's prenatal PA curriculum modules were delivered to home visitation clients. Findings showed: (1) less than half the OWs delivered all the content in the prenatal PA modules, (2) coverage was highest for Home Visits 2, 3, and 5 where the prenatal PA modules are outlined in the curriculum guide, ${ }^{6}$ (3) one-in-five clients received two or more prenatal PA and/or "other" curriculum modules according to intervention checklists whereas eight of the $10 \mathrm{OWs}$ expressed in focus groups that they deliver the prenatal PA modules at multiple, most, or all the home visits, and (4) the prenatal PA modules were delivered inside and outside the trimesters outlined in the curriculum guide, which is consistent with the MIHOW program's protocol and what the OWs reported. The 
quantitative results suggest that the MIHOW program's prenatal PA modules are delivered with fidelity whereas the qualitative results suggest some departure from fidelity attributable to the OWs occasional use of non-curriculum-based information. Moreover, the findings revealed the need for an enhanced way to assess fidelity to the prenatal PA modules and more clarity on the essential elements of the prenatal PA modules.

Aim 3 evaluated the impact of the MIHOW program's curriculum on home visitation clients' prenatal MPA compared to a propensity score matched comparison group. Results from the propensity score weighted zero inflated negative binomial (ZINB) model revealed: (1) when taking into account participants who do not participate in any absolute MPA MET minutes per week, the comparison group had a lower probability of decreasing their absolute MPA MET minutes per week by trimester three than the intervention group participants, (2) when taking into account participants who do not participate in any absolute MPA MET minutes per week, across time the comparison group participants had a lower probability than the intervention group participants of participating in absolute MPA MET minutes per week, and (3) comparison participants were less likely to not participate in any absolute MPA MET minutes per week. The results suggest that the more MPA content may be needed in the prenatal PA curriculum modules and that greater emphasis may need to be placed on MPA when these modules are delivered to clients.

\section{Conclusion}

Together, the above findings provide a detailed portrayal of the structural capacity, processes, and outcomes relating to the MIHOW program's prenatal PA curriculum modules. These findings suggest that home visitors' competencies relating to prenatal PA curricula modules and home visitors' implementation of prenatal PA curricula modules have the potential 
to influence the outcomes relating to these curricula modules. As a result, future evaluations should concurrently investigate the structural capacity, processes, and outcomes relating to home visitation programs' prenatal PA curricula modules in order to understand why these modules do or do not work. Results from these comprehensive evaluations will help home visitation practitioners to understand the essential elements that need to be implemented to achieve replication of the outcomes or where modifications may need to be made. Moreover, additional comprehensive evaluations are needed in order to understand if home visitation programs' prenatal PA curricula modules have the potential to lead to improved prenatal PA levels among clients and ultimately health benefits for both the mother and baby.

\section{Strengths and Limitations}

This dissertation project increased the scientific evidence on the structural capacity, processes, and outcomes relating to the MIHOW program's prenatal PA curriculum modules. Several strengths of this dissertation project were that it was the first to (1) investigate home visitors' knowledge, skills, and abilities in delivering prenatal PA curricula modules, (2) examine the fidelity with which home visitation programs' prenatal PA curricula modules are delivered, and (3) evaluate the impact of home visitation programs' curricula on pregnant clients' MPA using a quasi-experimental design with a propensity score matched comparison group. Another strength of this dissertation project is that our combined results offer insight into how OWs' competencies and their fidelity to the prenatal PA curriculum modules may impact the effectiveness of the MIHOW program's curriculum on pregnant clients' MPA.

Although this dissertation project has increased the scientific evidence relating to the MIHOW program's prenatal PA curriculum modules, it is limited in that these findings may not translate to other home visitation programs' prenatal PA curricula modules. Additionally, other 
limitations include not investigating Handler and colleagues ${ }^{, 44}$ framework in its entirety, such as (1) evaluating each resource, process, and outcome related to the prenatal PA curriculum module, (2) investigating the relationships between structural capacity, processes, and outcomes, and (3) examining the macro context and mission and purpose components outlined in the framework. These limitations demonstrate areas to be targeted with future comprehensive evaluations conducted on home visitation program models' prenatal PA curricula modules.

\section{Implications and Future Directions}

The collective findings from this study suggest that a systematic and comprehensive approach needs to be taken towards evaluating home visitation program models' curricula modules. Building upon the work of this dissertation project, this approach can be reached through continuing to use Handler and colleagues ${ }^{94}$ framework to guide any future evaluations. In applying this framework, ${ }^{44}$ precedence should remain on: (1) home visitation program models' structural capacity to deliver curricula module(s), (2) processes used by the home visitation program models' staff to deliver the curricula module(s), and (3) outcomes achieved through home visitation program models' delivery of the curricula module(s). Evaluating these components concurrently will begin to provide insight, as described above for the prenatal PA modules, into why the curricula module(s) do or do not work, where modifications may need to be made, and what essential elements need to be implemented to replicate the outcomes - all information that cannot be gained through outcome evaluations alone.

Future evaluations and research on home visitation program models' curricula modules should also give particular attention to confirming or identifying the essential elements that must be implemented to produce curricula modules' intended outcomes. In home visitors' practice, they are faced with the challenges of balancing delivering curricula modules to clients while 
simultaneously building rapport with clients and individuating home visits to clients' needs and interests. Therefore, mapping out the essential elements and relaying this information to home visitors through trainings, protocols, and/or curriculum guides will aid home visitors as they walk the line between being prescriptive and flexible when delivering curricula modules to clients. 


\section{References Chapters 1, 2,6}

1. Centers for Disease Control and Prevention, Division of Reproductive Health. PRAMStat [database online].

https://nccd.cdc.gov/PRAMStat/rdPage.aspx?rdReport=DRH_PRAMS.ExploreByTopic \&islClassId=CLA2\&islTopicId=TOP55\&go=GO. Accessed November 30, 2017.

2. Petersen AM, Leet TL, Brownson RC. Correlates of physical activity among pregnant women in the United States. Med Sci Sports Exerc. 2005;37(10):1748-1753.

doi:10.1249/01.mss.0000181302.97948.90.

3. 2018 Physical Activity Guidelines Advisory Committee. 2018 physical activity guidelines advisory committee scientific report. https://health.gov/paguidelines/secondedition/report/pdf/PAG_Advisory_Committee_Report.pdf. Published February 2018. Accessed April 4, 2019.

4. National Home Visiting Resource Center. 2017 home visiting yearbook. https://www.nhvrc.org/wp-content/uploads/NHVRC_Yearbook_2017_Final.pdf. Published 2017. Accessed April 8, 2019.

5. U.S. Department of Health and Human Services, Administration for Children and Families. Effectiveness research. Home Visiting Evidence of Effectiveness Web site. https://homvee.acf.hhs.gov/Models.aspx. Accessed April 9, 2019.

6. Vanderbilt University Center for Health Services. The MIHOW Home Visit Guide: The Prenatal Period. Nashville, TN: Vanderbilt University Center for Health Services; 2009.

7. O’Brien R. Nurse-Family Partnership Theory of Change Logic Model. 2008. https://fhop.ucsf.edu/sites/fhop.ucsf.edu/files/wysiwyg/NFP_TOC_Logic_Model.pdf. Accessed April 4, 2019.

8. Thomson JL, Tussing-Humphreys LM, Goodman MH, Olender SE. Physical activity changes during pregnancy in a comparative impact trial. Am J Health Behav. 2016;40(6):685-696. doi:10.5993/AJHB.40.6.1.

9. Joy EA, Barkdull TJ. Patient and family education. In: Ratcliffe SD, ed. Family Medicine Obstetrics. 3rd ed. Elsevier Health Sciences; 2008:95-101. https://www-clinicalkeycom.www.libproxy.wvu.edu/\#!/content/book/3-s2.0B9780323043069500094?scrollTo=\%23h10005108. Accessed November 29, 2017.

10. Downs DS, Chasan-Taber L, Evenson KR, Leiferman J, Yeo S. Physical activity and pregnancy: past and present evidence and future recommendations. Res Q Exerc Sport. 2012;83(4):485-502. doi:10.1080/02701367.2012.10599138.

11. American College of Obstetricians and Gynecologists. Exercise during pregnancy and the postpartum period: ACOG technical bulletin number 189-February 1994. Int $J$ Gynaecol Obstet. 1994;45(1):65-70. 
12. American College of Obstetricians and Gynecologists. Exercise during pregnancy and the postpartum period. ACOG committee opinion number 267. Int J Gynaecol Obstet. 2002;99(1):171-173.

13. Snyder JL. Aerobic exercise during pregnancy. J Am Board Fam Pract. 1990;3(1):50-53. doi:10.3122/jabfm.3.1.50.

14. U.S. Department of Health and Human Services. 2008 physical activity guidelines for Americans. http://health.gov/PAGuidelines/pdf/paguide.pdf. Published 2008. Accessed November 29, 2017.

15. U.S. Department of Health and Human Services. Physical activity guidelines for Americans, 2nd edition. https://health.gov/paguidelines/secondedition/pdf/Physical_Activity_Guidelines_2nd_edition.pdf. Published 2018. Accessed April 9, 2019.

16. Tobias DK, Zhang C, van Dam RM, Bowers K, Hu FB. Physical activity before and during pregnancy and risk of gestational diabetes mellitus: a meta-analysis. Diabetes Care. 2011;34(1):223-229. doi:10.2337/dc10-1368.

17. American College of Obstetricians and Gynecologists. ACOG committee opinion no. 650: physical activity and exercise during pregnancy and the postpartum period. Obstet Gynecol. 2015;126(6):e135-e142. doi:10.1097/AOG.0000000000001214.

18. Hesketh KR, Evenson KR. Prevalence of U.S. pregnant women meeting 2015 ACOG physical activity guidelines. Am J Prev Med. 2016;51(3):e87-e89. doi:10.1016/j.amepre.2016.05.023.

19. Physical Activity Guidelines Advisory Committee. Physical activity guidelines advisory committee report, 2008. https://health.gov/paguidelines/report/pdf/CommitteeReport.pdf. Published 2008. Accessed April 9, 2019.

20. Evenson KR, Wen F. National trends in self-reported physical activity and sedentary behaviors among pregnant women: NHANES 1999-2006. Prev Med. 2010;50(3):123128. doi:10.1016/j.ypmed.2009.12.015.

21. Evenson KR, Wen F. Prevalence and correlates of objectively measured physical activity and sedentary behavior among US pregnant women. Prev Med. 2011;53(1-2):39-43. doi:10.1016/j.ypmed.2011.04.014.

22. Zhao G, Ford ES, Tsai J, et al. Trends in health-related behavioral risk factors among pregnant women in the United States: 2001-2009. J Womens Health (Larchmt). 2012;21(3):255-263. doi:10.1089/jwh.2011.2931.

23. Pearce EE, Evenson KR, Downs DS, Steckler A. Strategies to promote physical activity during pregnancy: a systematic review of intervention evidence. Am J Lifestyle Med. 2013;7(1). doi:10.1177/1559827612446416. 
24. Currie S, Sinclair M, Murphy MH, Madden E, Dunwoody L, Liddle D. Reducing the decline in physical activity during pregnancy: a systematic review of behaviour change interventions. PLoS One. 2013;8(6):e66385. doi:10.1371/journal.pone.0066385.

25. Craike M, Hill B, Gaskin CJ, Skouteris H. Interventions to improve physical activity during pregnancy: a systematic review on issues of internal and external validity using the RE-AIM framework. BJOG. 2017;124(4):573-583. doi:10.1111/1471-0528.14276.

26. Gaston A, Prapavessis H. Maternal-fetal disease information as a source of exercise motivation during pregnancy. Health Psychol. 2009;28(6):726-733. doi:10.1037/a0016702.

27. Chasan-Taber L, Silveira M, Marcus BH, Braun B, Stanek E, Markenson G. Feasibility and efficacy of a physical activity intervention among pregnant women: the Behaviors Affecting Baby and You (B.A.B.Y.) Study. J Phys Act Health. 2011;8(Suppl 2):S228238.

28. Jackson RA, Stotland NE, Caughey AB, Gerbert B. Improving diet and exercise in pregnancy with Video Doctor counseling: a randomized trial. Patient Educ Couns. 2011;83(2):203-209. doi:10.1016/j.pec.2010.05.019.

29. Gaston A, Prapavessis H. Using a combined protection motivation theory and health action process approach intervention to promote exercise during pregnancy. $J$ Behav Med. 2014;37(2):173-184. doi:10.1007/s10865-012-9477-2.

30. Hawkins M, Chasan-Taber L, Marcus B, et al. Impact of an exercise intervention on physical activity during pregnancy: the Behaviors Affecting Baby and You Study. Am J Public Health. 2014;104(10):e74-e81. doi:10.2105/ajph.2014.302072.

31. Kong KL, Campbell CG, Foster RC, Peterson AD, Lanningham-Foster L. A pilot walking program promotes moderate-intensity physical activity during pregnancy. Med Sci Sports Exerc. 2014;46(3):462-471. doi:10.1249/mss.0000000000000141.

32. Choi J, Lee JH, Vittinghoff E, Fukuoka Y. mHealth physical activity intervention: a randomized pilot study in physically inactive pregnant women. Matern Child Health J. 2016;20(5):1091-1101. doi:10.1007/s10995-015-1895-7.

33. Downs DS, Dinallo JM, Birch LL, Paul IM, Ulbrecht JS. Randomized face-to-face vs. home exercise interventions in pregnant women with gestational diabetes. Psychol Sport Exerc. 2017;30:73-81. doi:10.1016/j.psychsport.2017.02.003.

34. Hayman M, Reaburn P, Browne M, Vandelanotte C, Alley S, Short CE. Feasibility, acceptability and efficacy of a web-based computer-tailored physical activity intervention for pregnant women - the Fit4Two randomised controlled trial. BMC Pregnancy Childbirth. 2017;17(1):96. doi:10.1186/s12884-017-1277-9.

35. Huberty JL, Buman MP, Leiferman JA, Bushar J, Hekler EB, Adams MA. Dose and timing of text messages for increasing physical activity among pregnant women: a 
randomized controlled trial. Transl Behav Med. 2017;7(2):212-223. doi:10.1007/s13142016-0445-1.

36. Gaston A, Cramp A. Exercise during pregnancy: a review of patterns and determinants. $J$ Sci Med Sport. 2011;14(4):299-305. doi:10.1016/j.jsams.2011.02.006.

37. Centers for Disease Control and Prevention, National Center for Chronic Disease Prevention and Health Promotion, Division of Nutrition, Physical Activity, and Obesity. Data, Trends and Maps [database online]. https://www.cdc.gov/nccdphp/dnpao/datatrends-maps/index.html. Accessed April 9, 2019.

38. Godin G, Shephard R. A simple method to assess exercise behavior in the community. Can J Appl Sport Sci. 1985;10(3):141-146.

39. Downs DS, Evenson KR, Chasan-Taber L. Obesity and physical activity during pregnancy and postpartum: evidence, guidelines, and recommendations. In: Nicholson W, Baptiste-Roberts K, eds. Obesity During Pregnancy in Clinical Practice. London: Springer; 2014:183-227. https://link-springercom.www.libproxy.wvu.edu/chapter/10.1007/978-1-4471-2831-1_9. Accessed April 9, 2019.

40. Evenson KR, Chasan-Taber L, Symons Downs D, Pearce EE. Review of self-reported physical activity assessments for pregnancy: summary of the evidence for validity and reliability. Paediatr Perinat Epidemiol. 2012;26(5):479-494. doi:10.1111/j.13653016.2012.01311.x.

41. Gaylor E, Spiker D. Home visiting programs and their impact on young children's school readiness. In: Tremblay RE, Boivin M, Peters RDeV, eds. Encyclopedia on Early Childhood Development [online]. http://www.child-encyclopedia.com/homevisiting/according-experts/home-visiting-programs-and-their-impact-young-childrensschool. Updated September 2012. Accessed April 9, 2019.

42. Filene JH, Snell EK, Lee H, Knox V, Michalopoulos C, Duggan A. The mother and infant home visiting program evaluation-strong start: first annual report. OPRE report 2013-54.

https://www.acf.hhs.gov/sites/default/files/opre/mihope_ss_final_12_24_13.pdf.

Published 2013. November 30, 2017.

43. Culp AM, Culp RE, Hechtner-Galvin T, Howell CS, Saathoff-Wells T, Marr P. First-time mothers in home visitation services utilizing child development specialists. Infant Ment Health J. 2004;25(1):1-15. doi:10.1002/imhj.10086.

44. Handler A, Issel M, Turnock B. A conceptual framework to measure performance of the public health system. Am J Public Health. 2001;91(8):1235-1239.

45. Turnock BJ. Public Health: What It Is and How It Works. Gaithersburg, MD: Aspen Publishers; 1997. 
46. Turnock BJ. Public Health: What It Is and How It Works. 6th ed. Burlington, MA: Jones \& Bartlett Learning; 2016.

47. Elkins T, Aguinaga Mdel P, Clinton-Selin C, Clinton B, Gotterer G. The Maternal Infant Health Outreach Worker program in low-income families. J Health Care Poor Underserved. 2013;24(3):995-1001. doi:10.1353/hpu.2013.0143.

48. Vanderbilt University School of Nursing. The MIHOW program. Vanderbilt University School of Nursing Web site. https://www.mihow.org/. Accessed April 9, 2019. 
Table. Prenatal Physical Activity Interventions' Structures Regarding Frequency, Intensity, Time and Type

\begin{tabular}{|c|c|c|c|c|c|c|}
\hline Study & $\begin{array}{l}\text { Intervention } \\
\text { Delivery Method }\end{array}$ & $\begin{array}{l}\text { Physical } \\
\text { Activity } \\
\text { Frequency }\end{array}$ & $\begin{array}{l}\text { Physical } \\
\text { Activity } \\
\text { Intensity } \\
\end{array}$ & $\begin{array}{l}\text { Physical } \\
\text { Activity } \\
\text { Time } \\
\end{array}$ & $\begin{array}{l}\text { Physical Activity } \\
\text { Type }\end{array}$ & Length of Intervention \\
\hline $\begin{array}{l}\text { Chasan- } \\
\text { Taber, } \\
\text { Silveira, } \\
\text { Marcus, } \\
\text { Braun, } \\
\text { Stanek, } \\
\text { Markenson }^{27}\end{array}$ & $\begin{array}{l}\text { Individualized } \\
\text { counseling }\end{array}$ & $\begin{array}{l}\text { Goal - at } \\
\text { least } 5 \text { days }\end{array}$ & $\begin{array}{l}\text { Goal- } \\
\text { Moderate } \\
\text { intensity }\end{array}$ & $\begin{array}{l}\text { Goal }- \text { at } \\
\text { least } 30 \\
\text { minutes } \\
(10 \% \\
\text { weekly } \\
\text { change })\end{array}$ & $\begin{array}{l}\text { Personal choice } \\
\text { (e.g., dancing, } \\
\text { walking, working } \\
\text { in the yard) }\end{array}$ & $\begin{array}{l}\text { The entire intervention } \\
\text { lasted } 12 \text { weeks } \\
\text { - The time taken to } \\
\text { complete the in-person } \\
\text { module was not specified } \\
\text {-The time spent on the } \\
\text { telephone calls or the } \\
\text { number of telephone } \\
\text { calls was not specified } \\
\text {-For the eight mailings, } \\
\text { the time spent on the } \\
\text { informational items was } \\
\text { not specified }\end{array}$ \\
\hline $\begin{array}{l}\text { Choi, Lee, } \\
\text { Vittinghoff, } \\
\text { Fukuoka }^{32}\end{array}$ & $\begin{array}{l}\text { Onetime in-person } \\
\text { informational module } \\
\text { done at the beginning } \\
\text { Messaging and } \\
\text { feedback provided } \\
\text { through Fitbit }\end{array}$ & $\begin{array}{l}\text { Goal - at } \\
\text { least } 5 \text { days }\end{array}$ & $\begin{array}{l}\text { Goal - } \\
\text { Moderate } \\
\text { intensity }\end{array}$ & $\begin{array}{l}\text { Goal }-8,500 \\
\text { daily steps } \\
(10 \% \\
\text { weekly } \\
\text { change })\end{array}$ & Promoted walking & $\begin{array}{l}\text { The entire intervention } \\
\text { lasted } 12 \text { weeks } \\
\text { - The in-person } \\
\text { informational module } \\
\text { took } 30 \text { minutes } \\
\text { - The daily time spent } \\
\text { utilizing the Fitbit } \\
\text { module was not specified }\end{array}$ \\
\hline $\begin{array}{l}\text { Gaston and } \\
\text { Prapavessis }^{26}\end{array}$ & Brochure & $\begin{array}{l}\text { Goal-not } \\
\text { specified }\end{array}$ & $\begin{array}{l}\text { Goal - not } \\
\text { specified }\end{array}$ & $\begin{array}{l}\text { Goal - not } \\
\text { specified } \\
\text { *an example } \\
\text { that was } \\
\text { provided } \\
\text { was } 15 \\
\text { minutes to } \\
\text { start }\end{array}$ & $\begin{array}{l}\text { Personal choice } \\
\text { * examples } \\
\text { provided were } \\
\text { brisk walking and } \\
\text { stationary cycling. } \\
\text { The authors did } \\
\text { not specify the } \\
\text { other examples. }\end{array}$ & $\begin{array}{l}1 \text { week between handing } \\
\text { out the brochure and } \\
\text { remeasuring prenatal } \\
\text { physical activity levels }\end{array}$ \\
\hline
\end{tabular}




\begin{tabular}{|c|c|c|c|c|c|c|}
\hline $\begin{array}{l}\text { Gaston and } \\
\text { Prapavessis }^{29}\end{array}$ & $\begin{array}{l}\text { Onetime in-person (or } \\
\text { telephone/internet) } \\
\text { informational module } \\
\text { done at the beginning } \\
\text { Onetime in-person (or } \\
\text { telephone/internet) } \\
\text { informational module } \\
\text { and a physical } \\
\text { activity planning } \\
\text { activity done at the } \\
\text { beginning + brief } \\
\text { email reminder to } \\
\text { continue doing the } \\
\text { activities } \\
\text { Onetime in-person (or } \\
\text { telephone/internet) } \\
\text { informational module, } \\
\text { a physical activity } \\
\text { planning activity, and } \\
\text { a barrier reduction } \\
\text { planning activity done } \\
\text { at the beginning }+ \\
\text { brief email reminder } \\
\text { to continue doing the } \\
\text { activities }\end{array}$ & $\begin{array}{l}\text { All three } \\
\text { interventions } \\
\text { promoted - } \\
3 \text { to } 4 \text { days } \\
\text { weekly }\end{array}$ & $\begin{array}{l}\text { All three } \\
\text { interventions } \\
\text { promoted - } \\
\text { moderate } \\
\text { intensity }\end{array}$ & $\begin{array}{l}\text { All three } \\
\text { interventions } \\
\text { promoted - } \\
30 \text { minutes }\end{array}$ & $\begin{array}{l}\text { All three } \\
\text { interventions } \\
\text { promoted leisure- } \\
\text { time activities } \\
\text { *examples that } \\
\text { the authors } \\
\text { provided were } \\
\text { aquafit, low } \\
\text { impact aerobics, } \\
\text { swimming, and } \\
\text { walking. The } \\
\text { authors did not } \\
\text { specify the other } \\
\text { examples. }\end{array}$ & $\begin{array}{l}\text { Each intervention } \\
\text { module took } 45 \text { minutes } \\
\text { The time spent reading } \\
\text { the email and completing } \\
\text { its' associated tasks was } \\
\text { not measured }\end{array}$ \\
\hline $\begin{array}{l}\text { Hawkins, } \\
\text { Chasan- } \\
\text { Taber, } \\
\text { Marcus, } \\
\text { Stanek, } \\
\text { Braun, }\end{array}$ & $\begin{array}{l}\text { Individualized } \\
\text { counseling }\end{array}$ & $\begin{array}{l}\text { Goal - at } \\
\text { least } 5 \text { days }\end{array}$ & $\begin{array}{l}\text { Moderate } \\
\text { intensity }\end{array}$ & $\begin{array}{l}\text { Goal }- \text { at } \\
\text { least } 30 \\
\text { minutes } \\
(10 \% \\
\text { weekly } \\
\text { change })\end{array}$ & $\begin{array}{l}\text { Personal choice } \\
\text { (e.g., dancing, } \\
\text { walking, working } \\
\text { in the yard) }\end{array}$ & $\begin{array}{l}\text { The entire intervention } \\
\text { lasted } 12 \text { weeks } \\
\text { - The time taken to } \\
\text { complete the in-person } \\
\text { module was not specified } \\
\text {-The time spent on the }\end{array}$ \\
\hline
\end{tabular}




\begin{tabular}{|c|c|c|c|c|c|c|}
\hline $\begin{array}{l}\text { Ciccolo, } \\
\text { Markenson }^{30}\end{array}$ & & & & & & $\begin{array}{l}\text { three telephone calls was } \\
\text { not specified } \\
\text {-For the eight mailings, } \\
\text { the time spent on the } \\
\text { informational items was } \\
\text { not specified }\end{array}$ \\
\hline $\begin{array}{l}\text { Huberty, } \\
\text { Buman, } \\
\text { Leiferman, } \\
\text { Bushar, } \\
\text { Hekler, } \\
\text { Adams }^{35}\end{array}$ & $\begin{array}{l}\text { Onetime telephone } \\
\text { enrollment }+ \\
2 \text { texts on physical } \\
\text { activity delivered at } \\
12 \text { pm during } \\
\text { pregnancy } \\
\text { Onetime telephone } \\
\text { enrollment }+ \\
2 \text { texts on prenatal } \\
\text { physical activity } \\
\text { delivered at } 12 \text { pm } \\
\text { weekly } \\
\text { Onetime telephone } \\
\text { enrollment }+ \\
6 \text { texts on prenatal } \\
\text { physical activity } \\
\text { delivered at } 12 \text { pm } \\
\text { weekly } \\
\text { Onetime telephone } \\
\text { enrollment }+ \\
6 \text { weekly texts on } \\
\text { prenatal physical } \\
\text { activity delivered at } \\
\text { each individual's }\end{array}$ & $\begin{array}{l}\text { Goal - not } \\
\text { specified for } \\
\text { any of the } \\
\text { interventions }\end{array}$ & $\begin{array}{l}\text { Goal - not } \\
\text { specified for } \\
\text { any of the } \\
\text { interventions }\end{array}$ & $\begin{array}{l}\text { Goal - not } \\
\text { specified for } \\
\text { any of the } \\
\text { interventions }\end{array}$ & $\begin{array}{l}\text { Goal - not } \\
\text { specified for any } \\
\text { of the } \\
\text { interventions }\end{array}$ & $\begin{array}{l}15 \text { to } 20 \text { minutes to } \\
\text { complete the telephone } \\
\text { enrollment } \\
\text { The intervention length } \\
\text { was unclear }\end{array}$ \\
\hline
\end{tabular}




\begin{tabular}{|c|c|c|c|c|c|c|}
\hline & daily time preference & & & & & \\
\hline $\begin{array}{l}\text { Jackson, } \\
\text { Stotland, } \\
\text { Caughey, } \\
\text { Gerbert }^{28}\end{array}$ & $\begin{array}{l}\text { Individualized } \\
\text { counseling }\end{array}$ & $\begin{array}{l}\text { Goal-not } \\
\text { specified }\end{array}$ & $\begin{array}{l}\text { Goal-not } \\
\text { specified }\end{array}$ & $\begin{array}{l}\text { Goal - not } \\
\text { specified }\end{array}$ & Not specified & $\begin{array}{l}\text { The intervention } \\
\text { components which were } \\
\text { assessed were completed } \\
\text { in one day } \\
\text { - The counseling } \\
\text { program took } 10 \text { to } 15 \\
\text { minutes to go through on } \\
\text { the computer } \\
\text {-The health care } \\
\text { provider's discussion of } \\
\text { physical activity with the } \\
\text { participant was not } \\
\text { specified in time }\end{array}$ \\
\hline $\begin{array}{l}\text { Kong, } \\
\text { Campbell, } \\
\text { Foster, } \\
\text { Peterson, } \\
\text { Lanningham- } \\
\text { Foster }^{31}\end{array}$ & $\begin{array}{l}\text { Onetime in-person } \\
\text { training module done } \\
\text { at the beginning } \\
\text { Walking program } \\
\text { done on their own }\end{array}$ & $\begin{array}{l}\text { Week 1- not } \\
\text { specified } \\
\text { Week 2- not } \\
\text { specified } \\
\text { Week } 3 \text { and } \\
\text { beyond- } 5 \\
\text { days }\end{array}$ & $\begin{array}{l}\text { Moderate } \\
\text { intensity }\end{array}$ & $\begin{array}{l}\text { Week } 1-50 \\
\text { minutes } \\
\text { Week } 2- \\
100 \text { minutes } \\
\text { Week } 3 \text { and } \\
\text { beyond - } \\
150 \text { minutes }\end{array}$ & Walking & $\begin{array}{l}\text { The length of the training } \\
\text { was not specified } \\
\text { The length of the } \\
\text { walking program was } 20 \\
\text { weeks or more. The } \\
\text { number of weeks } \\
\text { differed by individual }\end{array}$ \\
\hline $\begin{array}{l}\text { Downs, } \\
\text { Dinallo, } \\
\text { Birch, Paul, } \\
\text { Ulbrecht }^{33}\end{array}$ & $\begin{array}{l}\text { In-person modules } \\
\text { exclusively }\end{array}$ & $\begin{array}{l}2 \text { days per } \\
\text { week }\end{array}$ & $\begin{array}{l}\text { Moderate } \\
\text { intensity }\end{array}$ & $\begin{array}{l}\text {-Physical } \\
\text { activity } \\
\text { performed } \\
\text { for } 30 \text { to } 40 \\
\text { minutes } \\
\text {-Warmup } \\
\text { and } \\
\text { cooldown } \\
\text { each } \\
\text { performed }\end{array}$ & $\begin{array}{l}\text { Examples that the } \\
\text { authors provided } \\
\text { were walking and } \\
\text { jogging on a } \\
\text { treadmill, using } \\
\text { an exercise bike, } \\
\text { or performing } \\
\text { aerobics that were } \\
\text { low-impact. The } \\
\text { authors did not }\end{array}$ & $\begin{array}{l}\text { Both interventions lasted } \\
\text { a minimum of } 12 \text { weeks, } \\
\text { but physical activity was } \\
\text { not measured past week } \\
12 . \\
\text { In-person modules } \\
\text { exclusively } \\
\text { - Onetime } 30 \\
\quad \text { minute }\end{array}$ \\
\hline
\end{tabular}




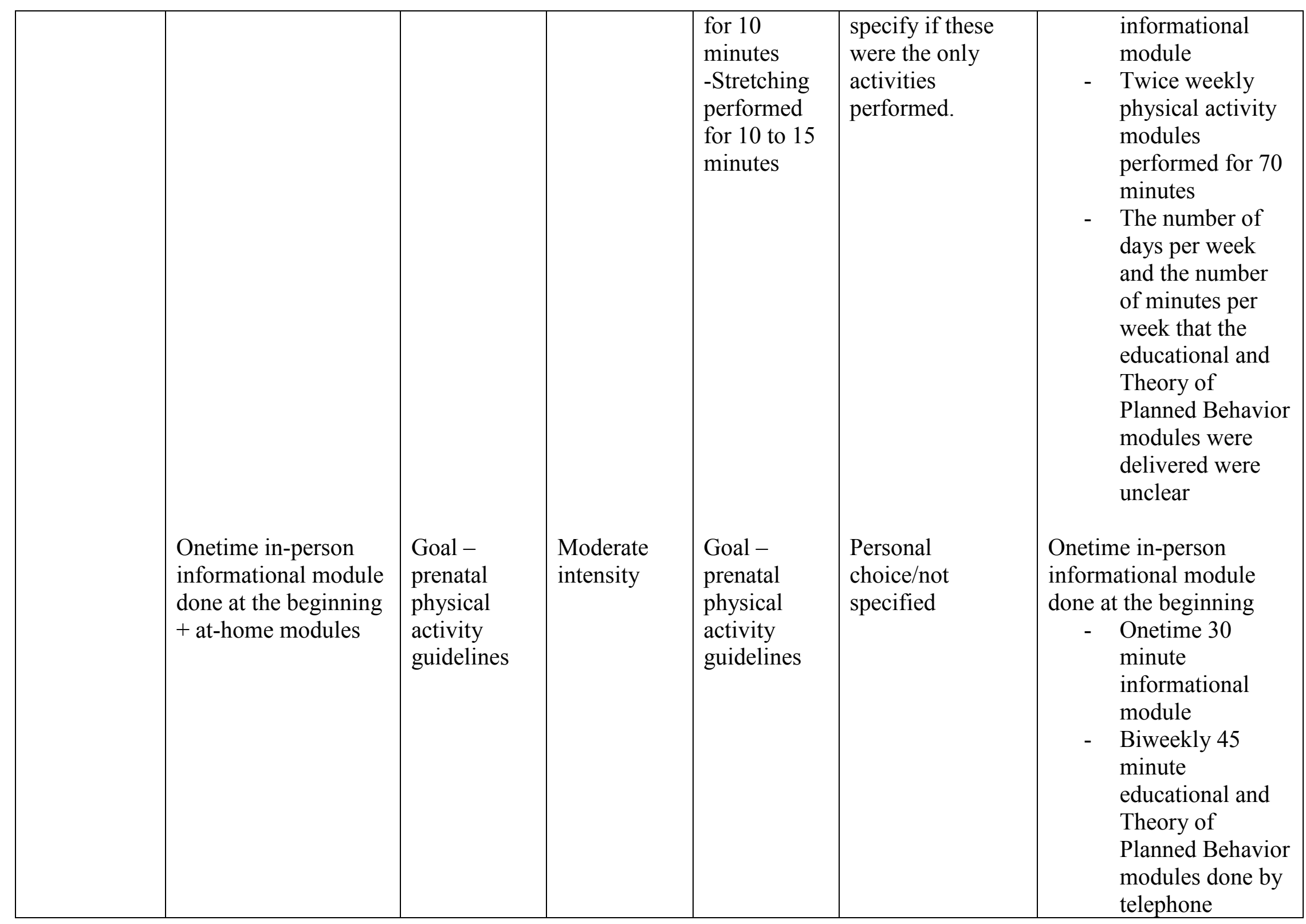




\section{Appendix 1}

\section{Focus Group Participant Demographic Questionnaire}

Please be honest. Your answers are confidential and any results reported will be pooled across all respondents.

1. What is your year of birth? Please write:

2. What is your gender (Please choose one option):
a. Male
b. Female
c. Transgender
d. Other (Please write):

3. What is your highest level of formal education? (Please choose one option):
a. Elementary school or less
b. Some high school but did not graduate
c. High school graduate
d. Some college but did not graduate with a degree
e. Undergraduate college graduate (e.g., BA, BS, Bed)
f. College graduate degree (e.g., MS, MPH, MA, MPhil)
g. Other (Please write):

4. From the list below, select the race that you would use to describe yourself.
a. African American or Black
b. American Indian or Alaska Native
c. Asian
d. Caucasian/White
e. Native Hawaiian/Other Pacific Islander
f. Other (Please write):

5. Are you of Hispanic, Latino/a, or Spanish origin? (Please choose one option):
a. Yes
b. No

6. How many months or years have you worked in total as a home visitor? Please combine all months or years of home visitation experience. If you are new to the field please write " 0 ".

Please write: months

Please write: years 
7. How many months or years have you worked in total as a home visitor for MIHOW? If you are new to the field please write " 0 ".

Please write: months

Please write: years

8. Are you working full-time or part-time as a home visitor for the West Virginia Home Visitation program? (Please choose one option):
a. Full-time
b. Part-time

9. Are you working full-time or part-time as a home visitor for MIHOW? (Please choose one option):
a. Full-time
b. Part-time

10. Which level(s) have you completed of the Competencies for Outreach Workers? (Please choose all that apply):

a. I have not completed any level of the Competencies for Outreach Workers

b. I have completed Level 1 of the Competencies for Outreach Workers

c. I have completed Level 2 of the Competencies for Outreach Workers

d. I have completed Level 3 of the Competencies for Outreach Workers

e. I have completed Level 4 of the Competencies for Outreach Workers

11. Which prenatal PA curricula module(s) have you completed with one or more clients? (Please choose all that apply):

a. Objective 4: Discuss Exercise During Pregnancy

b. Objective 3: Encourage Appropriate Weight Gain

c. Objective 3: Discuss Common Discomforts of Pregnancy and Ways to Ease Them 


\section{Appendix 2}

\section{MIHOW Home Visitor Focus Group Script}

\section{BEGINNING:}

Hello. For those of you who do not know me already, my name is Angie Dyer. I am a doctoral student, conducting a qualitative study for my Dissertation under the supervision of Dr. Abildso, an Assistant Professor in the Department of Social and Behavioral Sciences at the School of Public Health.

The study that I am asking you to participate in today is designed to investigate home visitors' perceived capacity, thoughts, and practices on delivering MIHOW's prenatal physical activity curriculum modules. Your participation in this project would be greatly appreciated because you are an expert on this topic and your participation will help me further understand home visitors' perceived knowledge, abilities, skills, and practices in delivering the prenatal physical activity curriculum modules to their clients and home visitors' perceptions of the barriers and facilitators to delivering the prenatal physical activity curriculum modules to their clients.

The focus group process will take approximately 60-90 minutes. Before we begin, I want to inform you of the following:

- This study has been IRB approved and your responses will be kept private and confidential

- All data will be reported without names and in a group format

- In order to participate, you must:

1. be currently employed as a MIHOW home visitor in West Virginia

2. have a Level 1 completion of the Competencies for Outreach Workers, and

3. have completed at least one prenatal home visit where physical activity during pregnancy was discussed.

- Your participation is strictly voluntary

- You each will receive a $\$ 20.00$ gift card for participating today

- You may choose to discontinue participation at any time during this study

- Ending your participation will not impact you receiving the $\$ 20.00$ gift card

- If you choose to end your participation, your information will not be used, and my notes on what you have spoken will be deleted and disposed of through confidential means

- Also, you may choose to not answer any questions throughout this process

After hearing all of this, do you have any questions? (If yes, address) Do you still wish to continue and participate in this study? (If yes,) Ok, great.

END:

\section{****Summarize Notes to Participant to Verify}

Thank you for participating in this study. If you should have any questions or concerns, please do not hesitate to contact me. My contact information is on the cover letter that I gave you at the beginning of the focus group. Have a great day.

1. Let's start out by discussing PA during pregnancy. What comes to mind when you think of PA during pregnancy? 
Transition: I'd like to talk a little bit about how you might discuss PA with your clients, especially those that are pregnant......

2. Can you tell me a little bit about what the MIHOW prenatal home visit guide says in regard to physical activity during pregnancy? (knowledge)

a. What does it tell you to discuss with them? (practices - components delivered/ knowledge)

b. What information in the prenatal home visit guide regarding physical activity during pregnancy do you discuss with your clients? (practices - components delivered/ knowledge)

c. What information do you not typically discuss? (practices - components delivered/ knowledge)

d. What physical activity during pregnancy activities in the prenatal home visit guide do you complete? (practices - components delivered / knowledge)

e. Are there any activities that you do not typically complete with your clients? (practices components delivered / knowledge)

f. When during pregnancy is the physical activity during pregnancy curriculums in the MIHOW prenatal home visit guide supposed to be discussed with clients? (knowledge)

g. When is it actually/usually discussed? (practices - components delivered / knowledge) 
3. What challenges do you face when trying to discuss the physical activity during pregnancy curriculums in the MIHOW prenatal home visit guide with your clients? (barriers)

a. Can you think of any reasons that you may not discuss the physical activity during pregnancy curriculums? (barriers)

b. What facilitates these discussions or makes it easier to discuss physical activity? (facilitators)

c. What organizational level factors (like the structure or polices of MIHOW) might facilitate or make it easier for you to discuss the physical activity during pregnancy curriculums with your clients? (facilitators)

d. What organizational level factors make it challenging? (barriers)

4. How comfortable are you in discussing the physical activity during pregnancy curriculums in MIHOW's prenatal home visit guide with your clients? (abilities)

a. What influences why you feel this way? (abilities)

b. What would influence you to feel differently? (abilities)

c. How does the physical activity during pregnancy curriculums influence or not influence your ability to discuss physical activity with your clients? (abilities) 
5. How might you rate your skills in discussing the physical activity during pregnancy curriculums in MIHOW's prenatal home visit guide with your clients? (skills)

a. What influences you to have this opinion? (skills)

b. What would change your opinion? (skills)

6. What final thoughts do you have on the physical activity during pregnancy curriculums in MIHOW's prenatal home visit guide?

****Summarize Notes to Participants to Verify 


\section{Appendix 3}

\section{Interview Participant Demographic Questionnaire}

Please be honest. Your answers are confidential and any results reported will be pooled across all respondents.

1. What is your year of birth? Please write:

2. What is your gender (Please choose one option):
a. Male
b. Female
c. Transgender
d. Other (Please write):

3. What is your highest level of formal education? (Please choose one option):
a. Elementary school or less
b. Some high school but did not graduate
c. High school graduate
d. Some college but did not graduate with a degree
e. Undergraduate college graduate (e.g., BA, BS, Bed)
f. College graduate degree (e.g., MS, MPH, MA, MPhil)
g. Other (Please write):

4. From the list below, select the race that you would use to describe yourself.
a. African American or Black
b. American Indian or Alaska Native
c. Asian
d. Caucasian/White
e. Native Hawaiian/Other Pacific Islander
f. Other (Please write):

5. Are you of Hispanic, Latino/a, or Spanish origin? (Please choose one option):
a. Yes
b. No

6. How many months or years have you worked in total as a Site Leader for MIHOW? If you are new to the field please write " 0 ".

Please write: months

Please write: years 
7. Are you working full-time or part-time as a Site Leader for MIHOW? (Please choose one option):

a. Full-time

b. Part-time 


\section{Appendix 4}

\section{MIHOW Site Leader Interview Script}

\section{BEGINNING:}

Hello. If we have not already met in person, my name is Angie Dyer. I am a doctoral student, conducting a qualitative study for my Dissertation under the supervision of Dr. Abildso, an Assistant Professor in the Department of Social and Behavioral Sciences at the School of Public Health.

The study that I am asking you to participate in today is designed to investigate home visitors' perceived capacity, thoughts, and practices on delivering MIHOW's prenatal physical activity curriculum modules. Your participation in this project would be greatly appreciated because you are an expert on this topic and your participation will help me further understand home visitors' perceived knowledge, abilities, skills, and practices in delivering the prenatal physical activity curriculum modules to their clients and home visitors' perceptions of the barriers and facilitators to delivering the prenatal physical activity curriculum modules to their clients.

The interview process will take approximately an hour. Before we begin, I want to inform you of the following:

- This study has been IRB approved and your responses will be kept private and confidential

- All data will be reported without names and in a group format

- In order to participate, you must currently be a MIHOW Site Leader

- Your participation is strictly voluntary

- You will receive a $\$ 20.00$ gift card for participating today

- You may choose to discontinue participation at any time during this study

- Ending your participation will not impact you receiving the $\$ 20.00$ gift card

- If you choose to end participation, your information will not be used and the recording and notes that I take will be deleted and disposed of through confidential means

- Also, you may choose to not answer any questions throughout this process

After hearing all of this, do you have any questions? (If yes, address) Do you still wish to continue and participate in this study? (If yes,) Ok, great.

END:

****Summarize Notes to Participant to Verify

Thank you for participating in this study. If it is alight with you, may I contact you in the future by email to share the results of the study and to get your feedback on if I got it right?

If you should have any questions or concerns, please do not hesitate to contact me. My contact information is on the cover letter that I gave you at the beginning of this interview. Have a great day. 
1. Can you share with me what comes to mind when you think of physical activity during pregnancy?

Transition: I know that you all discuss physical activity during pregnancy with your clients based on what the MIHOW prenatal home visit guide says........

2. Can you talk a little bit how that is going?

a. How knowledgeable are the home visitors of the physical activity during pregnancy curriculums in the MIHOW prenatal home visit guide? (knowledge)

b. What information in the prenatal home visit guide regarding physical activity during pregnancy is discussed with clients? (practices - components delivered / knowledge)

c. Okay great, now can you think of what information in the prenatal home visit guide regarding physical activity during pregnancy might not be discuss with clients? (practices - components delivered / knowledge)

d. What physical activity during pregnancy activities in the prenatal home visit guide are completed with clients? (practices - components delivered / knowledge)

e. Okay great, what physical activity during pregnancy activities in the prenatal home visit guide might not be completed with clients? (practices - components delivered / knowledge)

f. What areas of the physical activity during pregnancy curriculums in the MIHOW prenatal home visit guide do you think the home visitors know well? (knowledge)

g. What areas of the physical activity during pregnancy curriculums in the MIHOW prenatal home visit guide do you think the home visitors could improve their knowledge on? (knowledge) 
h. When during pregnancy is the physical activity during pregnancy curriculums in the MIHOW prenatal home visit guide discussed with clients? (practices - components delivered / knowledge)

3. What challenges might a home visitor face when trying to discuss the physical activity during pregnancy curriculums in the MIHOW prenatal home visit guide with their clients? (barriers)

a. Can you think of any reasons why the home visitors may not discuss the physical activity during pregnancy curriculums? (barriers)

b. What might facilitate these discussions or make it easier to discuss physical activity? (facilitators)

c. What organizational level factors (like the structure or polices of MIHOW) might facilitate or make it easier for the home visitors to discuss the physical activity during pregnancy curriculums with their clients? (facilitators)

d. What organizational level factors might make it challenging? (barriers)

4. In your opinion, how comfortable do you think the home visitors feel when discussing the physical activity during pregnancy curriculums in MIHOW's prenatal home visit guide with their clients? (abilities)

a. Can you think of any examples that lead you to feel that way? (abilities) 
b. How effective do you think the physical activity during pregnancy curriculums are at helping the home visitors discuss physical activity with clients? (abilities)

5. What is your opinion of the home visitors' skills in discussing the physical activity during pregnancy curriculums in MIHOW's prenatal home visit guide with their clients? (skills)

a. What influences you to have this opinion? (skills)

b. What would change your opinion? (skills)

6. Do you have any final thoughts on the home visitors' delivery of the physical activity during pregnancy curriculums in MIHOW's prenatal home visit guide?

****Summarize Notes to Participants to Verify 
Appendix 5

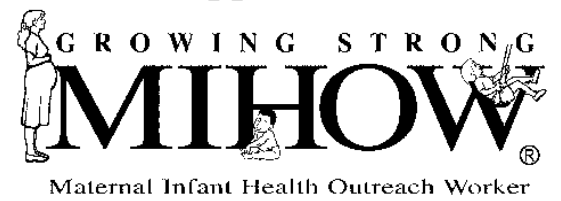

\section{PRENATAL HOME VISIT REPORT FORM VISIT 2}

\section{Participant's Name}

Date

\section{Home Visit \#}

Visit Plan: (To be completed before visit.)

1) What objectives do you plan to discuss with the participant?

$\square$ 1) Determine if she is receiving adequate prenatal care.

$\square$ 2) Help her identify social service needs and enroll in the WIC program.

$\square$ 3) Help her identify nutritional needs.

$\square$ 4) Discuss exercise during pregnancy.

$\square$ 5) Other

2) Did she have concerns or issues from the last visit that need reviewing this time?

\section{Description of Visit:}

1) What objectives and activities did you address?

2) What issues did she seem particularly excited about? 


\section{Home Environment:}

1) Who was present during the visit?

2) What is happening in the family that might affect or be affected by the pregnancy/child?

\section{Follow-up for Next Visit:}

1) Special concerns

2) Plans for next visit

3) Questions/topics to research for mother

4) What strength(s) did you see on your visit today?

5) Ideas/suggestions from participant about the MIHOW Program: 